
as Compositional Parameters in Sound Art

Peter Michael Traub

Charlottesville, Virginia

B.A., University of Florida, 1997

M.A., Dartmouth College, 1999

M.A., University of Virginia, 2008

A Dissertation presented to the Graduate Faculty of the University of Virginia in Candidacy for the Degree of

Doctor of Philosophy

\title{
Department of Music
}

\section{University of Virginia}

December, 2010

Judith Shatin, Ph.D., Chair

Matthew Burtner, D.M.A.

Ted Coffey, Ph.D.

Earl Mark, Ph.D.

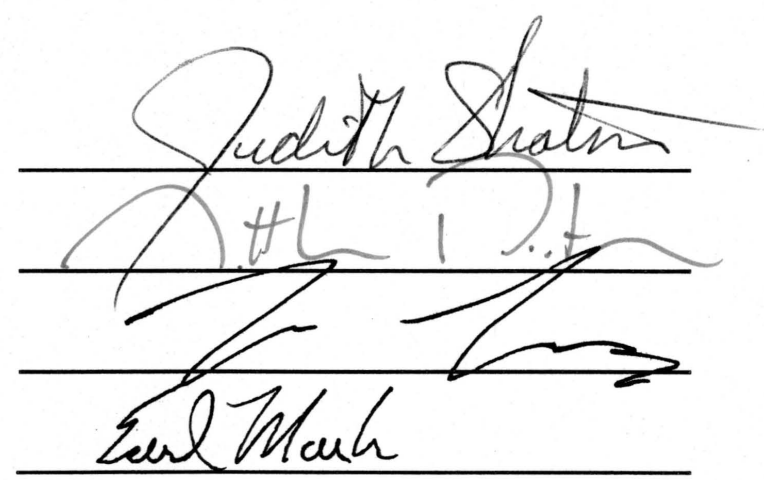


(C) Copyright by

Peter Michael Traub

All Rights Reserved

December 2010 


\begin{abstract}
This dissertation shows the potential of spatial design as a central site of compositional play. I begin by proposing a conceptual framework that elucidates the interrelationship of particular technological advances and developing notions of space and that emphasizes the compositional importance of decoupling space from time and place. I define two basic spatial types: physical and abstracted. These can be combined to form a third major type: hybrid. I trace the changing spatio-musical responses to architectural developments from the 1500 s to the present, and follow with a discussion of the effects of the scientific and technological revolution on modern perceptions and conceptions of space. I then analyze and situate pieces by representative composers within my conceptual framework. Finally, I discuss my own series of pieces, Five Spaces, a set of installations and performances that embody the types of space examined previously. I explain my compositional methodology and show how space decoupled from time and place can be recoupled in musically compelling forms.
\end{abstract}


Table of Contents

Abstract........................................................................................................................................... iii

Acknowledgements ................................................................................................... vii

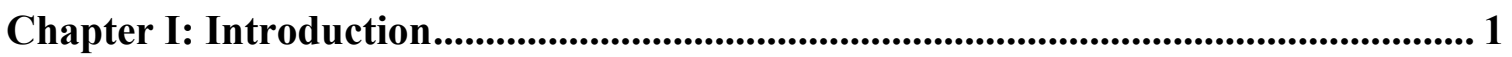

1. Overview

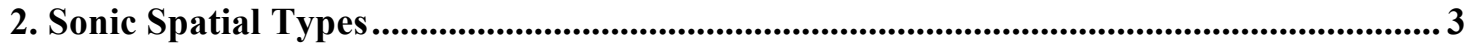

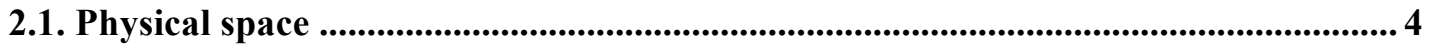

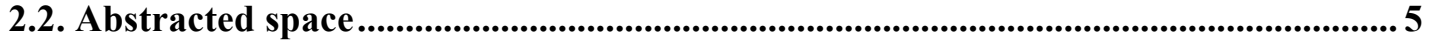

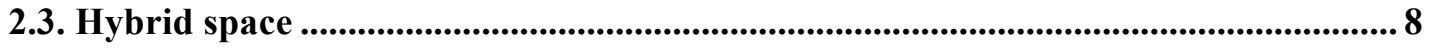

3. The Potential of Space .................................................................................................................... 13

Chapter II: A Brief History of Sonic Space........................................................ 15

1. The Aural World Before the Acoustics Revolution .................................................... 15

2. The Technological Revolution and the Separation of Space and Place........................... 22

2.1. Electronics enter the space: decoupling of space and place ........................................ 24

2.2. New art meets new spatial possibilities............................................................................ 29

3. Networks, Cheap Computing, and the Further Abstraction of Space............................32

Chapter III: Expanding the Bounds of Space ...................................................................... 36

1. The Causes of Expanding Boundaries …....................................................................................36

2. The Porous Borders of Modern Space........................................................................ 40

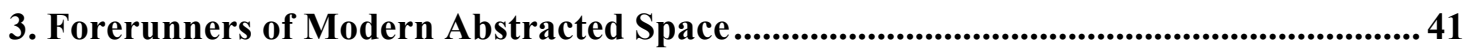

3.1. Acoustic spatial music ........................................................................................................ 41

3.2. The multi-channel and immersion pioneers ...................................................................... 43

3.3. Space as a processor ...................................................................................................................... 47 
3.4. Network music pioneers...............................................................................................................5 50

Chapter IV: Contemporary Spatial Players.......................................................... 56

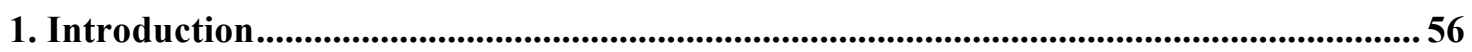

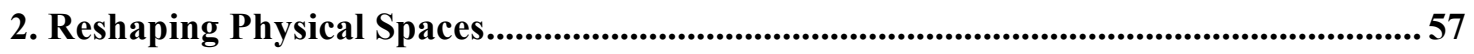

2.1. Site resonance

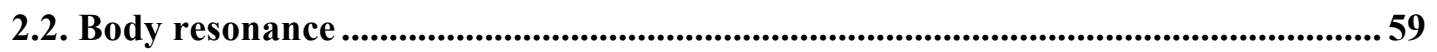

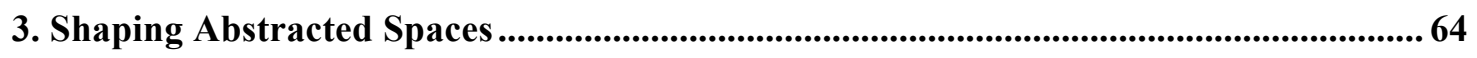

3.1. Abstracting space into multiple channels.............................................................................. 64

3.2. Abstracting space into virtual worlds.................................................................................... 71

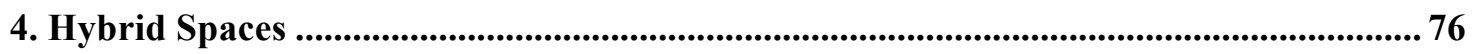

4.1. Networked hybrid space ............................................................................................................... 77

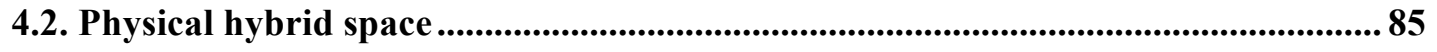

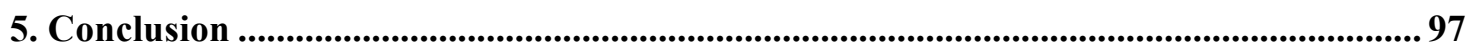

Chapter V: The Five Spaces .................................................................................. 102

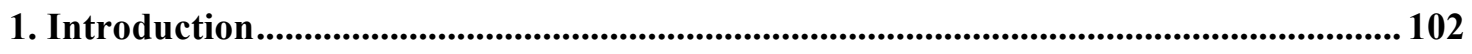

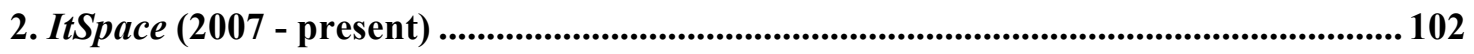

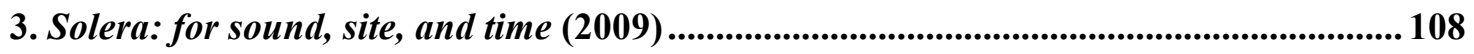

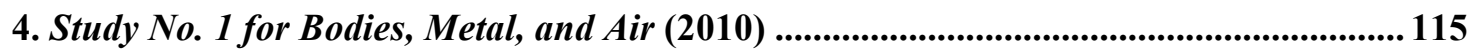

5. Passages and Recesses: for solo flute and hybrid space (2010)........................................120

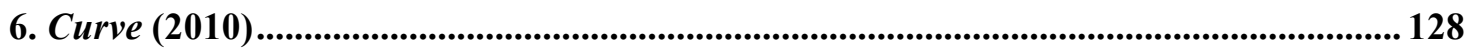

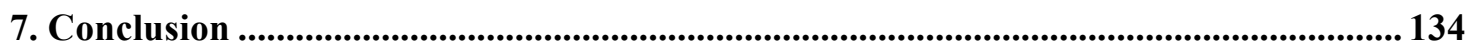

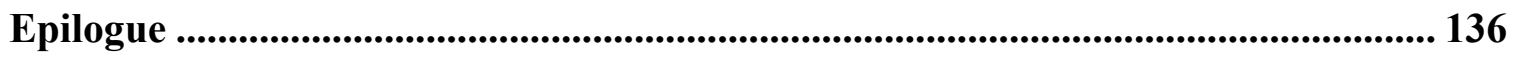

Appendix A: Passages and Recesses (2010) ................................................................. 139 


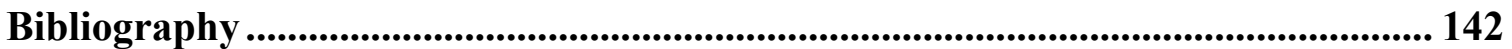




\section{Acknowledgements}

I am very grateful to Judith Shatin for serving as my advisor, and for her critical insights and guidance over the years. I am also indebted to Matthew Burtner, Ted Coffey, and Dave Topper for their teaching, advice, and friendship during my time here. Thank you to Earl Mark for serving on my committee. I am also grateful to Dinah Gray and Wayla Chambo for collaborating with me, and to Bill Bennett and Eric Schmidt in the Studio Art Department for their instruction and support.

I would not be here were it not for the generous financial support of John and Mary Scott Birdsall through the Jefferson Fellows Foundation, and the Graduate School of Arts and Sciences who funded my dissertation year. My dissertation pieces also benefitted immeasurably from funding by The Center for Undergraduate Excellence and Turbulence.org.

Finally, thank you to my parents, Joel and Susan Traub, for their love and support, and to my wife Jaimee and my son Ian, who provided the love, support, distraction, and occasional annoyance that kept me sane through grad school. 


\section{Chapter I: Introduction}

\section{Overview}

The technological developments of the past 130 years have allowed the decoupling of space from place and time, yielding fundamentally new compositional opportunities. I

develop an expanded concept of musical space that includes not only physical spaces, but also abstracted and hybrid ones. The second two categories are necessarily broad as the nature of abstracted and hybrid spaces, much like the spatial concepts they refer to, are fluid. Architect Marcos Novak, who theorized notions of cyberspace in the early 1990s, wrote of a "liquid architecture" in cyberspace that is relevant when considering contemporary compositional approaches to electronically mediated space:

A liquid architecture in cyberspace is clearly a dematerialized architecture. It is an architecture that is no longer satisfied with only space and form and light and all the aspects of the real world. It is an architecture of fluctuating relations between abstract elements. It is an architecture that tends to music. (Novak 1991, 284)

Musical spaces can now be enhanced by and constructed with such technologies as computer networks, virtual environments, multi-channel speaker projection, and artificial reverberation. These spaces can be used in combination, layered, mixed, and merged with one another in ways that speak to the fluidity of the medium to which Novak refers. 
He also wrote of the principals of 'minimal restriction' and 'maximal binding' when it came to defining cyberspace - a useful set of principals that should also be applied to the definition of sonic abstracted and hybrid spaces. Of 'minimal restriction' he wrote "that it is not only desirable but necessary to impose as few restrictions as possible on the definition of cyberspace, this in order to allow both ease of implementation and richness of experience" (Novak 1991, 277). In turn, 'maximal binding' "implies that in cyberspace anything can be combined with anything and made to 'adhere', and that it is the responsibility of the user to discern what the implications of the combination are for any given circumstance" (Novak 1991, 277). Applying these principals of open-endedness to my concept of hybrid space ensures a fluidity, and even an ambiguity, of definition appropriate to this evolving medium.

I will focus on the role of this expanded concept of musical space through the development of a framework and the examination of current approaches to space in the works of selected contemporary composers. Finally, I will discuss my accompanying series of pieces, entitled Five Spaces, examining not only the decoupling of space and time, but the recombining that it facilitates. In my pieces, I explore space through a variety of means, but always based on precise pre-compositional planning. This variously takes into account precise measurement of physical space; the visual, acoustic and symbolic properties of space; the sculptural properties of custom-made physical props that can interact with aural space; and the kinds of interaction made possible by the space of social media. 


\section{Sonic Spatial Types}

I divide space into three categories: physical, abstracted, and hybrid. Physical space includes all of the existing space of the world, whether built or natural. I define abstracted spaces as artificial spaces created through electronic technology and decoupled from the rules of the physical world. Hybrid spaces are created when elements of physical and abstracted space are combined. These categories are proposed as a means to better understand the compositional poetics of space-focused approaches. They also show how one might go about categorizing notions of space for sonic composition. While the category borders are somewhat fluid, they provide a guide to the parameters of aural space.

From the receiver's perspective, the story becomes more complicated. For one who experiences such pieces, all information must nonetheless pass through physical space to be processed by our perceptual systems. Whether or not abstracted or hybrid spaces are actually perceived as such may vary by individual and may be influenced by numerous factors. My focus, then, is on the compositional use of these spatial categories, and on how they extend the domain of spatially-based composition. Listener perception and reception are beyond my scope. Rather, they lie in the domain of cognitive psychologists and phenomenologists. 


\subsection{Physical space}

Physical space can be further divided into three subcategories: built, natural, and corporeal. Built space includes any constructed space such as cathedrals, houses, and public buildings. It also includes open spaces such as shelters, gazeboes, amphitheaters, and so forth. Natural space, on the other hand, encompasses all natural spaces, large and small. Valleys, forests, caves, canyons, and craters are all examples. Corporeal space is defined by the physical boundaries of the human body. My conception of corporeal space originates from my study of Bernhard Leitner's sound installations. A number of his installations, two of which are discussed below, involve speakers using low frequencies to vibrate listener's bodies. The intent is for listeners to feel the sound, for bone induction hearing to occur, and for people to become aware of their own resonating space. The body is the final arbiter of all external resonance that one perceives. It amplifies and attenuates certain frequencies, transmits those vibrations from the eardrum through the inner ear, and converts the physiological effects of the vibrations into neural information. It is, in this sense, both a physical and psychological filter. The body's resonant spaces are not just within the ears - our lungs and throat produce the impulse of our voice, our skulls resonate our voices, our torsos and limbs may resonate with certain low frequencies, and we may feel and hear our heart pumping in our chest or blood rushing

through our ears. We sense resonance throughout our bodies - think of how you feel loud bass in your chest or stomach, or how a loud thunderclap may 'rattle your bones'. 


\subsection{Abstracted space}

Abstracted space encompasses all of the imaginary and virtual spaces that we can conjure with technology. Popular culture's conceptions of virtual space most commonly associate it with practices including 3D multi-user environments, video games, and other visual representations of what was once commonly termed 'cyberspace'. Yet, this is just one subset of abstracted space. Abstracted spaces abound in our daily lives, often in the aural realm, and are not only derived from the Internet or computer-generated environments. In software development, one often uses the verb phrase 'to abstract' to mean the extracting of functionality into one place from where it can be reused over and over. I use the term 'abstracted' because these types of spaces are untied from the physical world and can be created on the fly, relocated, replicated, and parameterized in ways not possible with physical space. Abstracted spaces are artificial - a product of imagination and technology that we only experience with a limited number of senses. The primary means by which we interact with abstracted spaces are through sight and sound.

Perhaps the most commonly encountered aural example of abstracted space is that of artificial reverberation, which creates a virtual sense of space - a large sterile chamber, a warm wood and fabric studio, a cavernous hall, and so on. These spaces can be further manipulated to remove any trace of connection to physical reality - for example, a reverberation can be created with a near infinite decay time, or a delay time so long that it implies a physical structure far larger than has ever been constructed. Artificial 
reverberation simulates the acoustic properties of surfaces and their reflections. It concerns the material textures that bound physical space presented through sound.

Multi-channel pieces support another kind of abstracted space, with multiple speakers surrounding listeners and creating the illusion of sound either originating from specific points in space, or completely enveloping the listener. Alone, multi-channel spaces can communicate sound location and directional movement. In combination with artificial reverberation and other compositional techniques, they can create rich and immersive sound spaces that would be impossible to produce in physical space. There are many approaches to the use of multiple channels in contemporary composition, from live sound diffusion, as practiced by composers such as Jonty Harrison, to the precise 3D aural environments created by composers such as Natasha Barrett. These artists typically overlay composed abstracted spaces on physical spaces, often performing these pieces in a concert setting.

While all abstracted aural spaces are mediated by physical space before reaching the listener, there are some scenarios, such as binaural recordings, where the mediating physical space is nearly non-existent. Bernhard Leitner's 2003 CD, “Kopfräume,” ("Headspace") is a series of sixteen binaural compositions intended for listening through headphones. In these $3 \mathrm{D}$ sound sculptures, the spatial sonic information passes only the short distance between the headphone transducers and the listener's eardrums. With good sealed headphones in a quiet space, no outside resonance is perceived, but of course, the 
listener's ear and perceptual systems have their own biases that will mediate the experience. This is as close as abstracted spaces can get to bypassing transmission and mediation through physical space.

Network-based virtual spaces are another type of abstracted space and are most commonly associated with computer networks, but they are not exclusively digital. Computer networks can be used to share sound or images between spaces, effectively joining them and creating a virtual sonic space. Yet composed network-based sound spaces predate the Internet and the digital revolution: artists such as Max Neuhaus used public radio resources in the 1960s to compose shared sonic spaces to which participants across the continental US could contribute via telephone. However, contemporary network-based virtual spaces exist primarily in the digital realm of the Internet and local area networks (LANs). Writing in the early days of the Internet, when our first mass forays into the online domain produced numerous utopian and dystopian prognostications about the potential of the global information network, theorist Pierre Lévy argued presciently that the new multi-modal environments and simulations enabled by cyberspace would create new signs and new meanings beyond the reach of language alone, in which the creative effort would "be shifted from the message itself to the means, processes, languages, dynamic architectures, and environments used for its implementation" (Lévy 1997, 121). Contemporary network-based art in large part fulfills Lévy's prediction by using combinations of networks, virtual spaces, multi-media, social 
software, and group dynamics - to name but a few - to map uncharted aesthetic and semiotic territories.

Networks create a means of connecting spaces, and function as virtual spaces themselves. While these metaphorical spaces do not have a 'sound', the spatial metaphor is extremely useful when thinking about them compositionally. Composer Chris Chafe argues that "just like in air, sound waves traveling between hosts on the Internet can bounce off edges, boundaries and obstacles. These reflections give rise to a configurable sound world of rooms with enclosing walls that contain networked and network objects which vibrate and produce sound" (Chafe 2009, 414). I agree with Chafe's argument and contend that information traveling through a computer network is morphologically similar to sound traveling within a physical space. Much as air acts as the conductive material for audible vibrations, a network connects sender and receiver for the exchange of data, whether sonic, visual or textual. This is just one example of how a spatial metaphor may be applied to networks in the service of composition. Many other metaphors exist, many of them specific to the network application for which they are used, and some have yet to be imagined.

\subsection{Hybrid space}

When abstracted and physical spaces are combined, the result is a hybrid space (Fig. 1.1). Theorist Adriana de Souza e Silva defines hybrid space as a type of space in which the 
traditional boundaries between virtual and physical space are blurred, and where virtual or network-based contexts are embedded in the current physical context:

Without the traditional distinction between physical and digital spaces, a hybrid space occurs when one no longer needs to go out of physical space to get in touch with digital environments. Therefore, the borders between digital and physical spaces, which were apparently clear with the fixed Internet, become blurred and no longer clearly distinguishable. (de Souza e Silva 2006, 262)

This differs slightly from new media theorist Lev Manovich's notion of “augmented space" in which data, typically - but not always - from a network, are used to augment physical reality. 


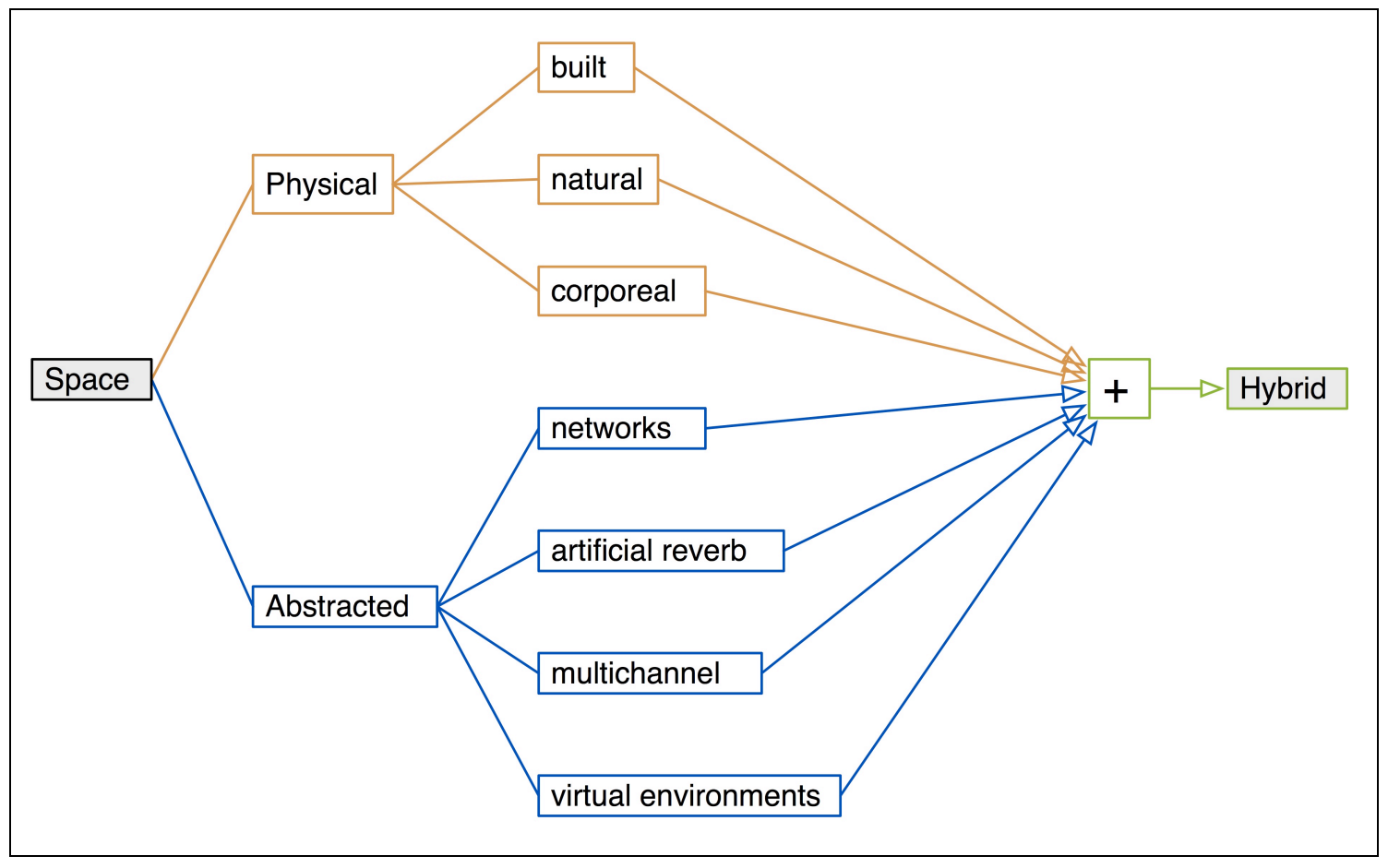

Fig. 1.1: The reconfiguration and combination of spaces to form hybrids.

... GPS, wireless location services, surveillance technologies, and other augmented space technologies all define dataspace - if not in practice, then at least in theory - as a continuous field that completely extends over, and fills in, all of physical space (Manovich 2006, 228).

de Souza e Silva, in citing Manovich, differentiates between his definition of augmented space and her definition of hybrid space, noting that unlike hybrid space, "communication and social interaction are still not required components for the construction of an augmented space." (de Souza e Silva 2006, 265). She requires that a 
network be present to enable her construction of hybrid space, whereas Manovich simply requires a layer of data, not necessarily from a network, as an additional field extended over physical space. It believe it is necessary for the term 'hybrid space' to be flexible in order to incorporate new technology-derived spaces that we have yet to encounter. This is not uncommon with terminology relating to cutting edge technology. For example, artist Eduardo Kac refers to the concept of telepresence in his 1993 essay, "Telepresence Art," as a hybrid of robotics and telematics "in which the anthropomorphic features of the robot matches the nuances of human gestures" (Kac 1993). We now use a much broader definition of telepresence that includes network-shared spaces, video conferencing, and other similar hybrid spaces. The term has been extended to other concepts as technologies have evolved.

The definition of hybrid space that I propose does not require a network or social context, but rather a combination of abstracted and physical spaces to enable the potential perception of a new space. Further, the spaces that comprise hybrids may be both real and metaphorical. This concept is embodied in my piece, ItSpace, which locates representations of physical objects and their sounds within an online social network, a metaphorical gathering space for friends. It is also at work in artist Janet Cardiff's sound walks, in which sonic data is used to augment a physical space, or create a path through a physical space. ${ }^{1}$ My intent in defining these spaces is similar to that of Lévy in arguing

\footnotetext{
${ }^{1}$ de Souza e Silva specifically cites Cardiff's sound walks as an example of augmented space but not hybrid space because they lack a network. Manovich discusses Cardiff's sound walks as an example of augmented space (or what I consider hybrid space), even though they are not predicated on networks or
} 
for the fluidity of cyberspace, that "the primary goal should be to prevent closure from occurring too quickly, before the possible has an opportunity to deploy the variety of its richness" (Lévy 1997, 122).

Because abstracted and hybrid spaces don't have to obey the rules of physical space, the metaphor of resonance can be exploited. For example, we don't have to consider the resonance of an abstracted or hybrid space as a purely acoustic or sound-driven phenomenon. Resonance makes an aural space 'present', so metaphorically resonating a network with data also makes that space present, revealing the extent, limits, and behavior of the space or network in which that data travels. We can resonate these spaces with the back-and-forth of a shared idea, with all manner of non-sonic content, even if the final result is musical in nature. For example, The League of Automatic Music Composers (1978 - 1983), based in the San Francisco bay area, was the first group of composers/performers to use computer networks as a means of live music making. They connected their early computers via an ad-hoc network and sent data about events, such as pitch, time, and duration hurtling across the web of connections, colliding, transforming, and resonating the virtual space of their network. Then, these interactions were converted into the audible sound of their performances. As the materials we can use to resonate these types of spaces are so varied, the range of compositional possibilities is enormous - I can explore but a few of them here.

even digital media (her first sound walk was on cassette tape). I choose to use the terms augmented and hybrid interchangeably. 
My methods for composing space in my Five Spaces series vary significantly from piece to piece, as the spaces in which these pieces reside vary from the real to the virtual to the metaphorical. However, they all share detailed pre-compositional planning appropriate to the application. For example, ItSpace was designed around the spatial implications of the metaphorical network of 'friends' within the digital network of MySpace, but it also incorporated the very real sound space of my house. It was also designed as a comment on, and parody of, the physically-isolating nature of social media. Solera, while installed in a specific space and by that measure was site-specific, was more generally directed at capturing the patterns of unfolding time within any space. My pre-compositional approach to the piece was not shaped by the sonic characteristics of the site where it was first installed: rather the piece was designed to be installed in any suitable enclosed public space. This meant careful technical planning to handle the large amount of sonic information collected and mixed. Curve, however, was designed as a response to a unique space, and my pre-compositional activities revolved around detailed measurement and analysis of the aural and physical properties of the architectural space. This enabled me to determine how best to speak to and aurally illuminate the space through my installation. I will discuss these pre-compositional approaches in more detail in Chapter V.

\section{The Potential of Space}

Space has not historically played a central role as a compositional parameter, yet spaces have had a profound influence on the types of music composed for them. An oft-cited 
example is the development of slow chant in response to the increased reverberation times of early large cathedrals (Blesser and Linda-Ruth Salter 2007, 90). More recently, the development of powerful amplification systems has influenced popular music's performance in large stadium concerts and clubs - usually loud enough to fill listeners' bodies with the sound of a distorted guitar or a pounding dance beat. With technology we can manipulate aural space to change the perceived size or resonance of a physical, abstracted, or hybrid space. We can actively engage and shape space, rather than passively acknowledge and account for its influence on other parameters like pitch, rhythm, and timbre. The importance of aurality in our perception of space can be appreciated with this simple thought experiment regarding physical space: imagine walking into Notre Dame Cathedral, the Pantheon, or Grand Central Station wearing earplugs. So much of how we respond to and remember these spaces is through our aural impressions that our spatial awareness would be strongly diminished without them. I will show that the sonic qualities of spaces like these, and indeed, the more mundane abstracted and hybrid spaces we encounter every day, are fertile ground for musical innovation. 


\section{Chapter II: A Brief History of Sonic Space}

\section{The Aural World Before the Acoustics Revolution}

Aural archeologists don't quite know how the world sounded prior to the development of recording technologies. A lack of material traces, such as the ruins and objects available to physical archeologists, prevents an accurate hearing of the pre-phonographic world. According to Emily Thompson, a professor of history at the University of California at San Diego who has written extensively on aural history, the first playable ${ }^{2}$ sound recordings were not made until the introduction of Thomas Edison's phonograph in 1877, a year after Alexander Graham Bell's telephone "announced the arrival of electrically reproduced sound. (Thompson 2002, 235)." We know what certain structures, such as the Parthenon in Athens, the Great Wall of China, or the Roman Coliseum looked like hundreds or even thousands of years ago, but before 1877, we don't know what they sounded like. This question is a source of both intense speculation and a great degree of mystery.

A partial aural record exists in the still-intact spaces of pre-phonographic cultures. One can walk into the Pantheon in Rome, the Taj Mahal in Agra, or early Native American cliff dwellings in the southwest United States and hear the resonances that shaped the sound world of the original inhabitants. Yet as Blesser and Salter point out in their book

\footnotetext{
${ }^{2}$ A New York Times article by Judy Rosen from March 27, 2008 discusses the recent discovery by audio historians of a recording that predates Edison's 1877 patent by 17 years. The recording -10 seconds of a singer singing "Au Clair de la Lune" - was made on a phonoautograph. The machine could create a visual record of a sound, but could not reproduce it. It took the work of researchers at Lawrence Berkeley National Laboratory to make it playable.
} 
“Spaces Speak, Are You Listening?”, “modern listeners experience the aural architecture of a twelfth-century cathedral without the religious feelings, faith, and worldview of listeners of that epoch. Even though the acoustics of the cathedral have not changed in the intervening nine centuries, modern listeners are unlikely... to feel transported to heaven on earth, as many, if not most, medieval listeners very likely did" (Blesser and Linda-Ruth Salter 2007, 68). We can speculate as to how pre-phonographic cultures listened to the spaces around them, but we cannot recreate the context in which they listened. What we do know is that prior to the sound/source decoupling technological advancements of the $19^{\text {th }}$ and $20^{\text {th }}$ centuries, sound was inextricably bound to the site and source of its production.

Much of the evidence that informs speculation about early aural environments comes from the physical design of the spaces themselves, or from visual evidence left within a space. Blesser and Salter describe archeologist Steven J. Waller's observation of early cave drawings in which pictures of animals whose movements generated large sounds were often placed in acoustically resonant chambers within a cave. When those spaces are resonated, the pictures "seem to come aurally alive" (Blesser and Linda-Ruth Salter 2007, 74-75). English scholar Bruce R. Smith describes his attempt to reconstruct the aural world of Shakespeare's Globe Theatre by correlating evidence such as "the resonance of building materials... indications of special sound effects in scripts... the directional properties of the building's shape" as well as "findings of modern linguistic research with respect to the mathematical modes of pitches of adult male voices reading 
aloud" (Smith 2004, 23). There are plentiful written accounts describing the sounds that filled pre-phonographic times and places. Composer R. Murray Schafer, in his book "The Soundscape", spends much of Part One quoting and analyzing aurally descriptive poetry and prose from centuries past in an attempt to conjure the sound worlds of a prephonographic planet (Schafer 1994, 15-67).

Architects Ted Sheridan and Karen Van Lengen argue that a sensate shift occurred in the progression from pre-literate to post-literate societies that changed conceptions of space. This shift was embodied in the Roman scholar Vitruvius's writings on architecture, and his theory of two architectural modes that explicitly coupled sound to the site and space of its production. In "proportional" mode, spatial dimensions were directly related to tonal harmony and Pythagorean harmonic ratios, creating a physical link between visual and aural experience. In the "actual" mode, design was derived from experience, experimentation, and actual knowledge of the behavior of sound in various situations. Sheridan and Van Lengen also note that he devoted as much text in The Ten Books on Architecture to acoustics as he did to site design, an amount they call "unheard of in current architectural writing". Lacking the scientific tools and knowledge to truly understand acoustics, Western approaches to sound in architectural design remained rooted in Vitruvian principles until the $19^{\text {th }}$ century (Sheridan and Van Lengen 2003,3 ).

Prior to the $19^{\text {th }}$ century - when the first scientific studies of acoustics were conducted Western musical tradition was still grounded in available public structures. Before the 
rise of secular music spaces, the church was both theologically and physically the major driving force in the development of early music. Around the fourth century church designs began to grow as a result of both increasing wealth and the need to accommodate more worshippers. These larger structures resulted in longer reverberations times, some as long as ten seconds (Blesser and Linda-Ruth Salter 2007, 90). Composers of early music were thus limited to slow-moving and melodic textures that made effective use of the extensive reverberation time. This music could reach parishioners in the back pews and was supported and enriched by the reverberation.

Because the reverberation time in large cathedrals was so great, the effects of space and surface became central in creating impressions of grandeur, eternity, and otherworldly existence. The notion of sound existing apart from its immediate spatial surroundings was a conceptual abstraction still hundreds of years away. Instead, music of this time evolved in response to and emphasized its connection to the physical spaces of its performance. Acoustician Leo Breakneck argues that "between 1600 and 1900 there was a relation between architecture and music in Europe, and that the music of each of the stylistic periods - Renaissance, Baroque, Classical, and Romantic - coincided with a contemporary acoustical environment sympathetic to its performance" (Beranek 1962, 44)

Around the middle of the $16^{\text {th }}$ century, composers such as Adrian Willaert began a practice of polychoral polyphonic composing derived from the cori spezzati (broken 
choirs) tradition of Venice. Willaert's innovation was to use two or more choirs usually positioned some distance apart - performing complementary parts of a single piece. The distance between choirs allowed for a range of effects - choirs might utilize call and response across the space or their material might be registrally differentiated. Composer Richard Zvonar's article, “A History of Spatial Music” (2005), describes Willaert's eight-part Vespers (1550) as the earliest known work of this type, featuring echo effects and dialog form between the choirs. Later works, such Thomas Tallis's Spem in Alium (1573) used up to eight choirs. In the case of Tallis's piece, each choir was divided into five separate voices, to create a piece consisting of 40 voices in total. ${ }^{3}$ These pieces often utilized the massive cross-shaped floor plans, such as that of the Basilica San Marco in Venice, by distributing choirs to various rooms within the cathedral and to various points along the cross. The music was coupled to both the sacred purpose of the space and the resonant and reverberant properties of its architecture.

Zvonar contends that there was little interest in spatial antiphony from the late Baroque through the Classical periods. However, by focusing only on antiphonal music, he neglects the works composed for the acoustics of particular concert halls and cathedrals. For example, Bach, while not directly using spatialization, certainly composed with the acoustics of his performance spaces in mind. Beranek notes that "Bach knew the difference between the live acoustics of the St. Jacobi Kirch in Luebeck and the relatively

\footnotetext{
${ }^{3}$ The artist Janet Cardiff, did a contemporary take on Tallis's piece called The Forty Part Motet (2001), in which individual recordings of each voice in a boy's choir singing Tallis's piece were then replayed through 40-speaker system as an installation. The speakers were set up in an oval, with each group of eight together, and installed in various resonant spaces for performance. Listeners could walk through the space and in-between the speakers, hearing individual voices close up, or the larger sound mass.
} 
dry acoustics of the Thomaskirche in Leipzig. His compositions for organ, written for churches like the St. Jacobi, differ markedly in style from his St. Matthew Passion, written for the Thomaskirche" (Beranek 1962, 31). Architectural acoustician Hope Bagenal contends that the shorter reverberation time of Thomaskirche and other Reformation-era churches allowed Bach "to write fugues for the organ with rapid bass parts. Many of the fugues, owing to their tempo, are lost in cathedrals, the bass parts becoming nothing but a confused roaring" (Bagenal 1930, 150). Thomaskirche's reverberation time is estimated to have been around 1.6 seconds when full, considered dry for a church of that time. Beranek quotes Bagenal as stating that the shorter reverberation time in "enabling string parts to be heard and distinguished and allowing a brisk tempo... [lead] directly to the St. Matthew Passion and the B-Minor Mass" (Beranek 1962, 46). Bagenal also noted that "an English Gothic church of this size would have some four or five seconds reverberation" (Bagenal 1930, 149). Blesser and Salter concur that these smaller spaces better supported "the delicacy of stringed instruments, and a more rapid ebb and flow of musical tempos" (Blesser and Linda-Ruth Salter 2007, 101).

In addition to the acoustics of the evolving architectural styles, social and economic shifts also had a significant influence on notions of musical and aural space. From the mid1700 s through the late 1800 s, a growing middle class that increasingly supported musical activities outside the church further enabled the rise of secular concert spaces. Although most music in the eighteenth century "was still commissioned by the court and the 
church... a wider secular appeal now gave a new impetus to the composer. Publishers of music, entrepreneurs, and purveyors of public entertainment all increased the composer's area of influence..." (Beranek 1962, 47). By the late eighteenth century, during the Classical period, secular concert halls had spread from England across Europe. Their reverberation times, which ranged from 1.3 to 1.5 seconds (Beranek 1962, 47) allowed for a far greater range of textures and tempi than were acoustically feasible in gothic cathedrals. Sheridan and Van Lengen argue that "in the eighteenth century, orchestral music came to require an architecture that did not yet exist: an architecture that would itself orchestrate the secular experience of music and would provide an acoustical foundation for the ever more complex harmonic and chromatic experimentation. The basic form of the concert hall was the final result, and it remains a remarkably consistent typology to this day" (Sheridan and Van Lengen 2003, 6). During the Romantic period, from the early nineteenth to the turn of the twentieth century, the growing popularity of these secular concert halls was paralleled by a growth in the size of orchestras, and the spatial requirements of the music changed yet again. The increase in audience and orchestra size resulted in the construction of even larger halls with longer reverberation times, often around 1.9 to 2.2 seconds. The music composed for these spaces "no longer required the listener to separate out each sound that he heard to the same extent as in Baroque and Classical music..." Rather, Romantic music "thrive[d] in an acoustical environment that provide[d] high fullness of tone and low definition" (Beranek 1962, 4749). A number of $18^{\text {th }}$ and $19^{\text {th }}$ century concert halls are still considered paragons of acoustic quality, such as Leipzig's Neues Gewandhaus, Vienna’s Grosser 
Musikvereinssal ${ }^{4}$, and Amsterdam's Concertgebouw, even though their design derived primarily from the aural experience of existing and historical spaces rather than through a quantifiable scientific approach that could calculate or predict the sonic characteristics of the spaces. Halls such as these were considered successful at the time and were widely copied (Forsyth 1985, 214).

\section{The Technological Revolution and the Separation of Space and Place}

By the late $19^{\text {th }}$ century secular spatial needs (such as clarity in the communication of scholarly lectures to large audiences) combined with scientific advances to create the first technological and scientific leap in the understanding of acoustics. It began with physicist Wallace Clement Sabine's (1868 - 1919) research on the acoustics of the auditorium at Harvard's Fogg Art Museum. Complaints about excessive echoes and reverberation during lectures prompted the president of Harvard to ask Sabine to develop ways to fix the hall's acoustics. Initially, Sabine's approach was to attempt to render the acoustic phenomena visible via such methods as a variant on Rudolph Koenig's "dancing flame”, a "device that transformed vibrations of sound in air into flickering flames" (Thompson 2002, 34 - 36). When that approach proved unsuccessful, Sabine began work measuring, both aurally and with instrumentation, the reverberation decay time of a $512 \mathrm{~Hz}$ organ tone in the space. What Sabine learned lead to a greater understanding of the acoustically

\footnotetext{
4 According to Forsyth, the Neues Gewandhaus and the Grosser Musikvereinssal were used by Wallace Clement Sabine in 1895 as models for his design of the revered Boston Symphony Hall.
} 
absorbent and reflective properties of various materials ${ }^{5}$, and Sabine's research eventually resulted in the first formula that could predict the reverberant qualities of a space prior to its construction (Thompson 2002, 41). ${ }^{6}$ This revolution in the understanding of acoustics combined with the later inventions of recording, playback, and amplification technology would eventually give musicians, architects, and engineers powerful new tools to control and manipulate sound. It was from these combinations of tools that the modern concert hall and the scientific approach to musical and public aural space was born.

The advances in acoustics pioneered by Sabine and those who followed enabled architects and engineers to create a separation between the visual qualities of a space and the sound that space produced in a way never before possible. Acoustically absorbent materials, irregular surfaces, and acoustic tiles could be strategically placed to dampen echoes and reverberation. From a musical perspective, these new techniques enabled the creation of acoustically 'correct' concert halls in which audiences and performers could hear clear sound from many different positions. The acoustic result of this desire to 'silence' was the "modern sound" of which Thompson writes:

\footnotetext{
${ }^{5}$ For example, simply putting seat cushions on the chairs in the auditorium caused a noticeable change in reverberation time.

6 Thompson gives an in-depth account of both Sabine's research and the development and revisions of his reverberation formula - most significantly by Carl Eyring in 1930. Eyring's reworking of Sabine's formula - based on research conducted with more technologically advanced tools than Sabine had access to - was considered to be far more accurate for a wider range of spaces, and in particular, recording studios. It replaced Sabine's formula as the mathematical tool of choice for acousticians and sound engineers.
} 
From concert halls to corporate offices, from acoustical laboratories to the soundstages of motion picture studios, the new sound rang out for all to hear. Clear, direct, and nonreverberant, this modern sound was easy to understand, but it had little to say about the places in which it was produced and consumed. (Thompson 2002, 3)

\subsection{Electronics enter the space: decoupling of space and place}

In addition to the new understanding of acoustics, a combination of three technologies microphones, loudspeaker amplification, and recording media - had the most dramatic effect on the sound world of the early $20^{\text {th }}$ century. These technologies enabled the decoupling, or abstracting, of space from place. A sound could be recorded in one physical space, and played back elsewhere. A sound could be amplified to fill a space in a way that it could not do acoustically. A sound could be instantaneously transmitted from one place to another via telephone or radio.

\begin{tabular}{|l|l|}
\hline Year & Technological Milestone \\
\hline $1820-1830$ & $\begin{array}{l}\text { The first telegraphs are invented and improved upon by Peter } \\
\text { Barlow, Joseph Henry, and Samuel Morse among others. }\end{array}$ \\
\hline 1876 & Alexander Graham Bell invents the telephone. \\
\hline 1877 & Thomas Edison invents the phonograph. \\
\hline 1877 & $\begin{array}{l}\text { Edison invents carbon-type microphone. It is quickly improved } \\
\text { upon by several other inventors, including Francis Blake and } \\
\text { Emile Berliner. }\end{array}$ \\
\hline
\end{tabular}




\begin{tabular}{|l|l|}
\hline $1870 s-1900 s$ & $\begin{array}{l}\text { Numerous inventors, including Jagadish Chandra Bose, Heinrich } \\
\text { Hertz, Guglielmo Marconi, and Nikola Tesla contribute to the } \\
\text { development of sound transmission via radio. }\end{array}$ \\
\hline 1915 & The first commercially viable loudspeakers become available. \\
\hline 1917 & Edward Christopher Wente invents the condenser microphone. \\
\hline 1920 s & Radio broadcasting enters the mainstream. \\
\hline 1925 & $\begin{array}{l}\text { Contemporary conical amplified loudspeaker developed by C.W. } \\
\text { Rice and E.W. Kellogg for General Electric. }\end{array}$ \\
\hline 1928 & $\begin{array}{l}\text { Acoustically isolated recording studios, such as the NBC Studios } \\
\text { in NYC, become common. }\end{array}$ \\
\hline 1930 & \begin{tabular}{l} 
Advent of early artificial reverberation techniques. \\
\hline
\end{tabular}
\end{tabular}

Fig. 2.3: Important early milestones in the development of sound recording, amplification, and transmission. (Beranek 1955), (Thompson 2002), (Hunt 1954)

For early telephone users, the new technology annihilated space by dissolving the physical distance between conversational participants. The spatial acoustics for participants in a telephone conversation were vastly different from those of a face-to-face conversation. A small cone placed by the ear transmitted sound directly without picking up any of the resonances of the listener's surrounding space. In this new communication environment, the extraneous background sounds of reverberation or room resonance were considered unwanted noise (Thompson 2002, 235). ${ }^{7}$

\footnotetext{
${ }^{7}$ A relevant personal observation: For the past several years I have been using online video chat tools such as Skype and Google Video Chat to communicate with relatives and friends in other states and countries. In these video chats, I have noticed that the conversation often seems both acoustically and behaviorally more akin to chatting in person rather than over the phone. Part of this is certainly accounted for in the visual connection, but there is also a strong aural component that differs from traditional phone conversations. The microphones on our computers pick up and transmit a much wider frequency range than telephone microphones, and our speakers play back a wider frequency range than a telephone earpiece. As we
} 
While new materials technologies, such as acoustic tile, enabled more effective noise reduction and reverberation dampening, new electronic tools facilitated a greater control over sound at its source. Nearly forty years passed between the invention of the telephone and phonograph, and the first commercially viable loudspeaker in 1915. Prior to that time, sound amplification was achieved through mechanical means such as the use of phonograph horns, and most telephone or recorded sound listening was done through either small earphones, or the coupling of earphones to a phonograph horn. The first electrical loudspeakers were developed by researchers at Magnavox and used electromagnetically driven diaphragms within a horn. The modern conical direct-radiator loudspeaker was developed at General Electric in 1925 by C.W. Rice and E.W. Kellog, and consisted of a paper cone driven by an electromagnetic transducer (Beranek 1955, 14). The new commercially available loudspeakers could be used to project sound over a distance that in an unplugged acoustic setting would have been audible only at close range. These loudspeakers found their way into public spaces as a means to amplify the spoken word or musical performances and into the private spaces of people's homes through radios, record players, and, eventually, televisions and sound systems.

The common denominator in these new technologies was the principal of electromagnetic transduction, in which physical vibrations are turned into electromagnetic fluctuations

typically talk from several feet away from the computer microphone, far more room reverberation is picked up and the general acoustic characteristics of the participant's spaces are clearly audible. The aural presence of the participants' physical spaces seems to engender a more natural interaction and conversation flow, and is a marked departure from the familiar acoustic experience of a telephone conversation. 
and back again. It was one of the first significant technological decouplings of sound and source, and its fundamental act of translating physical sound into electricity and back again allowed for sound's recording, transmission, and amplification over distances not possible acoustically. Transduction gave rise to an enormous shift in how humans create, distribute, and listen to sound. Like the modern digital video screen in all its sizes and variations, loudspeakers became ubiquitous, and the sonic ecology of the $20^{\text {th }}$ century was forever changed.

These electronic tools brought with them new creative possibilities as well as new problems. For example, recording no longer required performers to stand in front of a horn to play into a mechanical device that converted their sound into a disk. Instead, carbon and condenser microphones "immediately freed the musicians in the studio from the cramped spatial arrangements that acoustic recording had necessitated. Now, electrical amplifiers ensured adequate sound intensity" (Thompson 2002, 264). This in turn required that more attention be given to the acoustics of the recording space, eventually resulting in the construction of acoustically isolated recording studios, such as the new NBC studios in New York, circa 1928, that "exemplified state-of-the-art design for sound absorption and isolation" (Thompson 2002, 266). 


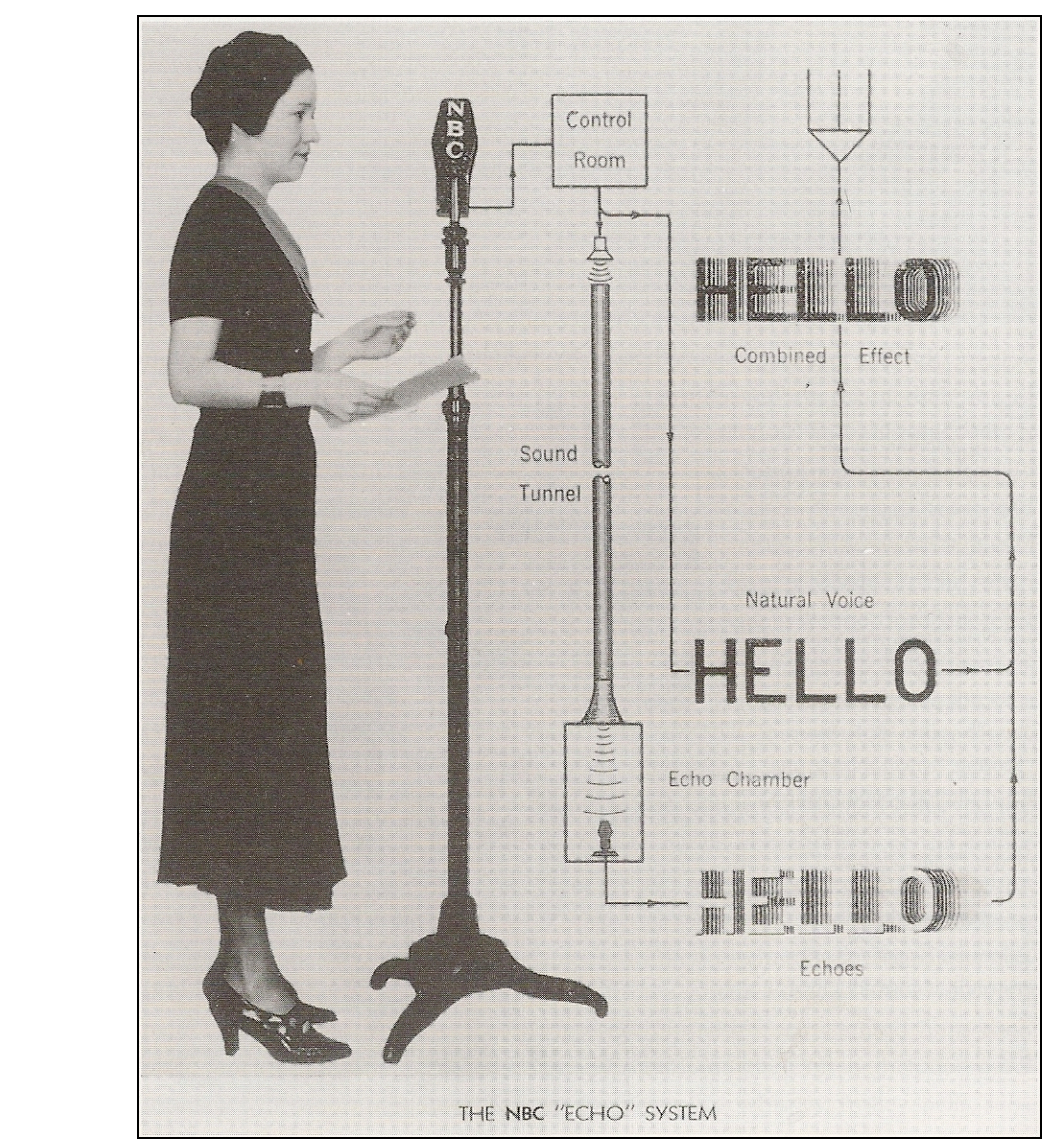

Image from David Sarnoff Library Collections, Courtesy Hagley Museum and Library

Fig. 2.3: An advertisement for an echo studio reverberation system that played live sound into another room used as an echo chamber. Microphones in the echo chamber then returned the sound to the studio where it was mixed with the dry microphone signal.

Questions and opinions abounded regarding the role of reverberation in recorded music, live performance, and film sound tracks. Thompson argues that the general trend of the first half of the $20^{\text {th }}$ century was to reduce reverberation wherever possible, classifying it as noise, or as an effect that could be added later on in the studio. ${ }^{8}$ With the advent of artificial reverberation techniques around 1930, “The sound of space could now exist free of any architectural location in which a sound might be created; it was nothing but an

\footnotetext{
${ }^{8}$ While a number of commercial artificial reverberation generators were available by 1935 , they were not typically used to introduce natural sounding reverberation, but instead were used for special effects.
} 
effect, a quality that could be meted out at will and added in any quantity to any electrical signal" (Thompson 2002, 283). In contrast to the earlier technologies, such as microphones and loudspeakers, that enabled sound to be decoupled from space and source, artificial reverberation enabled space to be decoupled from the sound that resonated it. The tools now existed to control the qualities of 'resonator' and 'resonated' independently, even though they were ultimately intertwined.

\subsection{New art meets new spatial possibilities}

The combined tools of recording, amplification, storage, and transmission created an explosion of new art in the 1940s and 1950s, first with records, then radio, talking movies, and eventually television. As means of sound amplification and projection became more available in the post-WWII decades, artists and producers began to experiment with spatial acoustic properties through speaker placement, manipulation of recorded media, and manipulation of architectural materials. Practitioners of musique concréte, analog synthesis, and early computer music all had an interest in creating immersive sonic environments that would engage the listener by projecting sound from different heights and directions, breaking with the front-projected model. Indeed, precise spatial placement of sound became an important orchestrational aspect. While there seems to be no clear agreement as to what constituted the first multichannel performance, composers such as Pierre Schaeffer, Karlheinz Stockhausen, Leon Theremin, Edgard Varese, and Iannis Xenakis all made use of multiple speakers, multiple microphones, and modified or specially designed architectural spaces for their performances. 
The 1950s and 1960s saw the construction of a number of unconventional spaces for multimedia and multichannel performance. These include: The Phillips Pavilion at the 1958s World's Fair with film projection and 425 loudspeakers over an 11-channel system; The Audium in San Fransisco, CA constructed in 1960 with 169 loudspeakers; and The Pepsi Cola Pavilion at EXPO 70 in Osaka, Japan with 37 speakers played over 37 channels (Zvonar 2005).

In addition to spaces for multi-channel composition, the second half of the $20^{\text {th }}$ century also saw a range of spaces constructed with highly variable acoustic configurations. Perhaps the most malleable of these is l'Espace de Projection, an experimental performance and recording space at the Institut de Recherche et Coordination Acoustique/Musique (IRCAM) in Paris, constructed in 1978. The surfaces on all six sides are variable, owing to a series of triangular panels that can be rotated to expose three different types of acoustic surfaces - absorbent, reflective, and diffusing. The ceiling is broken into three sections that can be raised and lowered, giving users the ability to create up to a 4:1 change in the volume of the room (Forsyth 1985, 316). The space's reverberation can be tuned from 0.4 to 4 seconds in duration, an enormous difference as far as reverberation times go. 

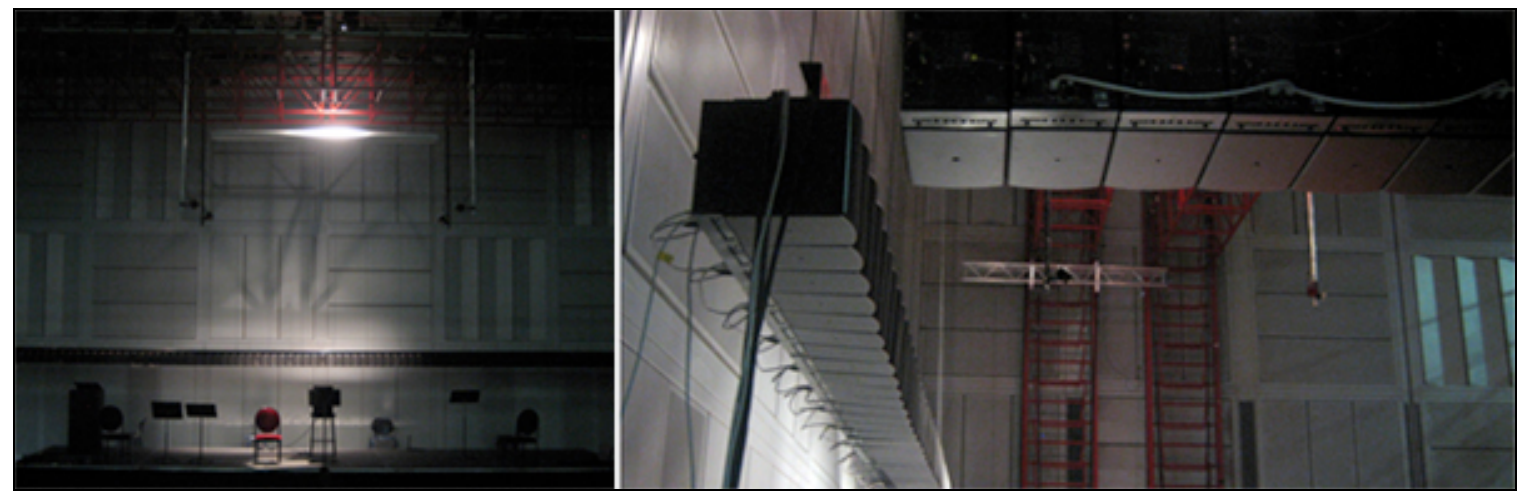

Photo courtesy of IRCAM / Sylvia Gomes

Fig. 2.3: Image showing the variable wall panels in IRCAM's Espace de Projection. The image on the right also shows part of the $\mathbf{1 2 8}$ speaker holographic sound system installed in late 2008.

Acoustics are not the only aspects that motivate designers and developers of unconventional spaces. In the case of Helmut-Lizt-Halle, designed by architect Marcus Pernthaler and constructed in Graz, Austria in 2002, the hierarchical layout of almost all traditional concert venues - with the audience forced to face toward a stage at one end was one that needed to be radically challenged. The Helmut-Lizt-Halle is described by composer John Sands as having "incredible crispness of sound along with a freedom of spatial configuration". The hall has no built in stage or seating, and can be arranged in a near limitless variety of configurations (Sands 2007, 218). The design of the hall takes an egalitarian approach to the physical nature of performance spaces, one that Sands argues is best summed up in the work of early $20^{\text {th }}$ century German musicologist, Heinrich Besseler:

Besseler saw the concert hall and the culture that emanated from it as detrimental to the experience of music. His assessment of the concert was, 
quite simply, a control mechanism that governed every aspect of music from its composition to its ultimate performance. (Sands 2007, 224)

In keeping with contemporary musical practices in which the lines between composer, performer, and audience are often blurred, the Helmut-Lizt-Halle presents space to artists as a far more malleable parameter than traditional venues. Musicians and composers who work in the hall can not only play with acoustic space, but also with social space in the freedom they have to design their physical relationship with the listener.

\section{Networks, Cheap Computing, and the Further Abstraction of Space}

If the technological and scientific advances of the late $19^{\text {th }}$ and early $20^{\text {th }}$ centuries allowed an unprecedented control over the sound of space and place, the advent of the Internet and cheap, powerful computers in the late $20^{\text {th }}$ century allowed for an even greater level of control over the spatial properties of music, and a near limitless freedom from the constraints of physical presence in musical, architectural, and social terms.

One of the earliest network pieces predates the Internet. Ray Johnson (1927 - 1995), a founding member of the New York School of Abstract Expressionist Correspondence and a leading advocate of "mail art", was one of the early practitioners of network art. Beginning in the 1940s, Johnson sent post cards to friends and artists with various drawings, inscriptions, and collages on them, often including the instructions to "add to..." or "send to...", ensuring that a particular piece of mail art would be augmented, 
modified, and passed through numerous hands during the process of its creation. This act of inclusive art building over time and distance is similar to contemporary laptop orchestras in which musical data is shared and modified to create a piece via the simultaneous activity of individual computer musicians - albeit at a much more rapid pace. This comparison shows how mail art is relevant in the history of network art, but it breaks down when we talk about networks as a type of space because of its temporal characteristics. The ability to perceive the passage of time within a space is one of the fundamental properties that allows us to experience a space as a whole, or even a series of connected fragments. Time allows us to walk around and see its boundaries, or in the case of sound, hear the boundaries and resonances that unify it as a perceptible object. If the ability to perceive a space is time-critical, then mail may be network art, but it is not spatial art - the time it takes for information to bounce across the mail art network is simply too long to create an impression of a singular space.

The network-based pieces discussed here either create or unfold within abstracted spaces, often mixing notions of singular physical space with concepts of spatial fragmentation, manipulation, and distribution. Composer and new media artist Chris Salter argues that networks as acoustic spaces offer a radical shift from traditional notions of hearing:

The space of the network, as both acoustic realm and transmission structure... completely challeng[es] the notion of any locus of hearing. By removing the concept of source and site in general, and shattering it across 
a multitude of non-places, we no longer comprehend the source, locale or temporal origin of sound. Listening to sound from the Net, we have no sense of from where a sound emanates, or why it is there in the first place. Sound rests in the ultimate non-place of the networked world: the territory of the server. (Chris Salter 2001)

One can argue for or against the inclusion of certain early events within the lineage of modern network art, such as the concept of Thaddeus Cahill's instrument, the Telharmonium ${ }^{9}$ or Max Neuhaus's radio piece from the mid-1960s, Public Supply ${ }^{10}-$ the technologies behind these pieces all enabled the creation of a network space, but at the atomic level they were still modifications of the existing analog technologies dating from the telephone and phonograph. Blesser and Salter maintain that there were two major revolutionary shifts in sound in the $20^{\text {th }}$ century. The first, discussed earlier in this chapter, was the ability of early recording, playback, and transmission technology to "split musical space temporally, spatially, socially, and artistically - partitioning what, where, and by whom music could be heard." The second major revolution occurred in the late part of the century when powerful computers enabled the "virtualiz[ation] of the space where music would be heard, how it would be created, and who would be

\footnotetext{
${ }^{9}$ Thaddeus Cahill's Telharmonium - built in several versions in very early 1900s - was the first attempt to create synthesized music and transmit it over phone lines to a network of subscribers (Holmes 2002, 4452). Although Cahill's company failed due to financial troubles in 1914, his system predated streaming audio on the Internet by 90 years.

${ }^{10}$ Public Supply used a local New York radio station and the public phone network to create a two-way aural space in which listeners were encouraged to call in and add their sounds to the space. Neuhaus mixed between ten phone lines coming into the station, and listeners were asked to keep their radios on in order to create feedback effects.
} 
responsible for its aural architecture” (Blesser and Linda-Ruth Salter 2007, 133).

Cahill's and Neuhaus's pieces and technologies fall somewhere in between these two

periods. These two revolutions of sound, book-ending the $20^{\text {th }}$ century, are the fundamental reasons that the pieces discussed herein are possible. 


\section{Chapter III: Expanding the Bounds of Space}

\section{The Causes of Expanding Boundaries}

Beginning in the late nineteenth century, we have developed increasingly sophisticated technological and conceptual tools to for decoupling space from time and place.

There is a repetitive cycle underlying these advancements that has had a major effect on the role of space in musical composition and performance. The mechanism of this cycle is shown in a simplified form in the central section of the diagram in Figure 3.1.

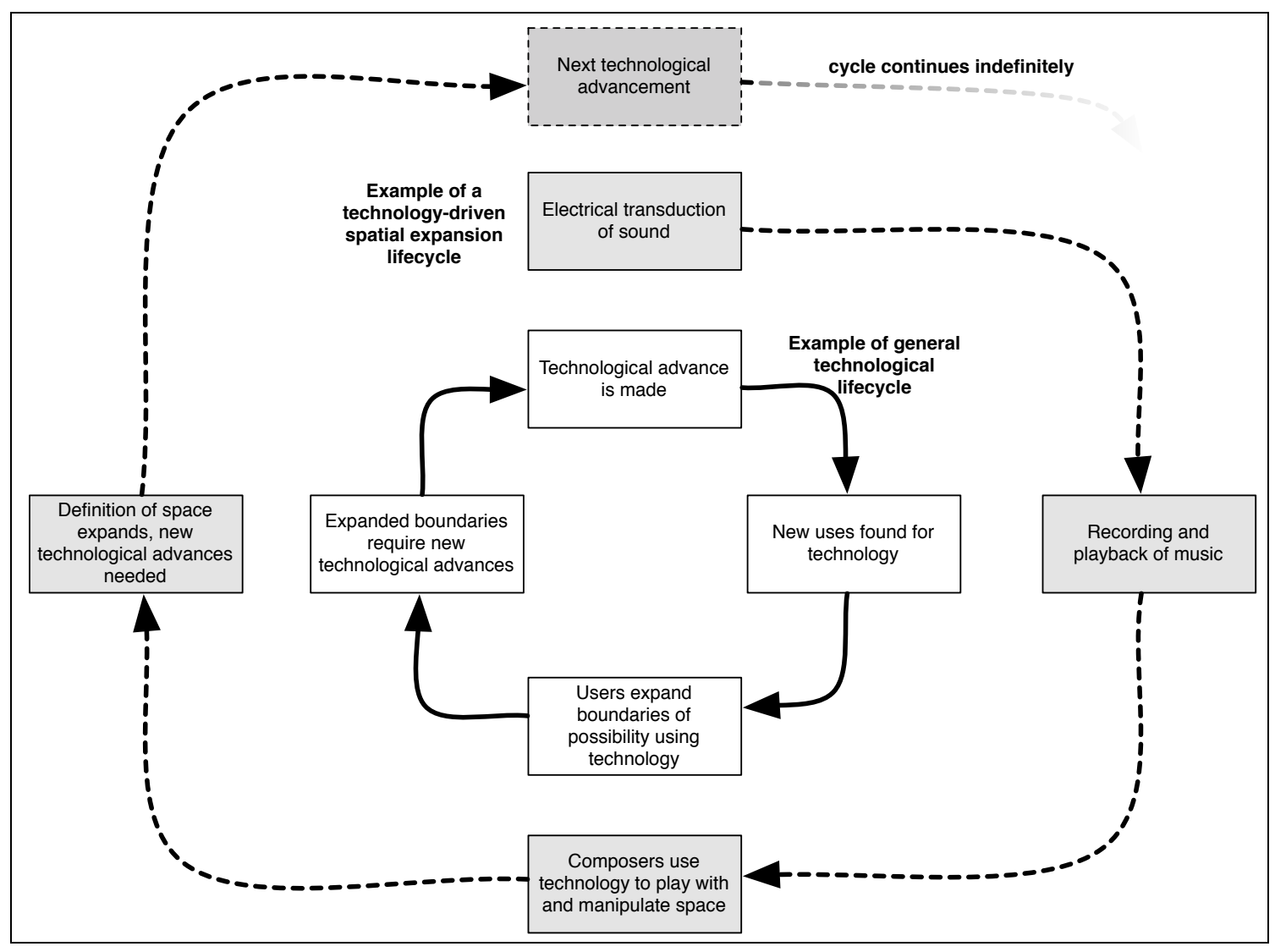

Fig. 3.1: Spatial Expansion cycle following the general technological advancement cycle 
The cycle is not unique to music, as it has driven the general advance of technology since the scientific revolution. Figure 3.1 does not speak to other external influencing factors or the branching that occurs at each turn in the cycle. With each advance, there are multiple new cycles that branch off as a result, each moving in its own direction but also feeding back into the others. In this context, the specific spiraling of these cycles has made possible the decoupling of space, time, and place that lies at the heart of our enhanced understanding of the compositional implications of space.

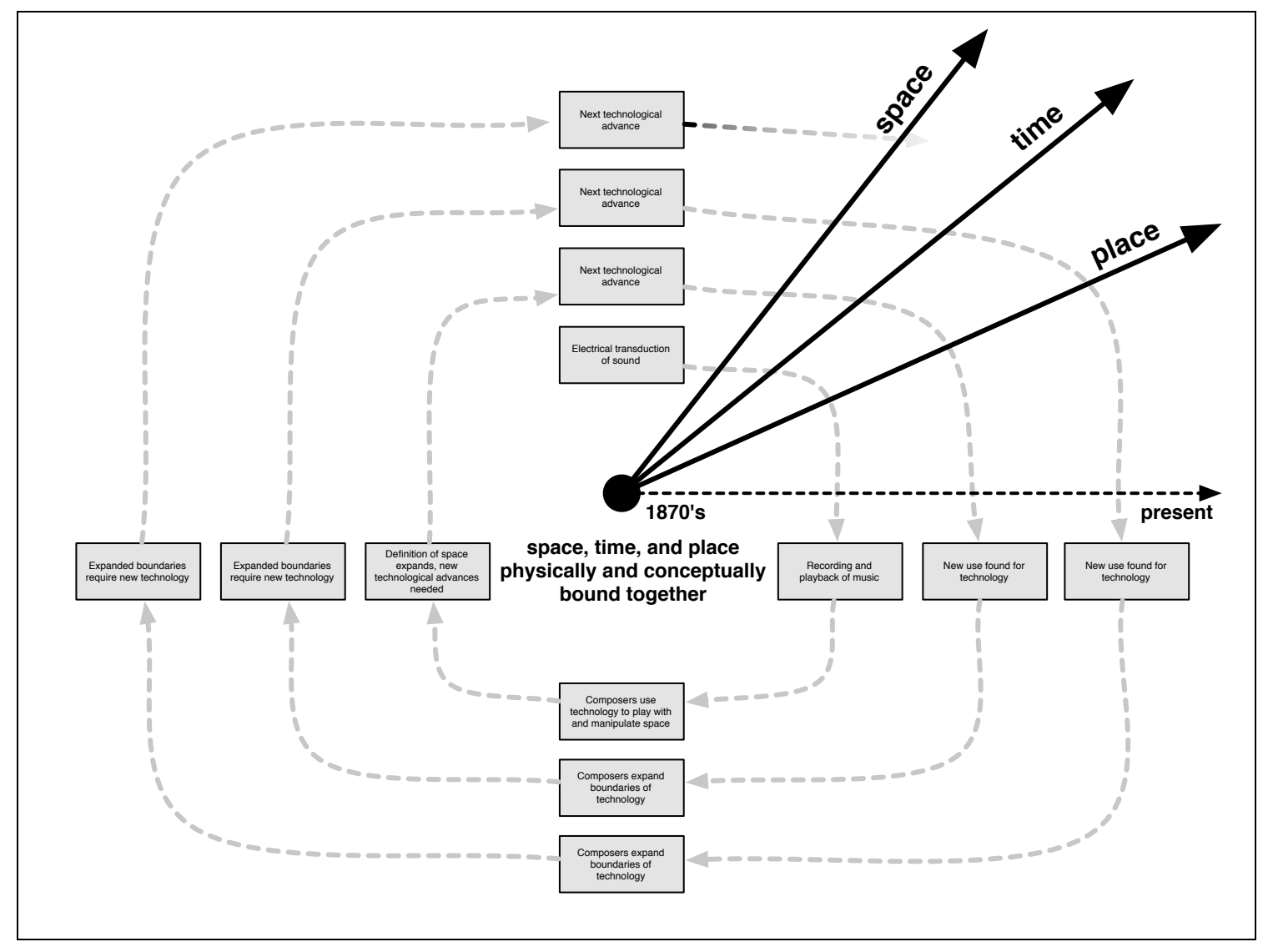

Fig. 3.2: This diagram shows the relationship between space, time, and place becoming increasingly decoupled with each new technological and conceptual advance. 
With every turn of the cycle, we have gained an increasingly granular ability to manipulate sound and decouple the physical acoustic world and its abstracted parameters, such as volume, placement, and direction. Figure 3.2 represents how space, time, and place have become technologically and conceptually separable from each other in relation to the technology cycle in Figure 3.1. This also follows Blesser's and Salter's notion of the two revolutions in sound, discussed in Chapter II, that describes a process of increasing abstraction and more focused granular control in transforming physical acoustic phenomena into electrical phenomena. The first revolution was enabled by the conversion of sound into electromagnetic waves for transmission and into engraved and magnetic representations on recorded media for storage. Sound was shifted into different media through its transduction into electrical variations. This further enabled the abstraction of acoustic space from the time and place of its creation: age-old immutable requirements of acoustic space, such as the need for performers and listeners to be in physical proximity, were no longer so. The second revolution involved the abstraction of those electrical variations into digital bits - allowing for even greater degrees of sound manipulation.

Figure 3.3 shows a number of technological milestones and the associated decoupling. This process happened simultaneously in the physical domain and conceptual domains. For example, the advent of audio recording physically separated sounds from an immediate physical or temporal connection to their source. 


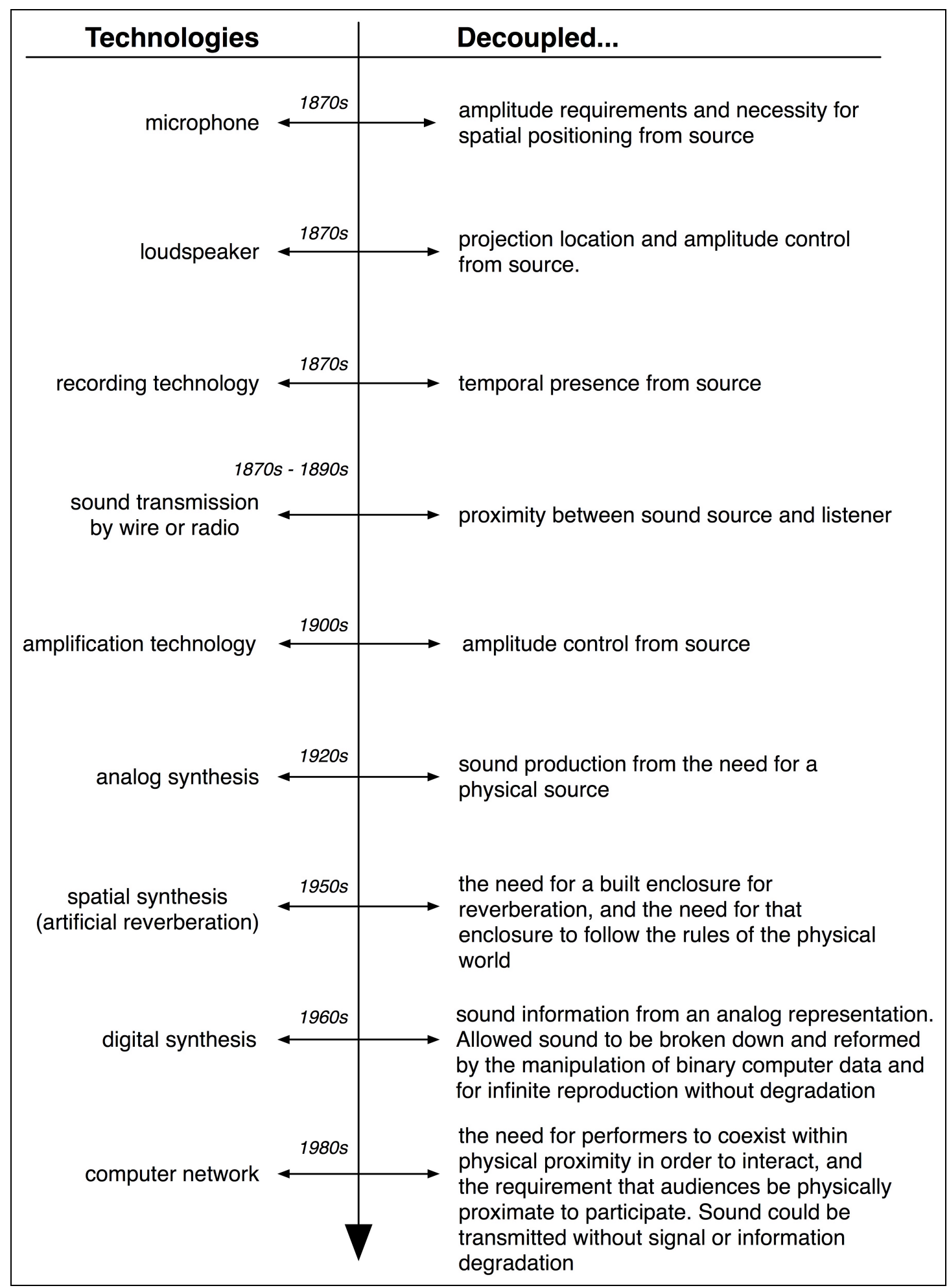

Fig. 3.3: Diagram showing technologies and the associated decouplings they caused 
Conceptually, listeners no longer thought of listening to a 'performance' as an act inextricably tethered to a live event with musicians present. Rather, they could listen to a recording of a performance, displaced in time and space. The telephone decoupled physical proximity and sound production as a necessary prerequisite for a conversation. Conceptually, the telephone decoupled the notion of a conversation as a verbal interaction between two people in each other's physical presence.

\section{The Porous Borders of Modern Space}

As we have gained greater access to spatiality as a musical parameter, the process of decoupling described above has also freed us to think about space removed from its attachment to the physical laws of nature. For instance, in the online virtual world, Second Life, participants take advantage of the ability to create abstracted spaces with few resources and at little or no cost. They build islands, and then fill those islands with houses, art, mountains, trees, and so forth. The world in which those islands exist has no fixed size other than the storage capacity of the computers that contain it - a capacity that grows at a rate that exceeds participants' ability to fill it. This property of abstracted space has led to an explosion in the creation of new ones:

...during the last century, rapid advances in computer and sound technology resulted in a continuous and organic process. As technology moved faster and faster, the rate of discovery increased from a new acoustic space per century (discovering a cave), to a new virtual space per 
day (modifying an algorithm). ${ }^{11}$ (Blesser and Linda-Ruth Salter 2007, 184)

\section{Forerunners of Modern Abstracted Space}

There are several composers who are especially central to the development of modern space-manipulating sound art. Composers such as Edgard Varèse, Iannis Xenakis, Max Neuhaus, Alvin Lucier, and Maryanne Amacher are some who contributed significantly to the expansion of notions of space. Their spatial conceptions are a function of the conceptual and physical decouplings described above. Within this group is a small subset of composers who do not use technology as a core component of their spatial work. For composers such as Henry Brant, spatial notions derive from a different - and older compositional lineage. These composers' contributions to the expansion of space will be discussed ahead.

\subsection{Acoustic spatial music}

While electronics are the primary route through which most composers have approached spatial composition, some twentieth-century composers pursued spatial composition purely through instrumental means. Although composers such as Béla Bartók, Pierre Boulez, Karlheinz Stockhausen, Kazimierz Serocki, and Iannis Xenakis all experimented with spatial placement of instrumental performers, Henry Brant $(1913$ - 2008) was the most established non-electronic spatial composer. He composed over 100 instrumental

\footnotetext{
${ }^{11}$ While Blesser and Salter are primarily referring to virtual spaces created through artificial reverberation and spatialization, one can certainly extend their "rate of discovery" statement to include virtual spaces created via networks.
} 
pieces in which performer and orchestra positioning was a central component. His first spatial work, Antiphony I (1953), "called for five spatially-separated orchestras.” And his piece, Voyage Four (1963) "required three conductors to direct percussion and brass on stage, violins on one side balcony, violas and celli on the other, basses on floor level at the rear, woodwinds and a few strings in the rear balconies, and several individual performers in the audience" (Zvonar 2005). Musicologist Maja Trochimczyk (known and cited as Anna Maria Harley in papers dating from 1987-2000), has written extensively on Brant and spatial music in general. Trochimczyk ties Brant's spatial music to the American experimental tradition exemplified, in particular, by Charles Ives, who's The Unanswered Question (1906) positioned a solo trumpet off stage, distant from the flutes and strings. Trochimczyk contends that "the elevated opinion of Ives's work indicates its importance for Brant's own spatial music, which is - like The Unanswered Questioncharacterized by a complete musical contrast of widely separated layers of sound..." (Harley 1997, 73). In taking such techniques and applying them to full orchestras and even multiple orchestras, Brant was primarily interested in space as a means of separating layers in his music, in much the same way that register and timbre are commonly used to create separate but simultaneous layers. Trochimczyk further notes that Brant's approach to spatial composition contrasted sharply with that of his contemporaries such as Stockhausen, in that Stockhausen only wanted to control those elements of space, such as distance, that could be serialized (Harley 1997, 74). Brant avoided electronic technology, including amplification, and as such, his spatial works followed a different path from that of his technology-utilizing contemporaries: 
Brant has not participated in the systematic search conducted by many avant-garde composers for new means of unifying musical structures. His spatial music has little in common with that of radical "structuralist" composers of spatial music such as Iannis Xenakis... or Pierre Boulez... Yet Brant's compositions... contain an abundance of ideas, relating mostly to space but also to form, rhythm, and perceptual experience. (Harley 1997, 88)

\subsection{The multi-channel and immersion pioneers}

Zvonar (2005) contends that while Leon Theremin's ensemble performances in the 1920s constitute the first technical example of multi-channel loudspeaker music (owing to the fact that each performer had his/her own speaker), Pierre Schaeffer was the first composer to truly use multi-channel spatialization with a series of tape works in the early 1950s. Considering early Theremin performances as multi-channel seems to be a purely technical conclusion. Although Theremin's performers used transduction and electronics, the players were always playing next to the transducer, so that sound emanated from their direction much as it does with a traditional instrumentalist. Theremin ensembles did not differ substantially, from a spatial perspective, from a traditional chamber ensemble except in their use of speakers and synthesis instead of acoustic sources. Schaeffer created a physical interface to control the spatial distribution of sounds from various tape players. Still, as each tape player produced a mono signal, the spatial dimension was 
limited to individual mono streams moving around a tetrahedral system. Zvonar credits Karlheinz Stockhausen with the first quadraphonic multi-channel performance, with Kontakte, from 1960 (Zvonar 2005). Here, sound was subject to several levels of decoupling. It was abstracted from its acoustic source via recording, and then passed into a system that could project it anywhere within a bounded space. What followed were works in which the composers did not need to keep their sounds static in spatial origin as if played by seated instrumentalists. The ways in which the sound moved were now under the control of the composer and could function as a structural component.

Varèse and Xenakis were also early explorers of multi-speaker ${ }^{12}$ and diffused audio. Their works used multiple speakers to surround the audience in three dimensions. Through multi-speaker performance, they could create immersive textures, highly directional sound or gestures, or phrases that moved along a path from one point to another. These techniques played with a layer of musical meaning - one in which large three-dimensional and immersive spatial gestures could be made, with their own proportions, relationships, and counterpoint. Spatial gestures could, in turn, be tied back into other aspects of a piece such as timbral, tonal, or temporal changes - adding another layer of musical material. Top-level spatiality as performed in these multi-channel/multispeaker pieces was not 'the sound', but the point(s) from which the sound originated. Within those sounds, other spatial modes and gestures could exist (the addition of

\footnotetext{
${ }^{12}$ I use the term multi-speaker here instead of multi-channel, as the two terms can mean different things. For example, Xenakis's Hibiki Hana Ma was both multi-channel and multi-speaker: It played 12 channels of audio through 800 speakers - the number of channels of information differing greatly from the number of speakers.
} 
artificial reverberation for example), but with diffusion and surround-sound, the relationship between space and sound was not mutually exclusive - the sound could exist without the need for multiple speakers, but the space could not.

Varèse and Xenakis' works, as showcased in the well-known Phillips Pavilion at the 1958 World's Faire, have been discussed extensively elsewhere, as they are milestones in the history of $20^{\text {th }}$ century music and multimedia. ${ }^{13}$ The Pavilion was and remains a seminal moment in the fusion of architecture, sound, and image, and one can view it as a precursor to contemporary commercial spaces such as IMAX theaters or home surround sound systems, as well as the contemporary practice of sound diffusion and multi-channel performance and the creation of immersive virtual environments. Several other multispeaker/multi-channel, multimedia environments of note followed the Philips Pavilion. These environments allowed composers to play with a variety of spatial shapes and different approaches to sonic and visual immersion. Such spaces included Karlheinz Stockhausen's spherical auditorium at the 1970 Osaka Expo, in which fifty loudspeakers were arranged in seven concentric circles above and below the audience, and John Cage's HPSCHD (1969), which used circular projection, multi-channel sound collage, and colored lights to transform the interior of University of Illinois's Assembly Hall into an immersive and otherworldly space (Forsyth 1985, 321-324). Through the use of loudspeakers, composers could both precisely control the timing and the points from which sounds could emanate. Current technology allowed for the decoupling of sound

\footnotetext{
13 See Marc Treib's "Space Calculated in Seconds" (1996), the definitive book on the history of the Philips Pavilion
} 
from an acoustic source, and the projection of the decoupled sound from an indefinite number of points in space (loudspeakers). By clustering hundreds of speakers together in architectonic forms, composers could then treat these sonic matrices as immersive threedimensional canvases from which to project any number of surround environments.

Early experimenters in multi-speaker/multi-channel and immersive sound were not only concerned with symmetrical surround experiences as is the case with Stockhausen's spherical auditorium. Xenakis created numerous pieces for distributed speaker systems, many of them in geometric designs that allowed him to create aural spaces not possible with a simple surround system. Architect Sven Sterken described Xenakis's desire to implement a 3D grid of hundreds of loudspeakers to create audible geometric structures in 3D space. "In Xenakis's vision, the acoustic grid was not only a highly sophisticated sound projection system but a device to generate ephemeral architectures and virtual spaces" (Sterken 2007, 38). Xenakis's desire, in this sense, was to literally draw figures and surfaces in sonic space. According to Sterken, Xenakis was only able to test this idea once at the 1970 Osaka Expo, when his electronic piece, Hibiki Hana Ma, was broadcast in the Japanese Steel Federation's Pavilion over 800 loudspeakers "following all sorts of geometrical configurations" (Sterken 2007, 39). Here, another conceptual decoupling occurs. If numerous sound emitting points can be spaced around listeners to attempt to recreate the three-dimensional sound that we experience in the physical world, then it follows that those speakers could be repositioned into radically different configurations to create spaces that are unrelated to our real-world acoustic experiences. 


\subsection{Space as a processor}

While Brant and many of his technology-focused contemporaries were experimenting with three-dimensional source placement to create surrounding experiences, artists like Maryanne Amacher and Alvin Lucier experimented with resonant space and the combining of resonant spaces from different locations to create hybrid spaces - sound as a means of joining spaces and making spaces present by playing them as if they were instruments. In many of their spatial works, the space and the sound are inseparable. Qualities of the space filter the sound as it is fed back into the space, reinforcing the filtering. In this approach, technology becomes a tool by which to augment an acoustic architecture - it enables sound that would otherwise disappear from the space to be instantaneously returned back into it, repeatedly and recursively multiplying the space's resonant qualities. I discuss this approach with respect to other artists in Chapter IV, and in respect to my own Five Spaces series in Chapter V.

Works that play with spatial resonance, such as those by Lucier, Amacher, and others, fit well into model proposed by Blesser and Salter for analyzing spatial relationships. They differentiate between primary acoustic enclosures, such as the body of an instrument, and secondary acoustic enclosures, such as the room surrounding that instrument. They assert that an instrument minus the space it is performed in is really a proto-instrument, and that when surrounded by an enclosed space, performers are really playing meta-instruments the instrument plus the response of the space to that instrument (Blesser and Linda-Ruth 
Salter 2007, 139). According to their model, the spatial resonance pieces discussed above are really performances of secondary acoustic enclosures or meta-instruments. From the primary/secondary enclosure perspective, these works use a primary enclosure to excite a secondary enclosure, and then feed that secondary enclosure back into itself, exaggerating its otherwise subtle or imperceptible properties.

The most well known example of the primary/secondary enclosure resonant feedback approach is Lucier's seminal 1969 tape piece, I Am Sitting in a Room. It records an impulse - Lucier's voice reading a short text - resonating the recording space. Then, in playing back and re-recording the original numerous times, Lucier's voice gradually disappears as the resonant frequencies of the space increasingly reinforce themselves. Lucier's act of exciting a system with an impulse, and then allowing that system to feed back, thus revealing its resonances, idiosyncrasies, and limits, is one that has been duplicated many times in various forms throughout experimental music. It exists on a very small technical scale, as with resonant pitched filters such as comb filters, to entire pieces such as my own piece, ground loops: for solo percussion and internet (2005), in which successive passes of sound through an MP3 encoder reveal virtual resonances within the processing software, much like Lucier's voice does with a room. Recently, composer and video artist Patrick Liddell did a version of Lucier's piece called I am Sitting in a Video Room ${ }^{14}$ (2010). Instead of resonating a physical room, Liddell read and processed a modification of Lucier's text through the video sharing website, Youtube.

\footnotetext{
${ }^{14} \mathrm{http}: / / \mathrm{www}$. youtube.com/watch?v=icruGcSsPp0
} 
Liddell passed the video through Youtube's encoders 1000 times, resulting in a series of videos in which both sound and image show the cumulative effects of repeated filtering through the digital encoding space.

Lucier's 1970 piece, Quasimodo the Great Lover, further expanded the notion of space as a means of sound processing, in that it specifies a system of connected spaces in which a microphone at the 'performance' end of the piece is played through a loudspeaker in another space. The sound from that loudspeaker is then picked up by another microphone placed far enough across the space that much of the sound it picks up is resonant coloration and reverberation. This series of microphone-speaker-microphone-speaker connections may go on indefinitely, accumulating and aggregating spatial resonance until it ends at a listening point some distance away. Lucier's description of acceptable spaces to resonate includes "prairies, glaciers, or ocean basins" as well as "rooms, foyers, and corridors of houses" (Lucier 1970). In this piece a similar system to I am Sitting in a Room is conceptually altered to decouple a room's resonance from the room itself. The resonance of the space becomes abstracted from the space and used as an impulse to resonate the following space. Using the primary/secondary enclosure model again, this piece takes an impulse and resonates it through secondary, ternary, quaternary, etc. enclosures, creating an accumulated sound that is a hybrid of the resonances of all spaces it has passed through 
In a similar vein, Amacher's Music for Sound Joined Rooms (1980 - 2002) was a series of site-specific pieces in which Amacher explored and then exploited the acoustic characteristics of built spaces such as houses and museums. She would do this by spending up to a month exploring the acoustics of the site, and then creating and tuning a work in which the materials of the site - walls, ceilings, floors - resonate and transmit sound throughout. Amacher credited Stockhausen for the idea of a musical house - his 1968 piece, Musik für ein Haus, involved musicians performing in four rooms of a twostory house. Microphones were used to mix sound between rooms, and in a fifth room a mix of the other four rooms could be heard (Forsyth 1985, 321). In Amacher's piece, the space is not just the resonating air within the rooms, but the materials of the rooms themselves. In connecting the spaces, she blurs the borders between secondary enclosures (the rooms), and in having one enclosure play into another and back, the borders between primary and secondary enclosures also become fluid.

\subsection{Network music pioneers}

In several of the pieces described above, transmission of audio between spaces was of fundamental importance, but at the time of their first realizations they were typically constrained to transmission via audio cable within a limited range. Composer and performer Max Neuhaus expanded that range with several continent-spanning pieces, beginning with his proto-networked space in his Public Supply series from the mid-1960s to mid-1970s. Composers such as Neuhaus imagined using communication networks to join people over distances in a single musical space. What differentiates Neuhaus's work 
from simple radio or television broadcast is that the communication - much like over a computer network - was bi-directional. Listeners created the content to fill the space. In this way, early network pieces invert the relationship between space and sound presented in the multi-channel works. Here, the space is created first via a series of connections and nodes, and then the space is filled with some sonic content. The space modifies the content through its noise, its resonances, and its sonic idiosyncrasies, and the listeners hear the summation of all of their input. Unlike multi-channel and diffusion works, these spaces - like an empty room - can exist without the sound, but the sound they contain cannot exist without the space.

The first of Neuhaus's radio network pieces, Public Supply (1966), used ten phone lines at New York's WBAI radio station to bring in sounds from callers. Callers could contribute any sounds they wished, while Neuhaus mixed them and broadcast them over the air. Callers were also encouraged to turn their radios up in the background, so as to create feedback tones between their radios and phones. Neuhaus performed four versions of Public Supply before moving on to Radio Net in 1977. Radio Net looped callergenerated sounds - in this case, Neuhaus request that people whistle - in five call-in cities. The outputs from each of the call-in cities were mixed at the affiliate in Washington, D.C., and rebroadcast. As Neuhaus described it, the piece "created a soundtransformation 'box' that was literally fifteen hundred miles wide by three thousand miles long” (Neuhaus 1994, 5-9). The decoupling that occurred here was within two technologies: radio and telephony. By combining these two technologies, it decoupled 
radio from its limitation as a one-way medium with isolated listeners, and it decoupled telephony from its limitation as a medium in which only two people could engage in a conversation. The removal of these limitations through the mixing of technologies conjured into existence a very large hybrid space. This early transcontinental sonic space was a precursor to the interactive telepresence compositions that would later share sound, video, and other information between performance sites.

The ideas behind the works mentioned above were on a collision course with the personal computer revolution of the 1980s, and the Internet revolution of the late 1990s. The new tools of the 'digital age' increasingly democratized the new media arts, giving lessestablished artists access to powerful yet inexpensive production and communication tools. The ability to convert analog media to digital bits - the de facto language of the modern computer - further enabled the decoupling of sound and space from their physical source. Data and sound would not degrade over a digital network. Data streams, collections, and signals could be copied and repeated infinitely with no cumulative loss in quality. This core property of the digital network would become key to early experiments in computer network performance. The real-time shared network space found it's first expression in the early experiments of the League of Automatic Music Composers. Formed in 1978, the League was a group of San Francisco Bay Area composers who used early microcomputers to synthesize sound and share performance data (pre-MIDI) between the machines such that one performer's pitch data could be used to influence a different musical parameter on another performer's machine. As John Bischoff, one of 
the members of the League describes, the KIM-1 microcomputers they used did not have monitors or keyboards in the conventional sense, and the network was made via adhoc physical connections between machines (Brown and Bischoff 2002, 4). In the shared data space used by the League, arbitrary parameters of a musical performance could be decoupled - the pitch contour of a gesture sent to one player, the rhythmic shape of the gesture to another player. This space wasn't resonant or reverberant in the traditional sense, but it was a virtual communication space - a medium through which information passed that modified and reconfigured that information according to a set of global rules. Changing the rules governing the space produced vastly different (and often unpredictable) effects, and was the basis for their compositions.

The League disbanded in 1983, but in 1986, League members John Bischoff and Tim Perkis formed The Hub, after using a KIM-1 microcomputer as a central "mailbox", or hub, in which one performer could post control data that other performers could access at will. This small central computer became a shared data space in which musical information could be passed back and forth. The Hub eventually expanded to include composers Mark Trayle, Chris Brown, Scot Gresham-Lancaster, and Phil Stone. Their first official concert took place in 1987, in which two performance spaces in New York, The Clocktower and Experimental Intermedia, were linked by a modem. The Hub split into two trios, one in each space. As Brown describes it, "Three of the pieces, 'Simple Degradation', 'Borrowing and Stealing', and 'Vague Notions', were designed as network pieces, that would use the modem network to create the acoustically divorced, but 
informationally joined sextet" (Brown and Bischoff 2002, 8-9). The trios were also networked among themselves in each space, so the music was different depending on where one was listening. The modem connection was extremely slow by modern standards and only simple control data could be shared, but it nonetheless created a shared data space over a distance, creating pieces that existed simultaneously in two places at once. Brown contends that the Hub was "the first (as far as we know) to make interactive, live electronic music in a computer network, and despite the primitive nature of that network (compared to those available at present) we were the first to experience its potentials and its problems" (Brown and Bischoff 2002, 20). The Hub disbanded in 1995 as members moved on to other projects, but they have on occasion reunited for short tours and performances.

The Hub's "Clocktower" performance was one of the first performances in which a network-enabled piece could only be received in part by any listener or performer. Depending on one's location during the concert, one would hear different material on either side - related through the joined network space of the modem, but different at the endpoints. Such multi-location pieces are fairly common today, often using ultra-highspeed networks to share multi-channel CD quality audio, high definition video, and other data. Stanford University's SoundWIRE group as well as Pauline Oliveros's Telematic Circle project, discussed ahead in Chapter IV, are just two of the numerous groups experimenting with high definition network-shared performances. In the model I have laid out so far, these types of pieces represent a radical decoupling across numerous 
dimensions - sound from instrument, sound from site, performer from audience, performance from physical space, site from physical space, and so forth. It is as if the entire artwork has been detached from an existence in rational or physical space: it is not possible for a human being to properly receive the entirety of a single performance, just one unique variation of it depending on their location.

The technological developments since the Hub's first concert have made networked musical interaction relatively easy to implement. Using a computer, a network connection, and any of numerous software packages, one can connect to other musicians and exchange data, audio, and video. Network music ensembles are now common among numerous academic programs, including Perry Cook's and Dan Trueman's Princeton Laptop Orchestra (PLOrk), Matthew Burtner's Mobile Interactive Computer Ensemble (MICE) at the University of Virginia, and, most recently, Ge Wang's Mobile Phone Orchestra (MoPho) at Stanford University.

The combination of the technologies in play, and the concepts of spatiality that have evolved because of them, have brought us to a point where the composition of space can be a highly controlled, rich, multi-parameterized domain. Much as the pitches available in an acoustic instrument or the colors available on a paint palette, artists can mix, match, and combine existing and new spatial types to form hybrids. In the following chapters, I will discuss the work of contemporary artists, and my own compositions, as they relate to this model. 


\section{Chapter IV: Contemporary Spatial Players}

\section{Introduction}

In this chapter, I examine pieces by contemporary composers that exemplify the spatial categories discussed above: physical, abstracted, and hybrid. I begin by discussing works for physical space by pioneering artists Bernhard Leitner and Maryanne Amacher. They created installations and performances that resonated existing physical spaces and the inner space of the human body. I follow by discussing artists who work with abstracted spaces produced and manipulated with electronics. These include Jonty Harrison and his multi-channel BEAST diffusion system, Natasha Barrett and her 3D Ambisonic installations, and the virtual sound sculptures of Adam Nash.

Finally, I discuss hybrid spaces in two subcategories: those that combine physical space with network space, and those that combine physical space with electronically manipulated sonic space. In the first subcategory, I discuss early and recent networked musical performances by composers Jesse Gilbert and Jonas Braasch respectively. Their telematic pieces spatially connected performers and audiences across distant sites. I also discuss a site-specific piece by Teri Rueb in which sound playback was tied to coordinate locations through the use of GPS. In the second subcategory, I discuss the site-specific sound installations of Janet Cardiff, Bill Fontana, and Jeff Talman. These pieces all use only recorded sound played through headphones or speakers to meld with the listener's surrounding physical space. As with most art, the pieces do not always fit cleanly within 
the categories to which I have assigned them. Yet they all serve to illustrate the various approaches those categories afford the artist when composing space.

\section{Reshaping Physical Spaces}

\subsection{Site resonance}

Violinist and new music historian, Gascia Ouzounian has written about aural architectures and embodiment in relation to both Maryanne Amacher's and Bernhard Leitner's works. She notes that "since the late 1960s, when a tradition of sound installation first blossomed on a large scale in and between music and visual arts arenas, composers and artists have variously conceived of the human body as a resonant space, one in which aural structures can develop" (Ouzounian 2006, 69). I will begin with Leitner, who holds a degree in architecture, and who discusses his work in architectural terms, thinking of sound as a 'structural material' (Leitner 1998, 7). In his piece, Water Mirror (1997), he works directly with an existing built space by altering its physical properties. This very simple and elegant installation was placed inside the Donautempel, a symbolic shrine at the head of the Danube River. The original shrine consists of four columns supporting a roof, with the sides of the structure open to the outside. A small aqueduct running under the temple spills water into the river. Leitner added two curved metal 'sound reflectors' suspended inside the temple above the listener. The sounds of the river are focused downward into the temple and onto whoever is beneath the reflectors (Leitner 1998, 265). The concrete floor also provides a degree of reflection back up to the 
listener and the sound mirrors. Water Mirror uses no electronic modification. Leitner describes it as follows:

In the metal arch, which also reflects the optical refractions of the undulating water surface, various frequency ranges are filtered from the deeper-lying, rushing sounds of the Danube. Through the searching, scanning, listening movements of head and body, the person wanders in the frequency fields of the vaulted ceiling. A dance-like dialogue with the Danube floating above one. (Leitner 1998, 265)

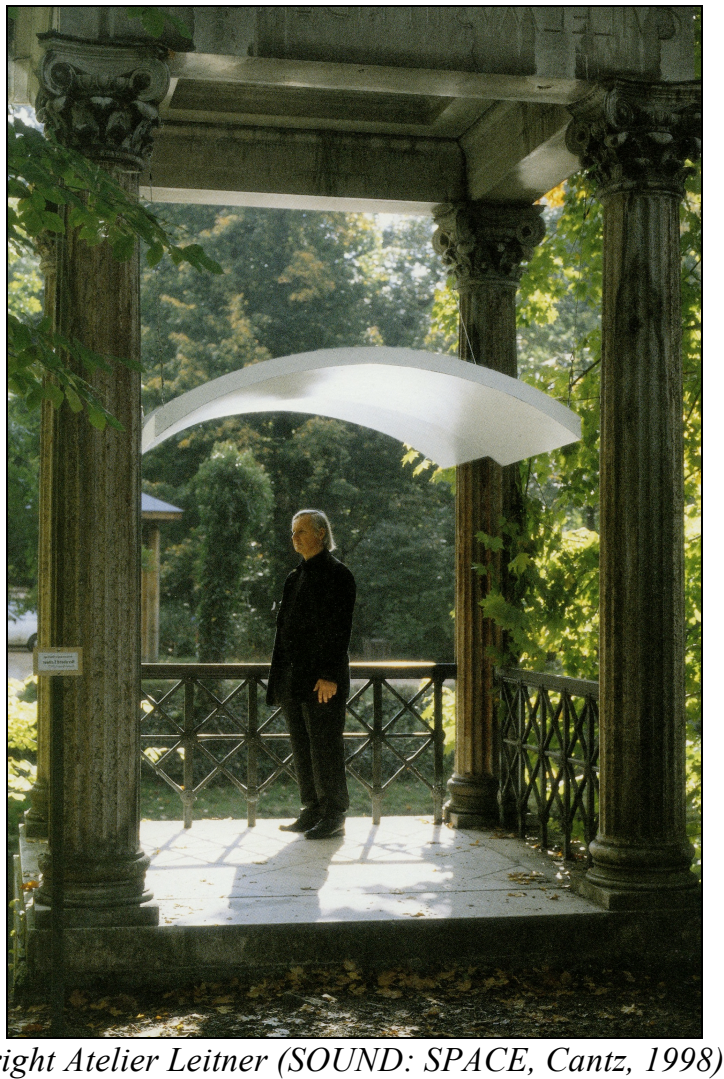

Fig. 4.1: Leitner standing beneath his installation, Water Mirror (1997) 
Although Water Mirror does not use electronic technology, it does use a scientificallygrounded understanding of acoustics to alter the aural architecture of the original space. It is fairly simple to resonate a physical space by turning on some speakers and playing sound into it, but without electronics, creating this type of spatial experience can be a difficult task, requiring familiarity with materials, acoustics, and physical design. Leitner's modification of the space enhances and concentrates properties of the physical space. In focusing the sound in such a way that moving within the space changes what one hears, he takes what is a public space and introduces a degree of acoustic intimacy the sound and spatial experience one has within the temple become personal, acoustically tuned to one's position within it. The intimate relationship of the visitor to the space reenforces its sacred nature, creating a sonic dialogue between listener and river: Water Mirror 'speaks' about the river to the listener. Experiencing the body as a central player in spatial sound is key to a number of Leitner's other pieces as well. It is also central to the work of Maryanne Amacher, who I will discuss in detail below.

\subsection{Body resonance}

Leitner's series, Sound Chairs I - III $(1975,1976,1991)$, is about sound as an experience within the body. Each successive version of the Sound Chair series is an advance on a design involving speakers mounted underneath a curved reclining chair. The first chair (see Fig. 4.2) used speakers beneath a deck chair. Further iterations advanced the physical design as well as the technology. 
Leitner's body-centric pieces are typically built for an individual listener. Low blown sounds, horn sounds, and so forth, are played into the body of participants, often moving back and forth or 'swinging' between speakers. The participant hears the piece with both their ears and their body, creating a deeply internal and corporeally-centered experience (Leitner 1998, 74). These pieces primarily heighten a listener's awareness of his/her own physical space. In experiencing them, the listener may become aware of the physical or felt space of their own boundaries as the sound vibrates their bodies and interacts with them through touch and induction.

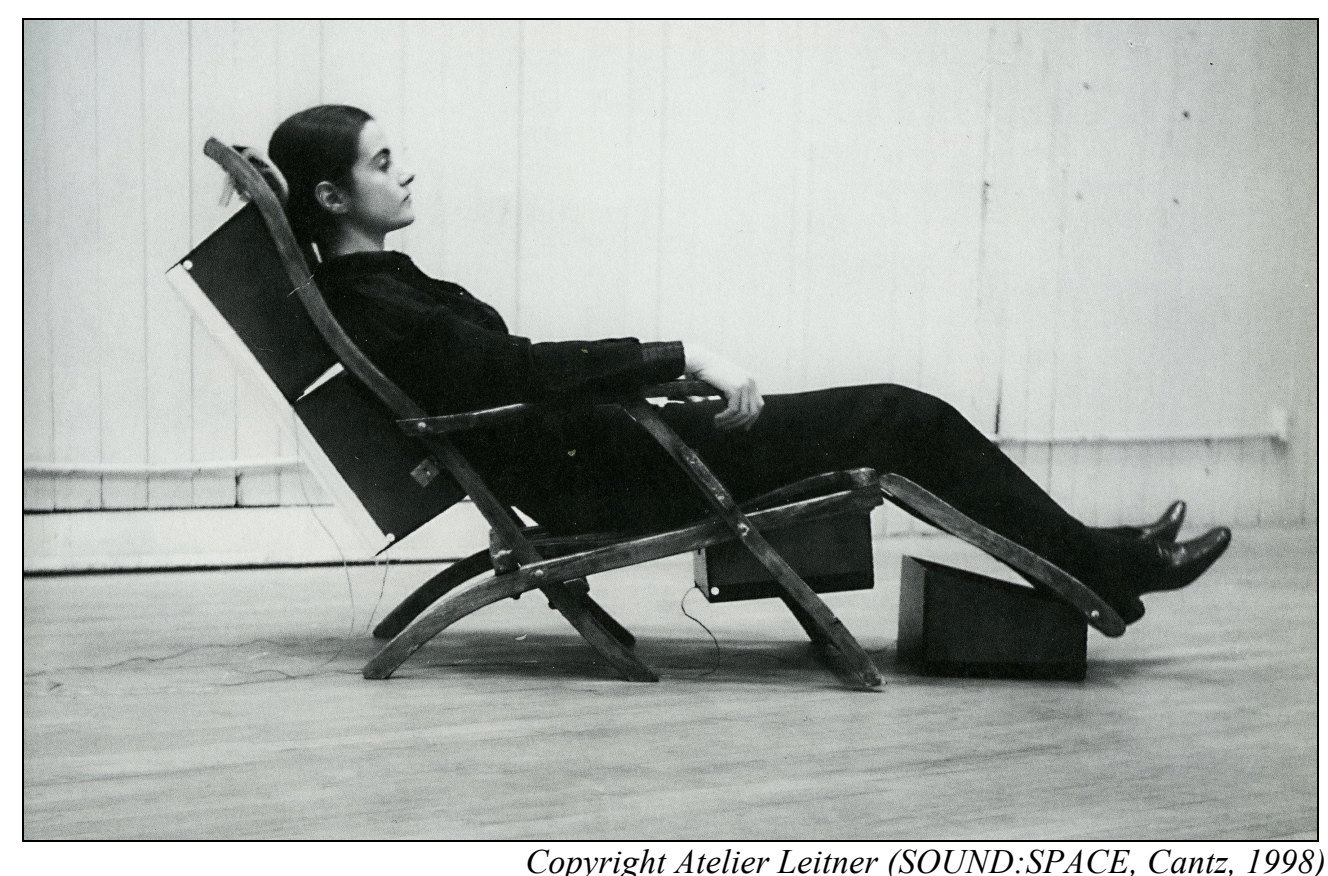

Fig. 4.2: A listener sitting in Leitner's Sound Chair I (1975

In his piece Vertical Space for One Person (1976), Leitner uses the body of the listener as a replacement for the shaft of a column. Two cylinders forming the base and capital are 
embedded with loudspeakers. The listener stands on the base, and sound moves up and down the axis of his/her body. Leitner attempts to conceptually merge sound and architecture as is evident in his description of the piece (note Leitner's italicizations):

The bowed or beat sound strikes strongly at the basis, wandering with decreasing intensity through the axis of the body towards the pianocapital. The column, the vertical posture is directed upwards. The feeling of levitation is alluded to acoustically. The skin on the top of the head hears the capital softly beginning to play. The sound sinks, while gaining intensity, through the body axis to the forte-base. (Leitner 1998, 230)

As in the case of the Sound Chairs, the body becomes the central space of resonance while the sound from the speakers may be audible to other listeners in the area, participating in the piece by becoming the physical space of the column is essential to the experience.

Composer Maryanne Amacher also used resonance within the body, and in particular, the creation of perceptual ambiguity in our hearing. In excerpts from her installations Music for Sound Joined Rooms (1980 - 2002), discussed briefly in Chapter III, the pieces Head Rhythm 1, Dense Boogie 1, and Chorale 1 use a well-documented phenomenon known as otoacoustic emissions, in which closely pitched externally generated tones create difference tones within the ear of the listener - the inner ear literally vibrates at a 
perceptible third frequency. Amacher termed this phenomenon "Third Ear Music", and described that "when played at the right sound level, which is quite high and exciting, the tones in this music will cause your ears to act as neurophonic instruments that emit sounds that will seem to be issuing directly from your head." In concerts, audiences "discover they are producing a tonal dimension of the music which interacts melodically, rhythmically, and spatially with the tones in the room" (Amacher 1999, Liner Notes).

It is critical to consider that, in their original incarnation as "sound characters" in her Music for Sound Joined Rooms installation, one's perception of these pieces in situ would be tied to the larger experience of music swirling throughout the physical space, emanating from walls, floors, and ceilings. Like Lietner, Amacher also described her piece in architectural terms:

Immersive aural architectures are constructed, linking the main audience space sonically with adjoining rooms through specially designed multiple loudspeaker configurations, creating the effect that sounds originate from specific locations and heights rather than from the loudspeakers. The idea is to create an atmosphere similar to the drama of entering a cinematic close-up, a form of "sonic theater" in which architecture magnifies the expressive dimensions of the work. (Amacher 2009) 
You could imagine that being in the space of Amacher's installation, you might hear and feel the building vibrating, and in addition you would hear tones and melodies that appear to emanate from inside your head ${ }^{15}$. A visitor to the installation might have the impression of being physically connected to the space via sound - an actor in a “cinematic close-up". Their bodies are creating sounds that meet and merge with the sound from the space, producing a spatial bonding. Ouzounian describes this experience as "an encounter of real and imagined spaces, wrought in the body, produc[ing] alternating fields of vibration - at times beating positively to create an augmented awareness of self, spirit and surrounding; at other times clashing to reveal the limits of the body" (Ouzounian 2006, 70). What separates these pieces from the pieces discussed ahead is that they are about the experience of the existing physical space of the site, whether that is the river shrine in Water Mirror, or the body in the Sound Chair and Sound Column pieces, or a combination of body and site in Music for Sound Joined Rooms. Whether through physical shaping of the site or electronic manipulation, the spaces emphasized by these pieces already exist in the physical world. In the pieces ahead, the spatial focus moves onto the creation of ephemeral and imaginary - or abstracted - spaces, and also onto the mixture of those spaces with existing physical ones.

\footnotetext{
${ }^{15}$ While I was not able to experience Amacher's installation first-hand, the "sound character" excerpts given on her CD provide a substantial experience of the "third ear" phenomena she described. When turned to a high enough volume, melodies appear to emerge out of the sound that I almost 'feel' coming out of my head. It is a slightly disconcerting experience and more physical - like a sense of touch - in its connection to the sound than one is accustomed to.
} 


\section{Shaping Abstracted Spaces}

In the context of abstracted spaces, sites and bodies may still be resonated, but the spaces created are temporary, conjured into existence through electronic media. A number of compelling questions come to mind regarding abstracted spaces: if an abstracted sound space is created within a physical space, as in an Ambisonic installation within a museum space, what properties differentiate it from its surroundings? What role does cognition play in differentiating abstracted and physical spaces? Is this distinction based more on conceptual and theoretical notions than on actual perception? I use this differentiation to illustrate the categories of compositional design. While the examples given here are differentiated for analytical purposes, in the real world the borders between abstracted and physical spaces are not always clearly defined.

\subsection{Abstracting space into multiple channels}

While there are numerous approaches to presenting multi-channel audio, composer Simon Emmerson ${ }^{16}$ divides these into two philosophical camps: the idealists and the realists. He writes that "the idealists believe that the function of concert loudspeaker systems is to present to the listener a soundfield as near as possible to that which the composer heard in the studio during composition" while the realists "argue that such an ideal cannot exist, or if it does it is meaningless. The studio does not resemble a concert hall: the room acoustic, the available equipment and limitations on its layout, all ensure we can never recreate such an ideal - even if it existed in the first place. The best that can

\footnotetext{
${ }^{16}$ Emmerson's book, "Living Electronic Music”, provides a detailed history of the various multi-channel performance systems and approaches, beyond the scope I am able to cover here.
} 
be done is to treat the presentation as interpretation" (Emmerson 2007, 147-148). Since the 1960s a number of well-known multi-channel performance systems have been implemented, with most of the designs reflecting the 'realist' approach. Researchers Adrian Moore et al. note historically important multi-channel systems such as François Bayle's Acousmonium at the Groupe de Recherches Musicales (GRM), Christian Clozier's Gmebaphone (later renamed the Cybernaphone) at Groupe de Musique Experimentale de Bourges (GMEB), and Jonty Harrison's Birmingham ElectroAcoustic Sound Theatre, or BEAST, which I will discuss in greater detail below (A. Moore, D. Moore, and Mooney 2004, 318).

Composer Jonty Harrison has composed and designed performance systems for abstracted spaces for several decades. He is particularly well known for founding the BEAST in 1982 at the University of Birmingham in the UK. The BEAST is primarily used as a sound diffusion system, in which performers manually move sound throughout the space using a specialized mixer. The BEAST system uses eight main speakers augmented with numerous other speakers of varying design and frequency range placed throughout the space and around the audience. The system is left-right symmetrical, but asymmetrical with respect to front, back, top, and bottom (Harrison 1998, 121-124). Most of the pieces played through the BEAST were originally composed for two channels. As Zvonar notes, "it is typical for BEAST composers to use a two-channel source. The stereo perspective of the source is generally preserved, so that the left channel signal is split and sent through all the channel strips feeding the left-hand speakers, while the right 
channel feeds all the right-hand speakers" (Zvonar 2005). The BEAST is somewhat unusual in this respect, as most multi-channel electro-acoustic concerts (at least in the United States) feature matched systems of speakers surrounding the audience in a symmetrical or near-symmetrical configuration. The purpose of the BEAST, however, is not to surround audiences with a sonic simulation of three-dimensionality, but rather to act as a mediator in the playback of acousmatic pieces. Interpretive performed diffusion through the BEAST's custom-made mixer (usually by someone trained in the art of diffusion) uses spatial movement and dynamics changes to accentuate various aspects of an acousmatic composition. The approach bears some resemblance to Brandt's use of space as a means of creating sonic clarity when multiple streams of information are present, except that this layer of the piece is often added by someone other than the composer. Harrison notes that one of the main objections to diffusion "is that the composer's intentions about space, dynamic, etc., can be overridden by the diffuser and the piece destroyed as a result. Of course, this can be true; but this is no more than saying that bad, unmusical, inappropriate or inept interpretations destroy Bach, Beethoven or Boulez. As with any other musical activity, there is good and bad diffusion" (Harrison 1998, 124). 


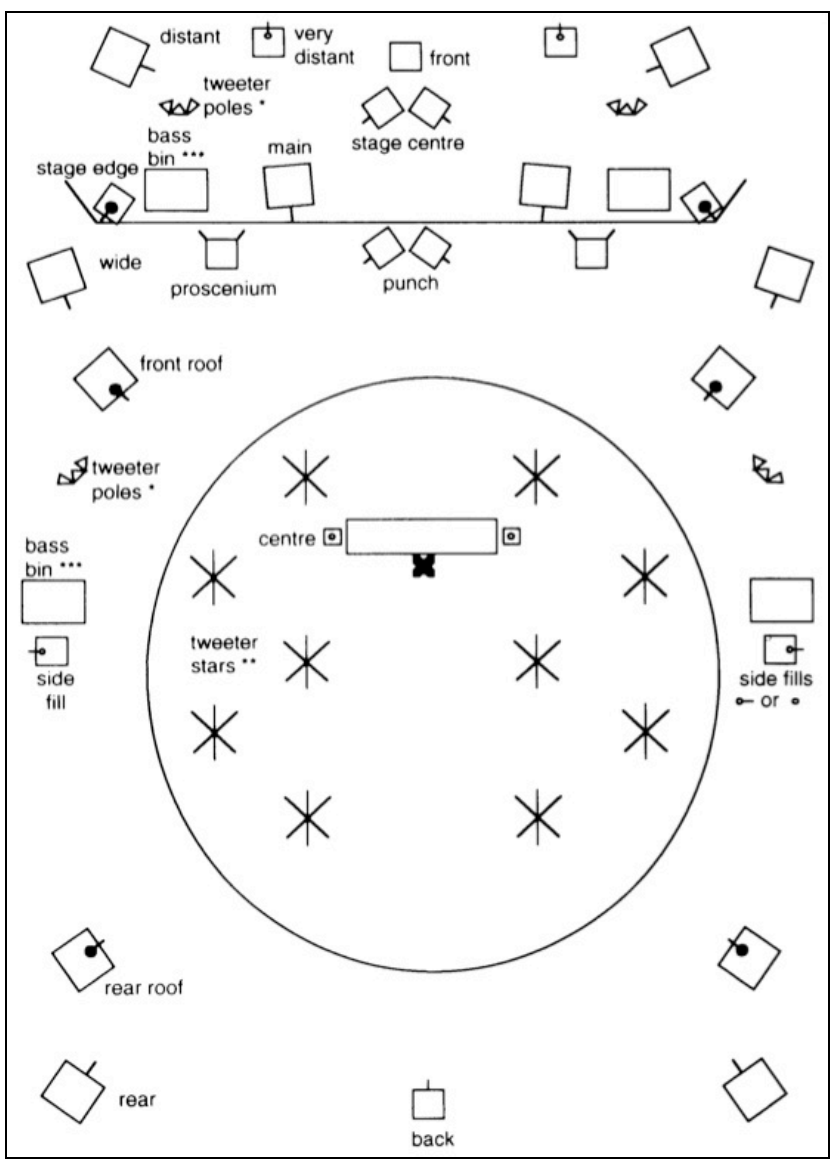

Image from Harrison, Jonty. 1998. Sound, Space, Sculpture--Some Thoughts on the 'What', 'How', and 'Why' of Sound Diffusion. Organised Sound 3, no. 2 (August): p.123.

Fig. 4.3: Diagram of the BEAST's layout.

Harrison falls into Emmerson's 'realist' camp in his larger contention that the spaces of electro-acoustic or acousmatic pieces don't typically scale well from the composer's studio to a given performance space, even with adequate sound reinforcement. In his opinion, the unpredictable acoustic interactions between abstracted spaces on fixed media and their highly variable performance spaces can't be solved with symmetrical multichannel systems. Rather, "It seems to [him] that the best approach to performing electroacoustic music in public spaces is not to deny the characteristics of the space in an attempt to recreate the sound as heard in the composer's studio (which is actually 
impossible) but to use those characteristics as part of the listening experience" (Harrison 1998, 124). I agree with Harrison's and Emmerson's contention that performances of electro-acoustic music often ineffectively address the enormous differences in spatial characteristics between the composer's studio and the performance site. Diffusion, though, is but one approach to this problem, and it comes with its own set of challenges. Among them is the need for specially trained diffusers, and most importantly, the fact that an entirely new layer of musical information is added to a piece in the process - a layer that the composer may have little to no control over. In having a piece diffused by someone else, the composer takes a risk that has the potential to greatly enhance the experience of a piece, but also - in the wrong hands - to ruin it. Given that composers of tape music often desire exacting control over the production of their pieces, this approach to spatialization may not appeal to everyone.

The proliferation of multi-channel performance systems, such as the BEAST, has also increased the popularity of composing for more than two channels. As composer and researcher Felipe Otondo noted, in his informal study, between 1997 and 2006 there was a marked rise in the number of composers using multi-channel formats for spatializing their music, especially 5.1, four-channel, and eight-channel systems (Otondo 2008, 78). While the study analyzed academic papers to determine the format usage in 1997, and used surveys to determine the format in use in 2006, it shows an unmistakable trend. ${ }^{17}$

\footnotetext{
${ }^{17}$ For the 2006 study, Otondo sent out surveys and received answers from 43 composers, most of who had been working in the field for five or more years. $72 \%$ were European, $14 \%$ South American, $12 \%$ North American, and 2\% Asian. Since no surveys were conducted in 1997, Otondo gathered data from articles
} 
Apart from diffusion, there are technical approaches that allow for the presentation of an abstracted space within a physical space, while maintaining the integrity and 'separateness' of the abstracted space. These depend, significantly, on the acoustic characteristics of the physical space in which the abstracted space is presented. A multichannel piece may have more undesired spatial integration within a highly reverberant space than within a heavily dampened one. One of Harrison's protégés, the composer Natasha Barrett, works with three-dimensional sound spaces that necessitate symmetrical surround-sound systems. Her concert pieces such as Exploratio Invisibilis (2003) and Kernel Expansion (2009) use the Ambisonic audio format, a technology in which spatial data is encoded and decoded within audio data, enabling the composer to effect the "direct transfer of composed spatial information to the listener" (Barrett 2009). Yet she has also presented numerous site-specific installations that interact with the physical and historical resonances of their locations.

Barrett's 2002 installation, Displaced:Replaced II, used an eight-channel cube to project three-dimensional sound into the installation space. Movement and processing of the prerecorded sound files was determined through real-time data collected from a series of remote weather sensors in Oslo, Norway. In Figure 4.4, a visitor stands in the center of the cube, positioned at its sweet-spot.

written in 1997 by seventeen well-established electroacoustic composers and published by the Institute International de Musique Electroacoustique of Bourges. 


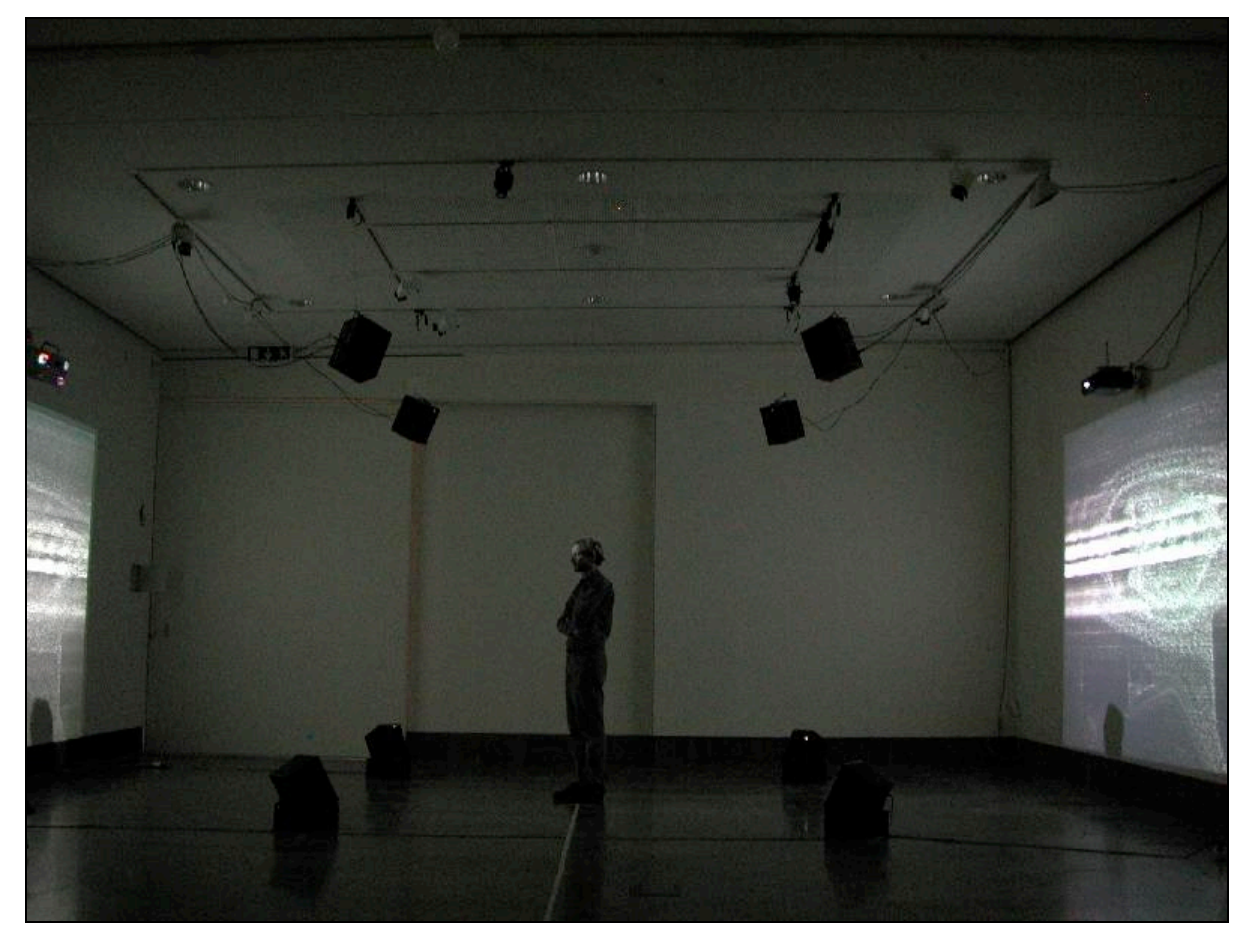

Photo courtesy of Natasha Barrett

Fig. 4.4: A visitor in the middle of Barrett's Displaced:Replaced II.

While this kind of speaker arrangement is necessary to produce a $3 \mathrm{D}$ effect, it is also one of the drawbacks of the Ambisonics approach - only a limited number of listeners can fit within the small sweet spot in which the spatial information is transmitted and perceived successfully. What type of space does this piece create? The piece appears to be situated in a non-descript gallery room, and one can assume from the size and shape of the space that it does not have an extended reverberation or extreme resonant properties. As Barrett does not mention the acoustic qualities of the physical space in her description of the piece, it is likely that she tries to avoid interacting with them in the piece - rather she uses the Ambisonic cube to carve out a new sonic space in the middle of the gallery. We can assume this because Barrett notes that "acoustics can be used advantageously in performance to smooth dynamic spatial diffusion, while in the Ambisonics sound field it 
interferes with the clarity of the spatial reproduction" (Barrett 2003, 321). Within the sweet spot of this installation space, one would ideally be immersed in a new space with a different set of properties from those of the enclosing room. To Barrett, "spatial information finds musical meaning when specific to, and developed from, the material as a totality. Sound contains an internal or inherent space in intrinsic terms and a connection to space in extrinsic or referential terms" (Barrett 2009). This piece is an example of a composed abstracted space because, while it exists within a physical space, it does not attempt resonate the physical space in a meaningful way. The new space, perceptible inside the Ambisonic cube, is portable, malleable, and does not have to follow the spatial laws of its enclosing physical structure. Barrett might argue that the Ambisonic and physical spaces in the installation are inseparable as she notes that in "the Ambisonics sound field [acoustics] interferes with the clarity of the spatial reproduction" (Barrett 2003, 321). Inevitably there will be acoustic interaction between the abstracted and physical spaces in the piece. However, the abstracted space of the installation does not speak to the space of the room in the way that Leitner's Water Mirror does to the Donautemple. Instead, it speaks to the content of the video projections, the weather data driving it, and the space it carves out with its own musical materials.

\subsection{Abstracting space into virtual worlds}

While Barrett's immersive abstracted spaces are still embedded within the physical realm, Adam Nash, an Australian new media artist, works in yet a more remote level of spatial abstraction. Nash has created and exhibited numerous sculptural pieces that reside 
within 3D virtual online worlds. His 2007 piece, 17 Unsung Songs $^{18}$, was a series of installations on a virtual island within the Second Life multi-user virtual environment (MUVE). A group called Odyssey, which is dedicated to virtual art and performance within Second Life, created the island and - much like a museum hosting an artist-inresidence - hosted Nash's installation series for the duration of its run. In Second Life, users are represented by avatars: three-dimensional beings that can be highly customized. They serve as the virtual eyes and ears of the participant. The world of Second Life mimics that of Earth to a point - there is land, water, and air, and thus a sense of physical familiarity. Yet Nash's pieces exploit those aspects of the space that do not mimic the physical laws we are accustomed to: avatars can fly, objects can float, and weight has no meaning. The 17 Unsung Songs are, by our real-world physical laws, impossible constructions.

\footnotetext{
${ }^{18}$ Although the piece is no longer installed in Second Life, you can see documentation videos of the installations on Youtube: part 1, http://www.youtube.com/watch?v=NenD8hmlnk0 and part 2, http://www.youtube.com/watch?v=nMC_e5b4yEU
} 


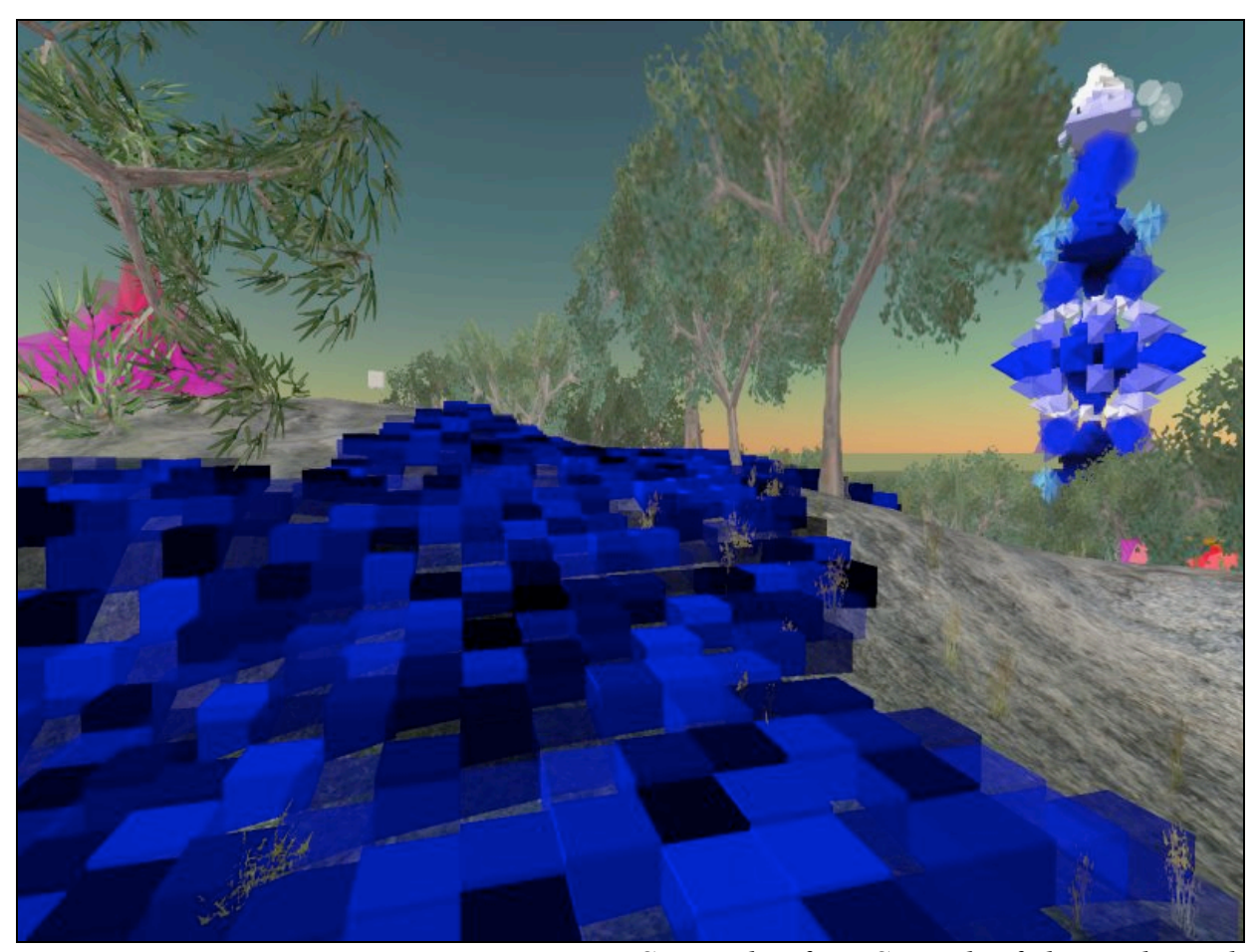

Screenshot from Second Life by Linden Lab

Fig. 4.5: Adam Nash's Unsung Song \#16: Blue Sound Ground

In Unsung Song \#16: Blue Sound Ground (Fig. 4.5), a series of blue cubes of different shades are spread out over a hillside. As visitors walk their avatars over the cubes, samples are triggered. The more one moves around the space, the more sounds are triggered and the denser the sound environment becomes. In another piece of the installation, Unsung Song \#15: Disaccumlator (Fig. 4.6), the avatar encounters a sculpture consisting of a series of floating red rectangles. As the avatar moves around and through the piece, small red balls fall from an upper platform, hitting the rectangles and triggering pitched metallic sounds. The effect is akin to playing within the haphazardly arranged bars of an otherworldly metallophone. 


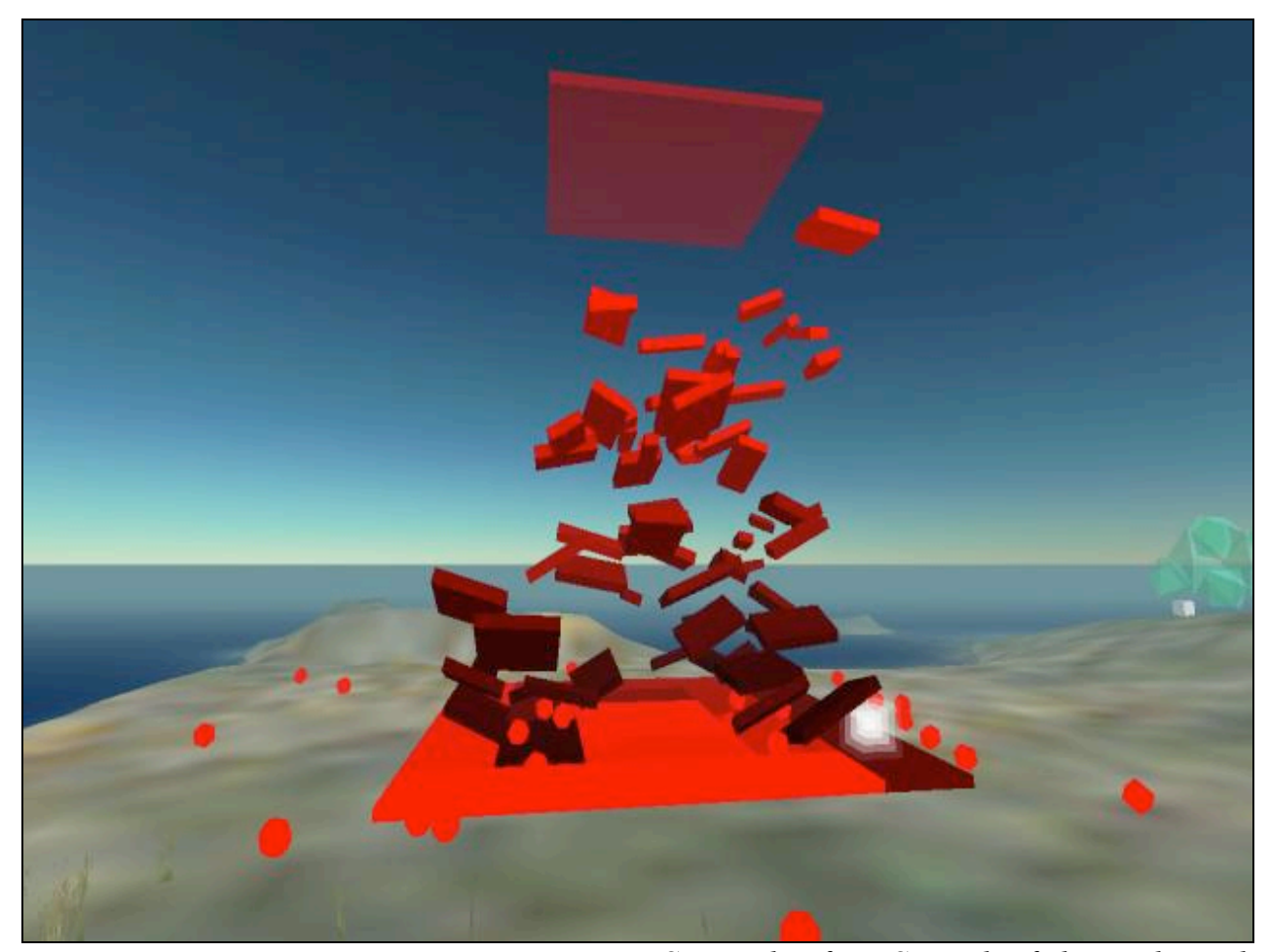

Screenshot from Second Life by Linden Lab

Fig. 4.6: Adam Nash's Unsung Song \#15: Disaccumulator

Unlike the relatively unlimited sonic capacity of high-resolution Ambisonic spaces, the sound environment of Second Life is quite limited in the number of sounds that can be played simultaneously, and the artist has no control over how quickly the sound fades out as avatars move away from the installation. Yet the spatial properties of Second Life - as mimetic of the physical world as they are - allow Nash to experiment because of the way in which the medium combines visual, aural, social, and network spaces. Nash refers to this type of medium as post-convergent, in that "no single media-element (sound, vision, sociality, network, time, etc.) takes precedent, rather they all exist equally in a symbiotic relationship, without which none of them could exist" (Nash 2007). He notes that "with this idea of the melding of the composition environment and performance environment, 
the act of creating work is often enormously enjoyable because you get to fly around and through your ideas, trying out different ways of navigation that you may never have realized were possible when conceiving of the piece. It's like a slightly more concrete iteration of the limitless imagination scape in which all these ideas are found" (Nash 2007). Nash's post-convergent world enables and even forces completely new approaches to composing and interacting with it.

From Nash's perspective, another significant limitation of Second Life and other similar MUVEs are the environments' mimicry of the physical world in terms of spatial properties and the concentration of the avatar's - and thus the user's - presence in one place. He notes that "even though it may seem natural to use 3D space to recreate physical space, that is only one possibility, and certainly not the easiest, because it can never recreate physical space, only represent it. Once we move into the sphere of representation, different modes of perception are required" (Nash 2007). The spatial properties of an environment like Second Life are both radical with respect to the physical world, but also not radical enough from the perspective of an artist working within the medium. Nash thinks that "it is not necessary for the user's avatar to be concentrated in one space. Ideally, for many of the works, the user would be able to branch off avatars and move spatially through works in different ways simultaneously" (Nash 2007). 
Art made in commercial virtual worlds such as Second Life demonstrates just a small fraction of the aesthetic potential unleashed when networks, social interaction, and abstracted spatial simulation are combined. Their relatively close mimicry of the physical world and our default modes of perception are limiting when met with the imagination of artists like Nash and others. The commercial needs of the site dictate many of those limitations, and so it becomes the job of the artist to figure out how to subvert them. It is somewhat ironic that the space and the art exist because of the work of these commercial entities, but it is also limited by the bounds set by the same commercial entities. There are rules within the space that cannot be broken, much like the natural laws of the physical world cannot be broken. It is thus left to artists to create new spaces that are free of these limitations (or have different ones), that challenge notions of what a virtual world can be and of how we can 'be' within that space. I confront a similar paradox in my own piece, ItSpace, that resides within the MySpace.com social network.

\section{Hybrid Spaces}

Earlier, I divided space into three top-level categories for the purpose of analysis: physical spaces and abstracted spaces that could then be combined to form hybrid spaces. Hybrid spaces occur when abstracted and physical spaces are joined to create the perception of a space with properties of both. The two most common approaches use physical space in combination with a different type of abstracted space. One combines physical aural space with virtual aural space, and another type combines physical aural space with network space. Both of these approaches merit discussion as individual 
categories. Yet my reduction to these two categories should not be construed as an assertion that these are the only ways in which artists create hybrid space - they are just two of the most utilized, and are also the two ways in which I have incorporated hybridity in my own work.

\subsection{Networked hybrid space}

As we saw in Chapter III, the use of networks combined with aural space has been a significant thread in experimental music for several decades, most notably in the work of the League of Automatic Music Composers and The Hub. With the increased ease of access to the Internet that began in the mid-1990s, the number of artists using the network as a tool and a medium expanded rapidly. One of these artists, composer and software developer Jesse Gilbert, has coordinated and directed a number of network-connected pieces, including Finding Time (1999) and interaXis (2001 - 2002).

In Finding Time, Gilbert worked with fellow composer Scott Rosenberg to create a piece that used the network to connect eight performers on four continents. The performers followed a real-time interactive graphical score animated in part by using brainwave feedback. The performers' live sound was encoded and streamed from each location to a central mixing station in New York City. The final mixed stream was available to listeners over the Internet, and was also sent back to the performers so that they could hear the rest of the group. In a 2005 interview I conducted with him, Gilbert noted that Finding Time was designed for an online-only audience and that it was "primarily 
concerned with mixing disparate streams together and providing a structural framework that allowed [them] to constitute an ensemble on multiple continents" (Gilbert 2005). The spatial hybrid they created existed online in the form of the final mix heard by listeners. The network space was used to aggregate a number of real-world spaces into a single aural space whose properties consisted of a mixture of the physical spaces and the idiosyncrasies of the abstracted network space, such as delay and compression.

interaXis, in which Gilbert was the project director, used a different approach to spatial hybridization via the network. The piece was more concerned with live performance in front of an assembled audience, as it connected ensembles in two spaces: one in New York and one in Los Angeles. The audio was shared between the spaces via the Internet and data was also sent over the network to control spatialization of the sound in multiple speakers at each performance location. Each audience's perspective of the interaXis performance combined a live local ensemble mixed with sounds from the remote ensemble spatially distributed through the performance space. One might expect that in such a scenario, the spatial placement of the remote ensemble's sound would be mapped to represent spatial placement of the performers on the other end of the connection. Instead, Gilbert used dynamic spatial placement of each remote ensemble within the local performance spaces, while amplified sound from the local performers was spatially static. Gilbert attributes this difference in the treatment of local and remote spaces to a desire to incorporate or interpret properties of the network space into physical space: 
I am less interested in trying to reproduce a wholly "accurate" reproduction of sonic reality between the sites than I am in using spatial processing to indicate the impact of the network on a visceral level to an audience. I find spatial systems intriguing as a means of "unbalancing" a listener's ears, taking them out of the comfort zone of familiar ways of hearing. For many reasons this seems to me a good parallel to the experience of performing across the network, where the temporal dislocations and the non-presence of the body force performers to reach for each other across data space. (Gilbert 2005)

Gilbert's spatial approach highlights one of the fundamental characteristics of networkshared spaces, especially earlier in the decade: lack of simultaneity caused by latency. The "temporal dislocations" he refers to are functions of buffering, processing, and transmission time. These properties of the space result in network-based hybrid spaces containing multiple and unaligned instances of 'the present'. As Gilbert and other composers, such as Chris Chafe, have discussed, such spaces require different and novel approaches to form and structure. The forms and structures composers create for these spaces usually minimize the importance of temporal accuracy in favor of other musical parameters.

Some questions arise here though: when space is shared but simultaneity is lost, what is perceived by the audience? Do they still perceive the performances as a unified space? 
Does the lack of simultaneity fragment the space in the mind of the listener? There is enough latency across a physical stage that a conductor is needed to synchronize an orchestra, yet if two performers were spread far enough apart within a single physical space such that they couldn't synchronize their playing, we would still perceive the performance as existing within that one space. With network shared space we have the added knowledge that the other performers are in a distant and possibly very different physical space. The latency issue thus becomes more salient as it relates to perceiving the unity or fragmentation of the space. There are, at present, no fixed answers to these questions: the audience's perception of the space likely depends, among other factors, on the amount of latency as it relates to the material of the individual pieces and the spaces of their performance.

Internet technology has improved dramatically since the performances of Finding Time and interaXis. Increased processing power and the ability to stream ever larger quantities of data over the network in real-time has solved earlier issues, such as the need for compression. Musicologist and acoustician Jonas Braasch argues that these telematic spaces should be treated as new types of instruments, or instrument extensions, rather than as an impoverished substitution for musicians performing in the same physical space. In his view, the human perceptual system will never mistake a telematic environment for a 'real' one, and so "from a phenomenological viewpoint, it becomes much easier to treat the telematic system as a unique environment instead of a copy of another place, which a rationalist would call the 'real' or 'physical' world" (Braasch 
2009, 424). To Braasch, then, the hybrid spaces instantiated for these performances are as much instruments as the physical instruments played within them. This is not unlike Blesser and Salter's notion of primary and secondary acoustic enclosures discussed in Chapter III. Although they do not discuss network art, one could reason that they may consider Braasch's telematic instrument as a 'secondary resonant enclosure' much as they consider a concert hall or artificial reverberation (Blesser and Linda-Ruth Salter 2007, 139). I would posit that it could even be considered a 'tertiary resonant enclosure', whereby the primary resonant enclosures are the instruments, the secondary resonant enclosures are the physical performance spaces, and the tertiary resonant enclosure is the abstracted space of the network encompassing the rest.

Experimenting with telematic environments, such as Braasch describes, has become increasingly common, especially in academic institutions with access to Internet 2. At Stanford University, composer Chris Chafe's soundWIRE Group has conducted many network-connected concerts with institutions across the United States and the world (Chafe 2009). These pieces run over Internet 2 and other ultra-high-speed networks not accessible to the general public, so they are not constrained by the same bandwidth limitations that characterized Gilbert's pieces from the early 2000s. These networks allow sharing of multiple channels of high quality uncompressed audio as well as highdefinition video. Unlike the much larger delays experienced in pieces such as Finding Time, the delays between ends of the network in performances running on Internet 2 are on the order of a few tens of milliseconds. 
While this delay is still problematic for performers in terms of rhythmic synchronization, it is also short enough - and the movement of data across the network fast enough - that Chafe thinks about it in terms of a sounding medium in that can be "entered from anywhere in the physical world connecting with a high-enough speed Internet connection" (Chafe 2009, 414). When considered in the context of Chafe's spatial analogy, Braasch's description that "the transmission delay between two telematic sites typically consists of two elements: the pure transmission delay (propagation latency) and the signal-processing delay of the telematic apparatus (system latency)" (Braasch 2009, 423), amounts to a description of reverberation time. This analogy finds expression in one of the SoundWIRE group's projects, in which the delay time of successive 'pings' across a network determines the pitch of a virtual string. The network latency becomes the length of a string, or in my analogy, the size of a room - both related acoustic concepts. The resulting sonic artifact is delay. In the reverberation analogy, that delay is akin to the return time of a sound wave that has bounced off of a room surface. In the string analogy, it is akin to the time it takes the string to go through one cycle of displacement.

In 2007, Braasch, Chafe, and composer/performer Pauline Oliveros collaborated on a colocated ${ }^{19}$ piece by Braasch called Tele-colonization in which performers from three spaces - Stanford University, Rensselaer Polytechnic Institute, and KAIST in Seoul,

${ }^{19}$ A term Braasch prefers in place of 'distributed music performance'. He argues that performers are already distributed across a stage, with speed-of-sound latencies between them, and that co-located more accurately describes a telematic performance. 
South Korea - played into a central performance space in Tanna Schulich Hall at McGill University in Montreal. The sites shared both multichannel CD-quality audio as well as digital video. The structure of the performance differed from the more common telematic setup in which ensembles are equally shared between multiple performance spaces and hybridity is revealed immediately. In the liner notes, Braasch states that "we assumed an opposite standpoint from the traditional telepresence co-located approach to highlight and create awareness of dislocatedness." In Tele-colonization, the audience at McGill observed as the ensembles from the other locations gradually entered and 'colonized' the shared space, both aurally and visually. As Braasch described, "telecolonization occurs when a group of people virtually populates a new area. During this process, both the new and old inhabitants will have to get to know each other through communication. Eventually they will have to adapt their cultures to share their habitat in harmony" (Braasch 2007).

The piece was divided into three sections in which the spatial relationship between the co-located ensembles was gradually revealed to the audience. The piece was a guided improvisation within a very experimental system, and so the directions were intentionally vague to give the performers the freedom needed to explore the hybrid space as it emerged. In the first section of the score, the McGill performers played alone in the physical space, while the remote ensembles were silent, defining it as the central territory of the performance. In the second section, the remote-ensembles gradually joined in, but they were directed to play in a contrasting style to that of the onsite ensemble. This set up 
a musical and spatial contrast between the onsite and remote ensembles, allowing the audience at McGill to differentiate between the various spaces before they merged. In the final section, the ensembles were directed to fuse their sounds together, merging musically and spatially into a single shared territory. It is not clear how audiences responded to the hybrid space, but as there were listeners at the central and remote locations, each one would have had a different experience of the emerging space and their own space's relationship to it.

Hybrid sonic spaces, as created through networks, can exist in other forms where hybridity is derived from factors other than sound sharing. The artist Teri Rueb is at the forefront of an installation practice that uses the Global Positioning System (GPS) as a means to create site-specific pieces that mix digital and physical space. Her 2007 piece, Core Sample, was a site-specific installation on Spectacle Island in Boston Harbor. For many years the island was a landfill and declared toxic, until a large-scale restoration program transformed the surface of the island into a public park. Rueb's piece used a combination of GPS and recorded audio to create a virtual layer of information and meaning over the physical area of the island. As Rueb described it, "visitors to the island borrow small computer/headphone units equipped with GPS and wander the island to hear sounds inspired by the island's complex material and cultural history. Sounds play back automatically as the GPS senses the visitor's movement in the landscape. Over 250 sounds are spatially and thematically organized according to elevation, evoking a 
metaphoric core sample. Open cell headphones allow blurring to occur between actual and pre-recorded ambient sound" (Rueb 2007).

In Rueb's piece, the hybridization occurs primarily in two modes: the overlay of virtual data space onto physical space and the mixing of headphone audio content with the aural environment of the island. The mixing of audio content between headphone or speaker and the external environment is a basic hybridizing gesture, used in site-specific installations such as Jeff Talman's White Sound Down and Janet Cardiff's The Missing Voice: Case Study B, which will be discussed below. The mixing of network-located data over a physical space, and the virtual tethering of that data to specific coordinates in the physical space is an example of hybrid space as defined by de Souza e Silva. Here, "the borders between digital and physical spaces, which were apparently clear with the fixed Internet, become blurred and no longer clearly distinguishable” (de Souza e Silva 2006, 264). The perceptual space that this blurring conjures is the locus of hybridity.

\subsection{Physical hybrid space}

The technology required to create hybrids from composed and physical aural spaces is minimal in comparison to that required for network-based hybrid space. A few speakers playing pre-recorded material into a physical aural space can have a profound effect when the relationship between composition and space is carefully considered. Artists Janet Cardiff, Bill Fontana, and Jeff Talman all work with variations on this type of hybridity, even though they do not describe it as such. The pieces discussed below all 
exemplify different approaches to aural hybrids using composed placement of speakers and sounds within specifically chosen performance sites.

Janet Cardiff's sound walks mix personal space with public space, live sound with recorded sound, and factual narrative with fictional narrative to create rich hybrids that bend the listener's sense of reality. She created her first site-specific sound walk in 1991 and while Cardiff is aware of the use of GPS in sound walks by other artists, she has no interest in it for her own work (Cardiff and Bures Miller 2007). In Cardiff's pieces, participants walk around spaces such as museums, city blocks, and parks while guided by an audio recording. The recordings mix narration, music, and sounds from the environment to divorce the participant from their current sense of the 'real', creating a space that is, at times, temporally, spatially, and psychologically fragmented. One important difference between Cardiff's and Rueb's walks, is that Cardiff employs a binaural recording setup when creating her pieces. She will walk the path of the piece, recording sound into the microphone-containing ears of a dummy head (see Fig. 4.7), often adding her own narration. When the listener embarks on the sound walk, the overlaid audio from the headphones exists in a 3D aural space, along with external environmental sound.

Cardiff's The Missing Voice (Case Study B) (1999) was a 50-minute sound walk through inner London in which the participant carried a CD player and was guided for the duration of the piece through backstreets near and around the Whitechapel Library. The 
piece combined narration and fictional and real sound recordings to create a private narrative in which each person's experience of the piece differed.

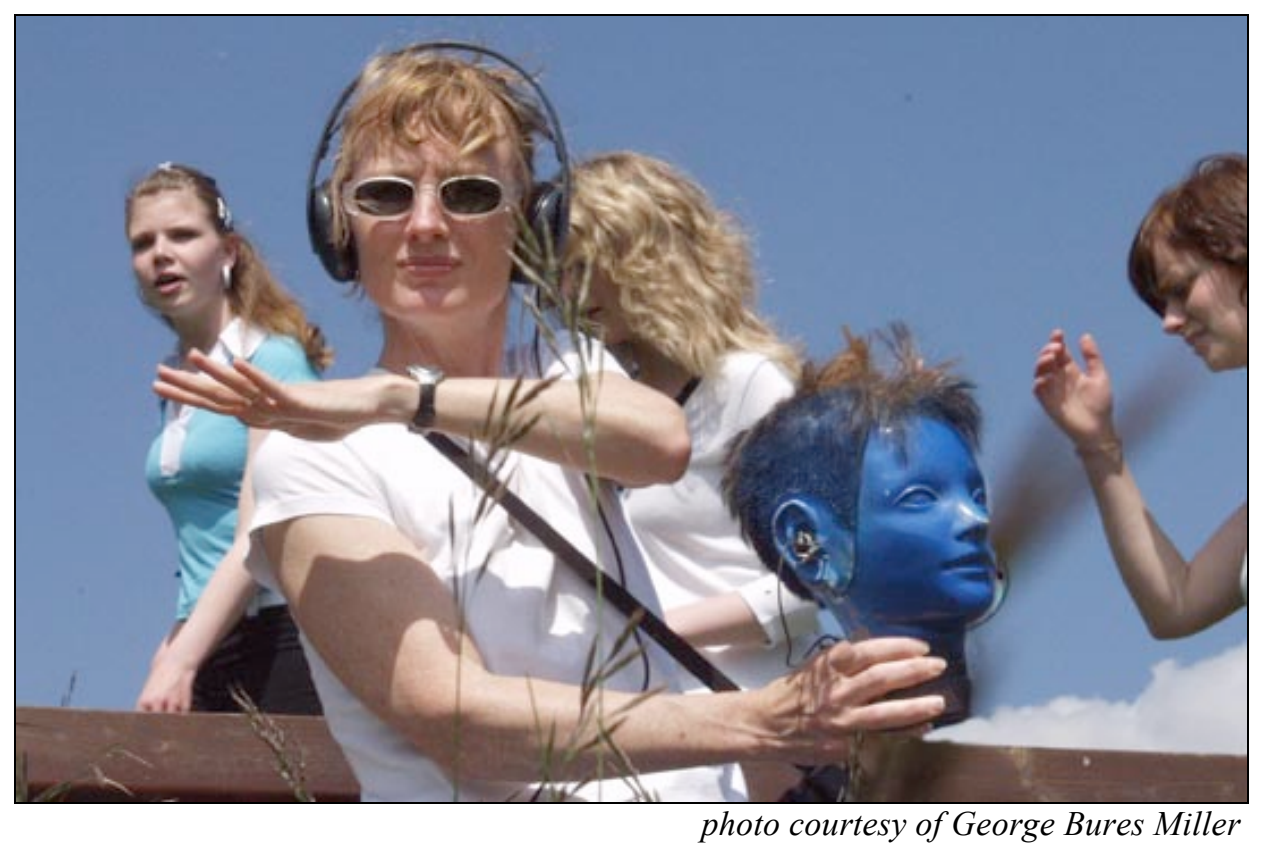

Fig. 4.7: Janet Cardiff creating a binaural recording for her 2006 piece, Jena Walk (Memory Field)

The narrative colored the listener's perception of their immediate surroundings, drawing them into the world of the narrator, and creating a hybrid space between the fictional world of the audio and the real world of their immediate environment.

In his essay on The Missing Voice (Case Study B), cultural geographer David Pinder recalls his experience of her piece:

The interweaving of recorded sounds with those of the city make it difficult to locate their sources and to discern their reality. There are 
fragments of conversations and the noises of vehicles and wailing sirens. A parade passes through Brick Lane as you walk up it. A tour guide is overheard describing the history of the Jewish population in the area. At times there is a naturalistic fade, at others a deliberate cut... It emphasizes the sensuousness of walking as a mode of apprehending the city that is tactile, aural and olfactory as well as visual. It is an activity that enunciates and gives shape to urban spaces; one that is not localized but that ‘spatializes'. (Pinder 2001, 5)

Cardiff's walks create hybrid spaces that exist on physical/perceptual, narrative, and temporal levels. The immediately perceptible hybrid is between the $3 \mathrm{D}$ sound of the recording and the sound of the surrounding environment. As Pinder notes, it is often difficult to discern which is which, and the use of binaural recording aids in effecting that ambiguity. Narratively, the piece emerges at the intersection between the space that was inhabited and then recreated by Cardiff, and the space that the listener inhabits in realtime. Cardiff's narrative mixed with the variable conditions of each walk and the differing perspectives of each listener results in a fusion of Cardiff's experience, her intended experience for the listener, and the actual experience of the listener. The temporal hybrid is evoked when sounds from the past are mixed with sounds from the present. 
A listener may walk down a street and hear a cyclist pass by, but that cyclist is only in the recording. As the listener attempts to account for the aural-visual discrepancy, the tension between the invoked sonic past and the heard sonic present creates a sense of different temporal space, one that is somehow 'outside of time'. The space the listener inhabits at that point becomes a mix of temporal, narrative, and perceptual discontinuities that results in an almost dream-like experience. Cardiff, in recalling the experience that lead to the creation of her first sound walk in 1991, noted that the layering of past onto the present "had a strange quality of creating a new world, blending together the physical and the virtual" (Cardiff 2005, 1).

Another point of deep spatial intersection in the piece is between the public sound space and the private metaphoric thought-space of Cardiff and the listener. The human voice, when heard closely miked and without a visible speaker, can be an intimate and enthralling presence. Cardiff's soft-spoken narration of The Missing Voice and other sound walks ${ }^{20}$ - as if she is almost telling you a secret - creates the feeling of an intimate conversation between the listener and the narrator. Her "thoughts are transmitted through the headset creating a very private space for the audience in the midst of a very public area" (Cardiff 2005, 2). The tension between the public and private aural thought-spaces of the piece create another type of hybridity, as the bounds between personal and public, and individual versus shared experience are repeatedly confused.

\footnotetext{
${ }^{20}$ Cardiff provides audio samples of a number of the walks on her website. I have also experienced an audio-video walk by Cardiff called The Telephone Call (2001), which was available during the 010101 Exhibit at the San Francisco Museum of Modern Art in 2001. The effects of the binaural sound environment and her style of narration were both unsettling and mesmerizing.
} 
Similar hybridizing gestures are found in the works of Bill Fontana. Although significantly different in practice from Cardiff's sound walks, they also combine aural past and present and play with the recollection of spatial memory. His pieces often bring environmental sounds into urban environments and recontextualize sounds one might otherwise take for granted.

Fontana's 2007 installation, Pigeon Soundings, explores the sonic memory of the St. Kolumba gothic cathedral in Cologne, Germany. In 1994 he visited the site of the cathedral ruins to make eight-channel recordings. The cathedral was an active church until Allied bombing during WWII destroyed it. According to Fontana, the ruins of St. Kolumba were inhabited by "a large number of pigeons. Deep within the bowels of this place, 2000 years of Cologne's history lay partly visible in the form of old walls, columns and crypts possessing a strong sense of timelessness. This extraordinary site was framed by the partially destroyed exterior walls of the old church, and a temporary wooden roof in whose rafters the pigeons lived" (Fontana 2007a). In his essay, "Resoundings", Fontana describes his conception of the pigeons' sonic presence in the space as a means of returning the space to a primal state over the decades since the church's destruction:

In this 50-year span of pigeons sounding in the ruin, many timeless generations of pigeons came and went. In this passage of nameless birds, the space was returned to a pure state of timelessness, where all of its 
soundings were supposed to be unheard. These pigeon soundings became the space dreaming to itself... (Fontana 1997)

Fontana installed the permanent piece on the lower level of the new Kolumba Art Museum during its completion in 2007. The museum, designed by architect Peter Zumthor, was constructed atop the ruins of the old church. Photographs of the interior and exterior of the museum show a structure that is not simply built over the old ruins, but integrated with it - hybridized. Sections of new wall wrap around and incorporate sections of old wall (see Fig. 4.7). Pigeon Soundings replays the sounds of the pigeons and Cologne from 1994 at a low volume through the newly constructed porous walls beneath the museum, invoking the sonic memory of the space. The walls also allow some sound from outside of the building to enter into the space.

In both its relationship to time and to space, Fontana's piece incorporates spatial and temporal hybridity as a compositional keystone. If the body of the museum can be considered a hybrid of two structures, new and old, then Pigeon Soundings is a sonic gesture in a similar direction. The speakers embedded in the walls of the space move the pigeon sounds around following composed spatial trajectories. The sonic memory of the space is abstracted and displaced from its original time, reframed in both the physical and musical context of modernity. 


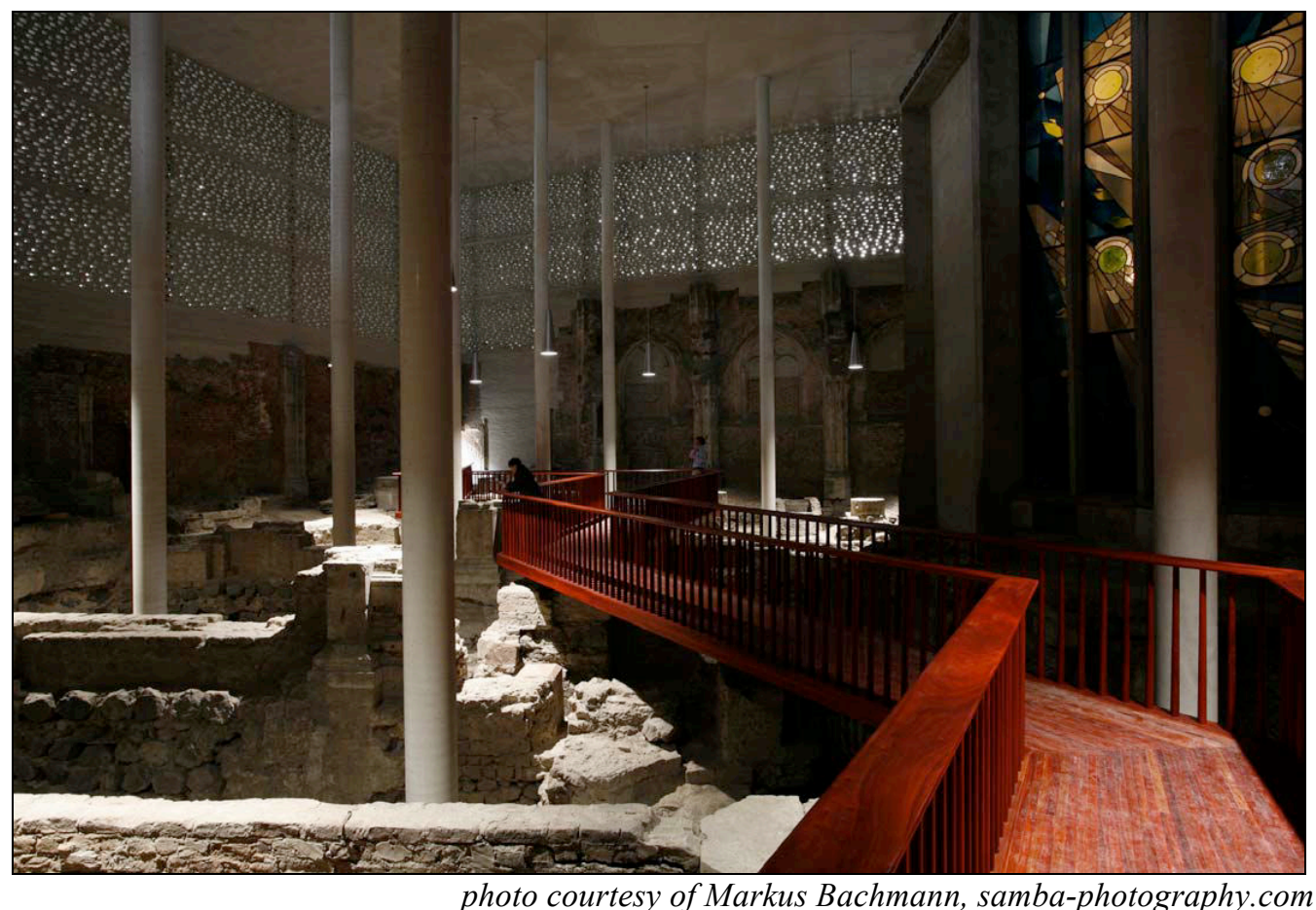

Fig. 4.7: The lower level of the Kolumba Museum. An elevated walkway traverses the ruins, and the integration of the original and new walls is visible in the background.

A visitor to the space, in experiencing this, would likely feel some sense of displacement as they are confronted with the temporal contrasts within the physical structure and temporal contrasts within their aural environment.

The dialog between past and present is embedded in multiple features of the space.

Unlike the case of Cardiff's sound walk, Pigeon Soundings is continuous and there is no explicit narrative. Yet the spatial effects, while on different scales, are similar. In The Missing Voice (Case Study B), the sound of the external environment mixes with the sound from the headphones. The porous walls of the Kolumba Museum allow a similar effect because they let in external light, air, and sound. One can imagine that outside sound mixes with inside sound and with Fontana's piece, so sounds of modern Cologne 
mix with the sounds of the site from 1994. Although Fontana describes composing the spatial trajectories of the pigeon sounds throughout the installation space, I believe that the primary spatial gesture is that of temporal mixing and displacement within the space. When I asked Fontana about this effect in a 2007 interview, he responded:

In historical spaces like in Cologne or Berlin, I also in a strange way believe that the sounds and the memory of all the sounds that happened in these spaces is still palpable, and I wish to bring this sense to the surface in my work. I believe that music and sound art deals with creating different sensations about the passage of time, the most interesting temporal sensation for me is timelessness, like in the Zen meditations, that if you listen well to the sound of a decaying bell, its sound never stops. (Fontana 2007b)

The concept of playing a recording of a space back into itself is a thread that connects a number of the pieces discussed in this paper, from Lucier's I am Sitting in a Room, to Cardiff's sound walks, to Fontana's Pigeon Soundings, and to my own pieces, Solera and Study No. 1 for Bodies, Metal, and Air (to be discussed in Chapter V). However, the nature of the time-scale embedded in the practice accounts for crucial differences in its musical effect. Instantaneous playback of a space into itself, as in my piece Solera, creates feedback tones. Recording a short segment of time in a space and replaying it, as in I am Sitting in a Room, gradually acquires and enhances spatial resonance, but also 
stretches out the gesture as more time is needed for the effect to materialize. Recording an even longer segment, such as the 24-hour recordings in my piece Solera, creates layered cycles that become apparent over days and weeks. In Pigeon Soundings, the replayed space is so temporally distant from the current space that the sense of temporal continuity is very different. In this case, it is more a function of long-term spatial memory and meaning than short-term spatial resonance or reverberation.

Composer Jeff Talman's installations use yet another approach to the playing of spaces back into themselves. Instead of using feedback like Lucier or temporally displaced recordings like Fontana, he makes detailed recordings of installation sites and then analyzes them for their salient frequencies, otherwise known as room tones. Talman then filters the recordings to highlight the frequencies, and replays them into the space with multichannel speaker arrays. As the spaces are already resonant at the emphasized frequencies, the filtered recordings resonate strongly within them. Talman considers this act an enhancement of the already existing acoustic background of the space:

When my installations re-constitute a background, for instance in the atrium of a hotel or in an office space, the enhanced envelopment makes the place somehow seem more like itself — and consequently, people seem to stop and look (and listen) further into where they are. They become aware of where they are. It's a form of "stopping the world." (Talman 2007c) 
Some of Talman's work, however, uses this technique to resonate natural outdoor spaces. His 2007 piece, White Sound Down, used recordings of snow falling in the forest as the resonating material. The piece consisted of five speakers suspended from trees around a cross-country skiing trail in the Bavarian forest near Althütte, Germany. Talman made recordings of the snowfall in the winter of 2006, then analyzed the material for its primary frequencies. He filtered the audio to emphasize those frequencies, and created a five-channel installation that would play via DVD for 24-hours-a-day (Talman 2007b).

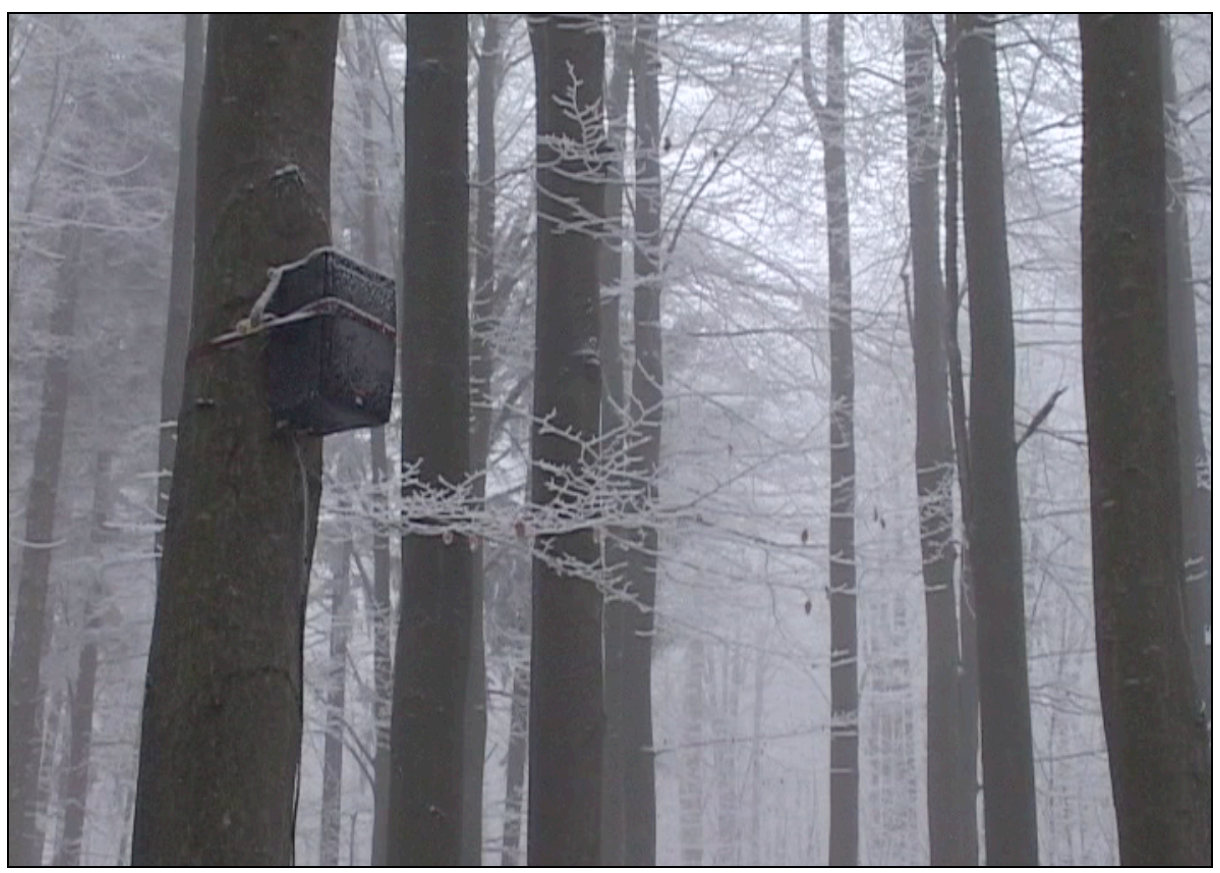

Screenshot from Jeff Talman's documentation DVD

Fig. 4.8: A speaker mounted to a tree for White Sound Down.

The piece ran for a week in the middle of ski season, from December 28 to January 6 , 2008. The audience - mostly cross-country skiers - passed through the installation via the 
series of trails surrounding it. The sound field covered 35,000 square feet of forest, and according to Talman, the sound carried on the wind far beyond the installation site (Talman 2007a).

I cite this piece because it elicits the question: why is this piece considered a hybrid space, while Leitner's Water Mirror is considered physical space when both manipulate the natural sound of the environment by enhancing the sound of the site? I maintain that here, the hybridity is created through the way the sound is treated in relation to the space it creates. In Water Mirror, I would expect that while one's sense of the sonic space would be enhanced by the structure, that enhancement would seem natural, much as the reverberation within a cathedral. Our experience tells us that certain physical shapes and materials will produce a certain type of acoustic. On the other hand, the sound within Talman's piece is both embedded in its environment, but also physically at odds with it the forest cannot produce the enhanced sound just through its own acoustics. The digital filtering and multichannel playback form an abstracted space that becomes part of the new space, even if its content is a version of the sound of the space itself. An acoustic space exists within the resonating material from the speakers, as it also does in the natural sound of the forest. The seamless mixture and interplay of the two creates the hybrid.

Talman does not typically make recording samples of his installations publicly available, as he feels strongly that "it would make no sense divorced from the installation sites, and no sense apart from a sound field presentation" (Talman 2008). Yet one can imagine 
what the piece may sound like from the perspective of a cross-country skier passing through the sound field: wind in your ears, heart beating, heavy breath, the deadened sound of a snow-covered forest, and a pitch in the wind that varies gradually as you move through the space, changing amplitude as you get closer or farther from the speakers. In watching and listening to documentation of the piece, which consists of various shots of snow falling along the ski trails and audio of the processed snow sound, I am struck by how much is missed by not being there. One hears just the filtered snow sound, minus any of the resonance, dynamics, or dimensionality that the space would impart. These qualities, as Talman emphasizes, are impossible to capture and relocate as far as his work is concerned. It is akin to listening to the sound of a bowed string on an instrument that has no body.

\section{Conclusion}

In this chapter I have discussed the work of a group of artists who use space as a central compositional parameter. Bernhard Leitner and Maryanne Amacher used sound to modify specific physical spaces, including the body, transforming those sites. I categorized these pieces as composing physical space since they speak to and about the physical spaces of their performance. Electronics, when used in these pieces, are a means by which to resonate or enhance the existing physical space, but they do not create an abstracted space of their own. The notion of resonance here is, for the most part, literal: Leitner's Sound Chairs resonate the body and Amacher's “Third Ear Music" resonates the inner ear. 
When abstracted spaces are used, the notion of resonance can also be conceptually abstracted from the physical realm. Jonty Harrison, Natasha Barrett, and Adam Nash all resonate electronically generated abstracted spaces in aural and metaphorical ways. In Harrison's multi-channel diffusion approach the spatial characteristics of the performance site are taken into account and even utilized for effect, but the pieces themselves are not about the physical space of their specific performance site. The abstracted space is resonated, or made present, through the performed movement and mixing of sound throughout the distributed speaker array. In Barrett's pieces, the abstracted space is created unto itself without an attachment or reference to the space encapsulating it. In her piece, Displaced:Replaced II, external weather data metaphorically resonates the aural space of the Ambisonic installation. Adam Nash's audio-visual sound sculptures within online multi-user virtual environments allow unusual and radical approaches to the creation of abstracted space. When we interact with his pieces via online avatars, which themselves are abstractions of our physical bodies and proxies for physical presence, the means by which his spaces are resonated are, by design, abstracted.

A number of contemporary artists mix both physical and abstracted spaces to create hybrid spaces. I divided these spaces into two major types: those that mix the abstracted space of the network with physical space, and those that mix abstracted aural space with physical space. Composers such as Jesse Gilbert, Jonas Braasch, Chris Chafe, and Teri Rueb use networks to create spatial hybrids by connecting performers and audiences 
across distant sites. Network latency inhibits rhythmic synchronization, and so composing for such spaces requires approaches that are less dependent on performer synchronization. As these pieces show, there is also ample opportunity for composers and performers to mediate and shape the transmitted spaces as they pass through the network. In these types of spaces, resonances too can be hybrid: a sound resonating a physical space on one end of a telematic performance may also metaphorically resonate a network space as it is transformed into bits and data packets. While moving through the network it may accumulate delay, trigger other network events, and even encounter network glitches before being transduced back into physical sound on the other end. For artists like Rueb, the network is used as overlay on top of physical space, augmenting physical space with an abstracted data space and creating "a continuous field that completely extends over, and fills in, all of physical space" (Manovich 2006, 228). Her use of GPS creates a virtual network space that merges with the physical space of the installation site. In Core Sample, the blurred border between physical space and network space becomes the perceptual material of a hybrid space. The resonances here are also conceptually abstracted: the combination of recorded and live sound is used to metaphorically resonate the spatial memory of the site and the listener's sense of real and imagined, past and present.

Composers Janet Cardiff, Bill Fontana, and Jeff Talman also create hybrid spaces, but without using networks. Although their individual techniques vary, they all use electronically manipulated sound projected into physical space to create hybrids. The 
technical methods for hybridization in these pieces are fairly simple and, in fact, not that different from playing a tape piece at a concert. The spatial act resides in the material of the pieces themselves and its explicit connection, whether by narrative, history, or spectral content, to the material of the space in which it plays. Again, notions of resonance play across multiple facets of the pieces. Cardiff's and Fontana's works focus on metaphorically resonating spatial memory, the border between reality and fiction, and the disconnect between the visual and aural properties of their hybrid spaces. In Talman's pieces, the resonance is more literal, as he emphasizes the resonant sound frequencies of the performance spaces.

With a few exceptions, such as Nash's MUVE pieces, most of these spaces cannot be properly experienced except by live experience. In this way, space differs from other musical parameters such as pitch, timbre, or rhythm, all of which can be accurately represented by means of recording. No performance is truly captured through recording: sample rates, microphone quality and placement, and many other factors bias the sonic information that is eventually represented on a recording. In a live performance recording, the audience/performer dynamic may not translate at all. Yet space suffers most in this regard: while I have heard recordings of Henry Brant's spatial pieces, I do not think I have actually heard them - not in the way that Brant intended. Space was a central element in his compositions, carefully composed as a means to present multiple layers of musical information. Yet his spatial constructions are completely lost on a normal stereo recording, while the other compositional parameters survive. The only way 
to hear the spatial constructions in Brant's pieces is to hear them performed live.

Thus, it is important to consider what is missing when analyzing and writing about these spatial pieces. I have not experienced most of the pieces discussed above and have had to make educated guesses based on past experience as well as aural, visual, and written documentation. This situation is emblematic of the larger issues involved in creating and performing spatial-centric pieces: audiences are limited to those who can visit the piece, recordings are not a substitute, and writers and critics may have to base their analyses on circumstantial evidence. Visiting installations (those that do not exist online) can be expensive and time consuming. But there is simply no true substitute for experiencing these pieces in person. 


\section{Chapter V: The Five Spaces}

\section{Introduction}

As I have demonstrated, our conceptions of space and distance are now vastly different from what they were 100 years ago. We can now decouple, fragment, and reconstruct space in ways that invite philosophical and aesthetic contemplation and exploration. Each of my Five Spaces pieces engage space as a central compositional element in their own way, exploring such concepts as spatial fragmentation, reconstruction, ambiguity, and expansion. For example, ItSpace composes virtual, physical, and social space, while Solera and Study No. 1 for Bodies, Metal, and Air compose different aspects of physical space. Passages and Recesses and Curve create hybrid spaces, the former through a network and the latter through the overlaying of composed sound in an idiosyncratic aural space.

\section{ItSpace (2007 - present)}

I created a network of pages within the social networking site MySpace.com for ItSpace. My goal was to explore the intersections of social space within network space, and to create a collective musical network composition. It was commissioned by the Networked_Music_Review blog and I officially launched the piece on 11/15/07. While social networking sites such as MySpace and Facebook typically feature profile pages of people, or sometimes interest groups or bands, I subverted this convention by creating nine profile pages that feature everyday household objects. Each page has a photo of the 
object, a description, and most importantly, a one-minute composition made from recordings of the object being struck and resonated in various ways. All of the pages, or objects, are 'friends' with each other, so that visitors who discover one object may jump to the others by clicking on the 'friends' pictures at the bottom of each page.

ItSpace is also a participatory piece in that visitors are invited to create new ItSpace pages with pieces made from their own household objects and link those as 'friends' of the original set of objects. They are also invited and encouraged to remix and combine existing objects into new compositions, which they can also link as 'friends' of the originals. At this time, approximately thirty more objects have been added to the network by other contributors.

My initial contribution of nine profiles, when viewed or heard as a set, also tells something about the space in which I live and the nature of its inhabitants. In a typical social network scenario, one learns about friends via entries in their profiles such as 'favorite movies', 'favorite foods', 'relationship status', photos, and audio - but always with restrictions and within a prescribed format. I wanted visitors to ItSpace to learn something about me that could not fit into the limiting format of a personal profile. Instead, they encounter a collection of objects from where I live, listen to how I treat those objects musically, and consider my gesture of placing those objects into a network meant for people. 


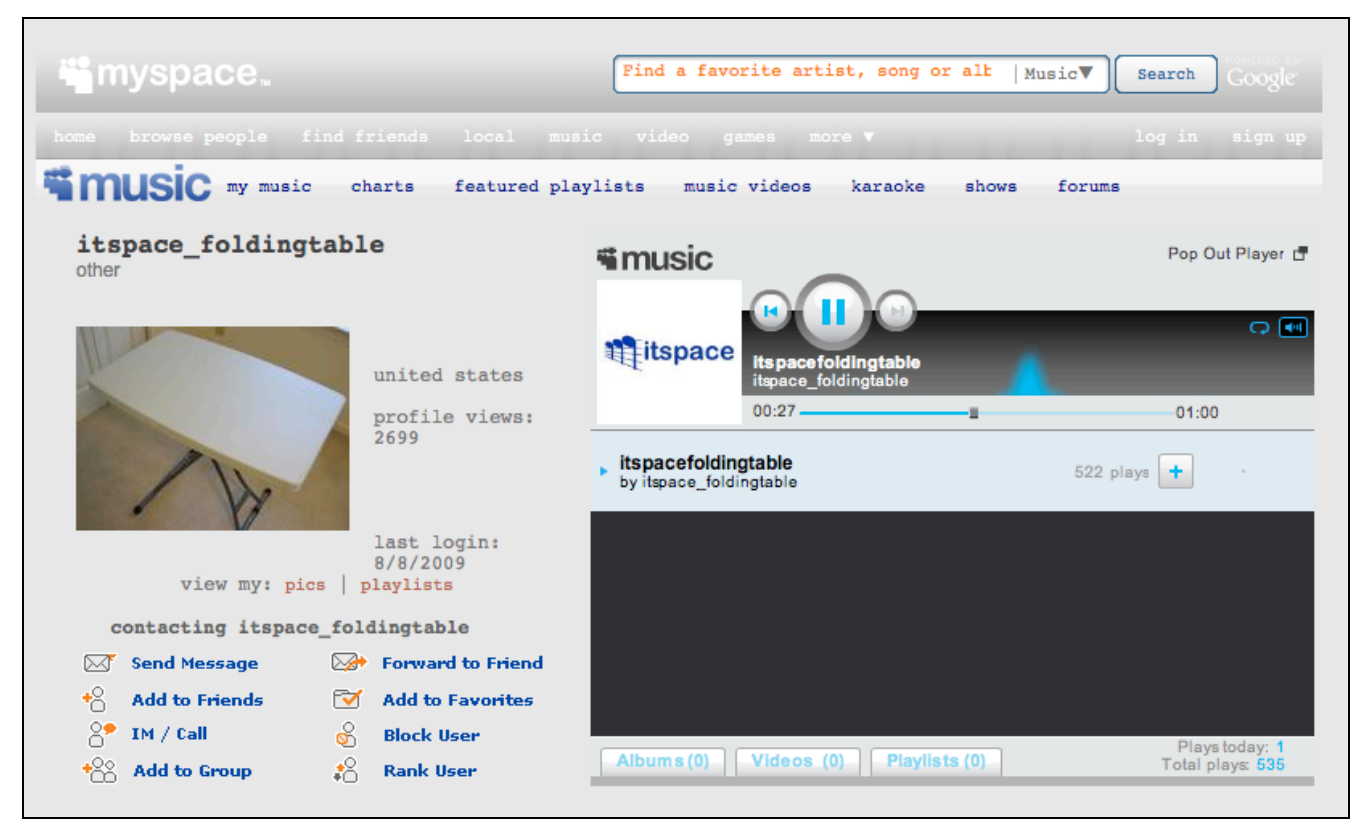

Fig. 5.1: The main MySpace page for itspace_foldingtable.

By bringing $m y$ space into MySpace, I created a hybrid space that combines physical, network, and social space. I did this by decoupling, fragmenting, and recoupling various properties of the discrete spaces from which ItSpace was produced. At a basic level, I decoupled the sounds of the objects from the physical objects themselves, electronically reconstituting them into the miniatures. The pieces became intermediaries between the physical bodies of the objects and their online representations. I decoupled the relationships of the objects in physical space and recoupled them in a new set of spatial relationships within the online social network. The process of putting the pieces online and linking them as friends created a new context for them. In our house, the objects aren't necessarily related as they have different purposes, sit in different rooms, and so forth. Online, and in the context of each other, they become part of a whole that is not possible to represent in physical space, but that speaks about the physical space to the 
visitor. Finally, I decoupled the fixed concept of the MySpace social network from the tool of its creation, the MySpace website software, gesturing toward a new social network by subverting the existing one. The virtual transference of objects from my physical world into a virtual space intended for humans was an attempt to parody the physical isolation implied by online social networks and to call into question our assumptions about presenting oneself in such a space. I also tried to expand the bounds of meaningful interaction within this model of online presence by challenging the expectation of the space as a place where humans only interact via the corporately prescribed channels of communication. By mixing physical and metaphorical resonance, collective participation and feedback, virtual and real space, fragmentation and fluid recoupling, the piece embodies the type of new work that Lévy imagined, in which the artist "attempts to construct an environment, a system of communication and production, a collective event that implies its recipients, transform[ing] interpreters into actors, [and] enabl[ing] interpretation to enter the loop with collective action" (Lévy 1997, 123).

To create the initial miniatures, I chose objects that both spoke about the space in which I live and produced compelling sound samples. The objects were: a wooden banister, a showerhead, a pillow, wine glasses, kitchen timers, a decorative metal bowl, a recliner, metal vases, and a plastic folding table. Figure 5.2 shows a spreadsheet from my precompositional notes comparing both acoustic and other properties of the final set of objects. I aimed for a balance between pitched versus unpitched objects and groups (wine glasses) versus single objects (showerhead). I also chose objects to represent a range of 
materials and locations. I made a point of playing and recording the objects in the spaces where they are normally found in order to capture any acoustic coloration from their resident locations.

\begin{tabular}{|l|l|l|l|l|l|}
\hline & $\begin{array}{l}\text { Pitched / } \\
\text { unpitched }\end{array}$ & percussive & material & multiple & location \\
\hline metalbowl & yes & yes & metal & No & $\begin{array}{l}\text { dining } \\
\text { room }\end{array}$ \\
\hline vasepair & yes & mixed & metal & yes & $\begin{array}{l}\text { dining } \\
\text { room }\end{array}$ \\
\hline recliner & no & mixed & metal spring & no & $\begin{array}{l}\text { family } \\
\text { room }\end{array}$ \\
\hline banister & partially & yes & wood & no & $\begin{array}{l}\text { family } \\
\text { room }\end{array}$ \\
\hline wineglasses & yes & mixed & glass & yes & kitchen \\
\hline showerhead & no & mixed & plastic & no & bathroom \\
\hline pillow & no & no & fabric & no & bedroom \\
\hline egg timers & yes & no & mixed/metallic & yes & kitchen \\
\hline folding table & no & mixed & plastic/metal & no & studio \\
\hline
\end{tabular}

Fig. 5.2: Spreadsheet from my pre-composition notes showing the properties of the various objects

In some of the miniatures processing obscures the spatial acoustic coloration, although those qualities still contribute to the final sonic result. In other pieces, the coloration is clearly audible, as in the short bright resonance of the shower stall in itspace_showerhead, or the longer reverberation of our high-ceiling, wood-floored living room in itspace_banister.

In composing the individual pieces, I also explored a range of processes and approaches. For example, itspace_metalbowl is strictly metric and quantized as I explore groups of polyrhythms moving at different tempi, diverging and converging over one minute. 
itspace_pillow, on the other hand, involved transformed sounds from the fabric of my down pillow to convey the textural impression of ocean waves lulling the listener to sleep. Some of the miniatures, such as itspace_recliner, turned out to be unexpectedly (yet rewardingly) humorous: audiences usually laugh when they hear the magnified sound of the creaking springs within the recliner as it opens and closes.

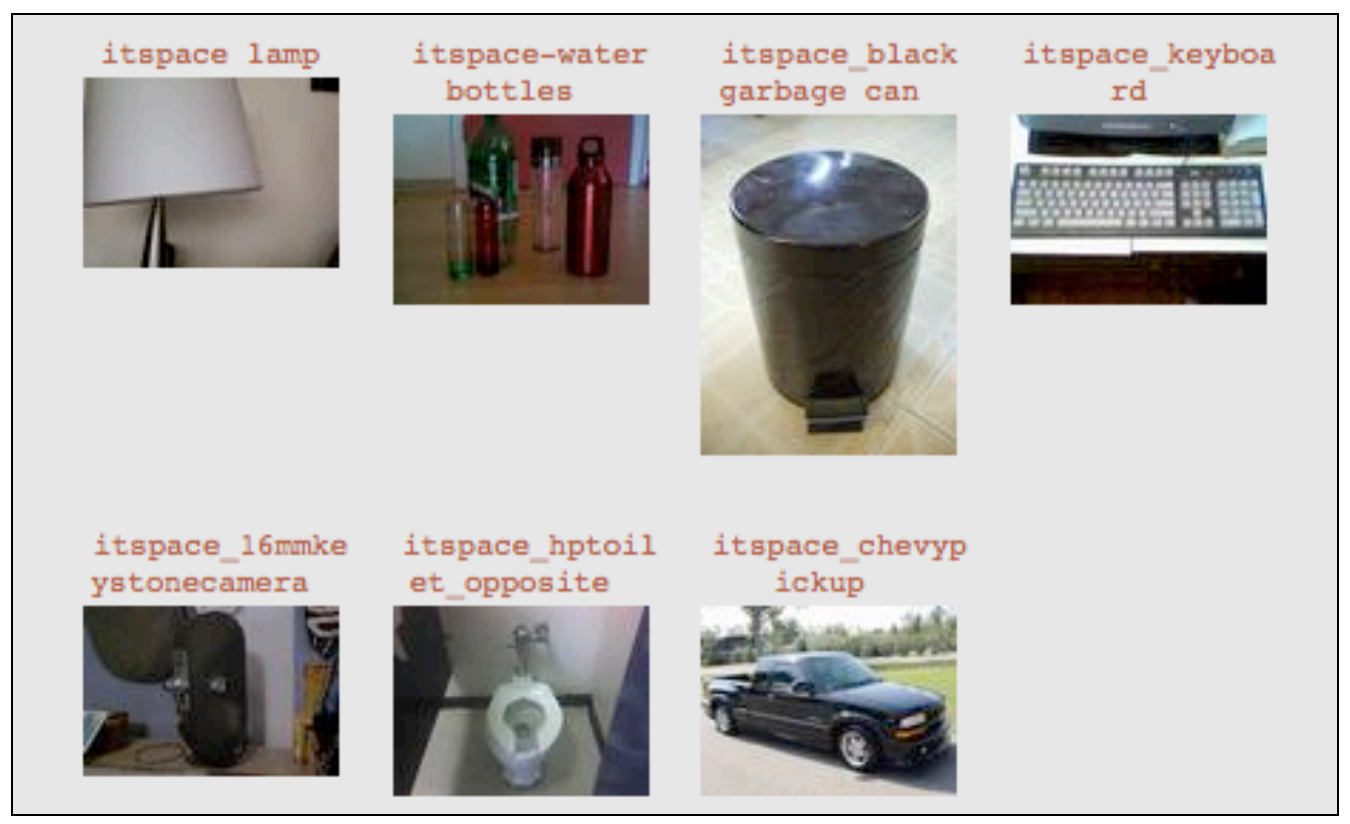

Fig. 5.3: An ItSpace object's list of friends

Numerous artists have created interactive online pieces since the early days of the World Wide Web, including my own work with web-based sound art dating back to $1999^{21}$. Many of these pieces use the virtual space of the Internet as social connectors. Max Neuhaus's Auracle 22 $^{2004)}$ uses a browser-based interface to allow participants anywhere in the world to 'jam' together using a built-in software synthesizer. Visitors do

\footnotetext{
${ }^{21}$ My first piece of net art was my Masters thesis project, bits \& pieces. http://www.fictive.org/bits ${ }^{22} \mathrm{http}: / /$ auracle.org/
} 
not need musical experience, as the operation of the synthesizer is intuitive and based on a real-time spectral analysis of the user's voice (Traub 2005, 470). Chris Brown's 2003 piece, Eternal Network Music ${ }^{23}$, allows participants to meet online and make music through a shared interface. This piece also doesn't require any expertise on the part of the user as the interface consists of small colored circles that users move around to change the pitch, volume, and timbre of tones (Traub 2005, 467). Although the online and participatory nature of these pieces make them precursors to ItSpace, ItSpace plays within the relatively recent space of the online social network - a phenomenon that expanded rapidly on the internet beginning in the mid-2000s. It was, to my knowledge, the first piece of online sound art created using a social networking site.

\section{Solera: for sound, site, and time (2009)}

The initial idea for the Solera came about when I was musing on the process for making the fortified wine, sherry. It is a mixture of wines of different ages, with the amount of older wine diminishing as a percentage of the bottle. The mixture is accomplished through a system, called 'solera', in which young wine is deposited at the beginning of a series of barrels ranging from youngest to oldest. Periodically, a percentage of each barrel is moved into the adjacent barrel, progressing from younger to older. By the time the original wine reaches the last barrel, it has been mixed with wine from many previous years. In Solera, I took this idea and applied it to sound.

${ }^{23} \mathrm{http}: / /$ www.transjam.com/eternal/eternal_client.html 


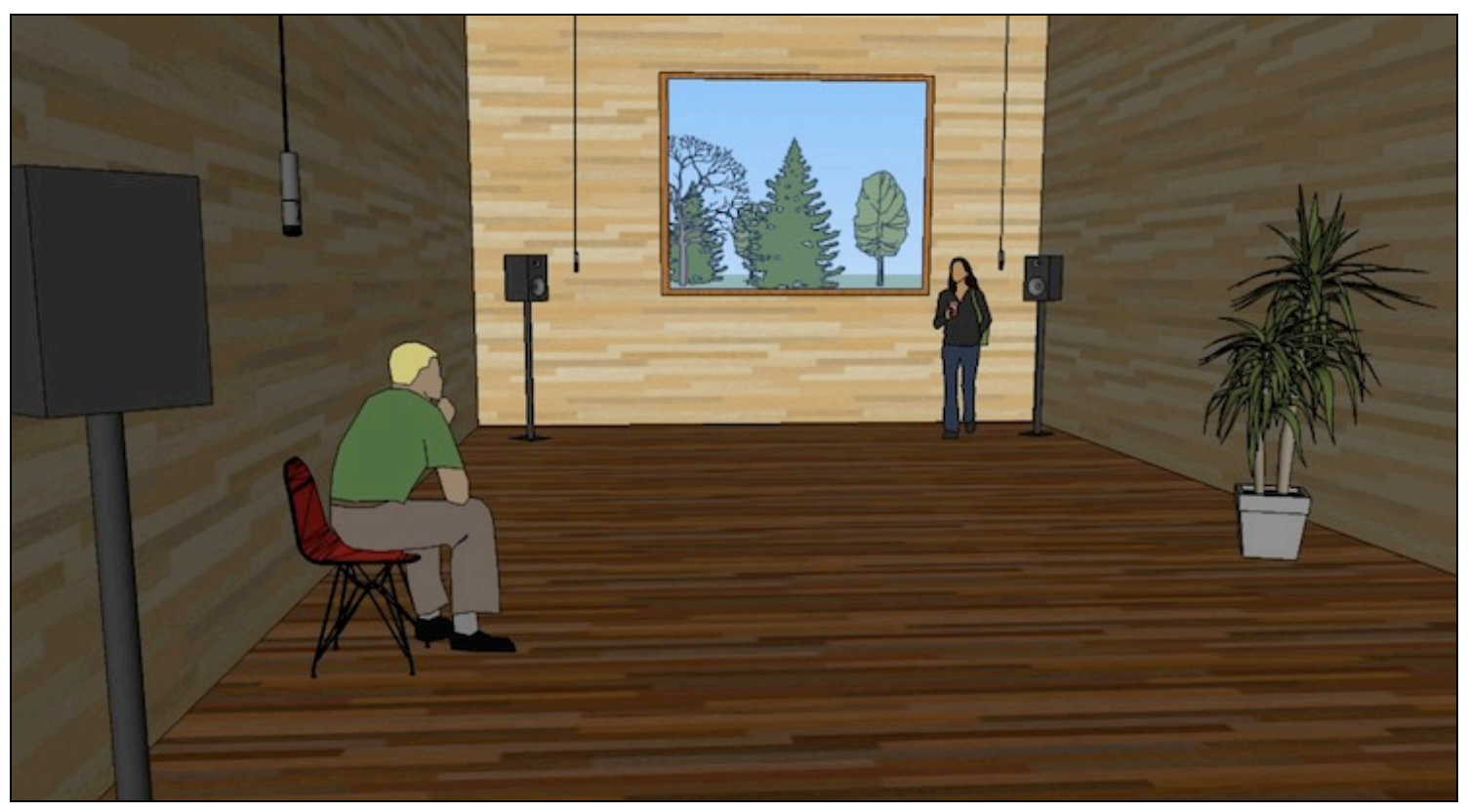

Fig. 5.4: Diagram from a grant proposal for Solera, showing its initial conceptualization.

My goal in creating Solera was to augment a physical space by slowly drawing out and making present the sonic patterns that inhabit a space over time. This would create an installation that was, through its implementation, inherently site-specific while designed without a specific site in mind. The installation recorded and replayed four channels of audio in 24-hour cycles, playing the previous day's audio overlaid with the current day. Four suspended microphones and four suspended speakers were installed in the lobby with each positioned in, or close to, the corners of the space. The 3D rendering in Figure 5.4 shows the original conception. Each microphone was positioned to pick up the live audio of the space while also picking up the accumulated, temporally-aligned audio played back from its corresponding speaker. The resulting sound was that of each day's recording layered with the previous day's, on into the past. The microphones and monitors were connected via a Firewire audio interface to a Mac Mini computer running 
Max/MSP. Recording and maintaining two 24-hour long sets of four-channel audio turned out to be a tricky task due to a file-header size limitation for AIFF and WAV formats that does not allow files sizes larger than approximately $2 \mathrm{~GB}$. Since that is approximately three hours of mono audio at $44.1 \mathrm{kHz} / 16 \mathrm{bit}$, or 50 minutes of four-channel audio, there was no way to record continuous 24-hour long files. Solera was instead programmed to simultaneously record three-hour long mono files, one for each speaker. Every three hours, those files would be closed and new ones opened, resulting in eight four-file sets per day, or 32 2GB files in total for a 24-hour period. Despite the occasional crash, this approach worked, although the channels had a tendency to desynchronize over time from small delays that accumulated each time the files were changed out at threehour intervals. The initial installation of Solera took place in the main lobby of Ruffin Hall, the studio art building at the University of Virginia, where it ran for three weeks from $10 / 26 / 09$ to $11 / 14 / 09$. 
Solera moves in a different direction from ItSpace, going from the virtual domain into the physical. In its formal structure, Solera draws on the spatial processing pieces pioneered by Lucier and Amacher as discussed in Chapter III. It is a piece about physical space, not hybrid space. Unlike the process in Jeff Talman's White Sound Down, there is no analysis or filtering of the sound for compositional purposes - it is simply replayed

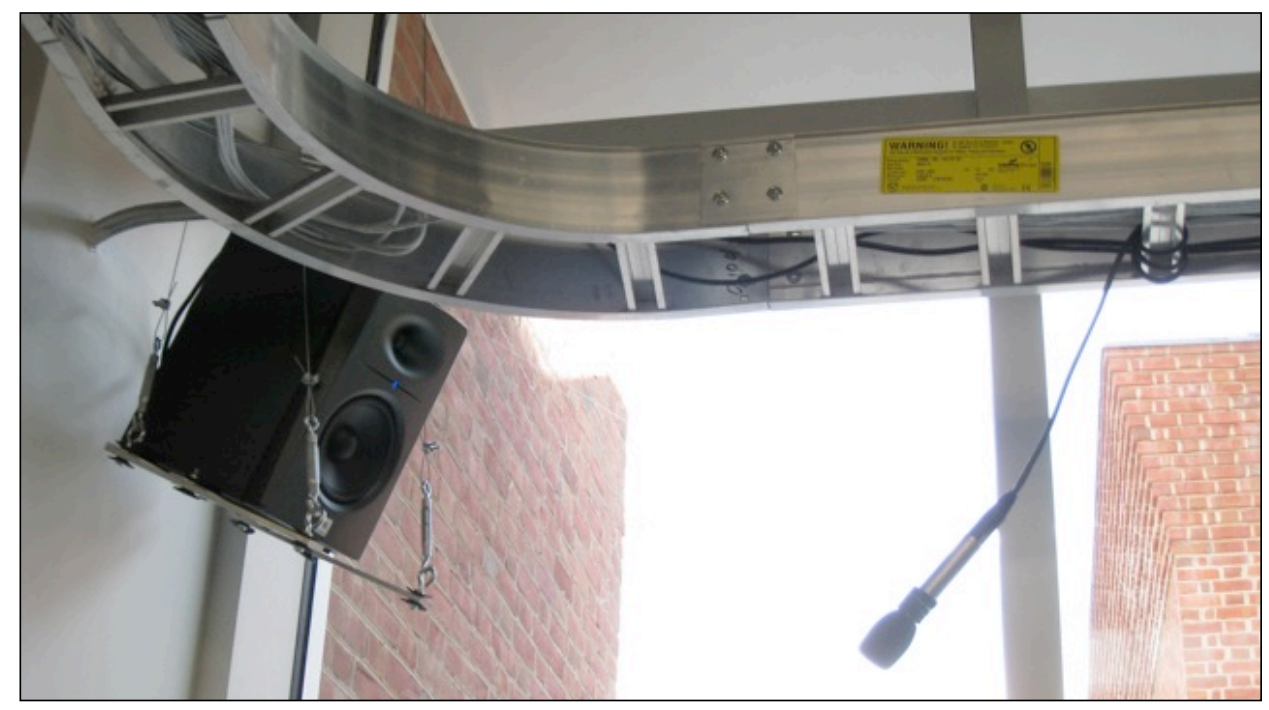

Fig. 5.5: One suspended speaker and microphone pair in the premiere installation of Solera.

into the space. As in Lucier's I am Sitting in a Room, the space becomes the processor, but it takes the basic recording/playback process and stretches it over a much larger timespan, letting the sound evolve in real time and in different ways depending on the location of microphones and speakers throughout the space. Solera also draws influence from installations such as Fontana's Pigeon Soundings (2007), in which ambient sound from the installation space's past inhabits the present. 
Solera uses technology to displace the sound of the space in time, adding a new aural dimension to the site that its physical structures cannot provide. In this sense, I consider the installation an almost architectural material of the site. It reflects the sound much like the walls, floor, beams, and windows that comprise the space, yet unlike those surfaces, this material has an aural memory. Again, the technology takes on the role of spatiotemporal decoupler, separating the sound of the space from its immediate attachment to the 'now' of the space. The 24-hour recordings become the foundations for a larger structure, one that evolves and builds over time in direct relation to both the instantaneous and aggregate sound world of the space. In addition, it thrives on the presence and (potential) participation of its receivers - the public - who contribute to the fabric of the piece with every sound they make in its presence.

Over the run of the installation a constant, slightly varying drone emerged. I knew from previous pieces, such as Lucier's I am Sitting in a Room, and my own groundloops: for solo percussion and internet, that drones develop when a spatial resonance is fed back into itself repeatedly. The most prominent frequencies will reinforce themselves and stretch out, eventually resulting in a drone. In Solera, the drone resulted from several factors: the reinforced resonance of the space, the feedback between the microphones and speakers, and the constant and fairly loud hissing of the ventilation system in the building. 


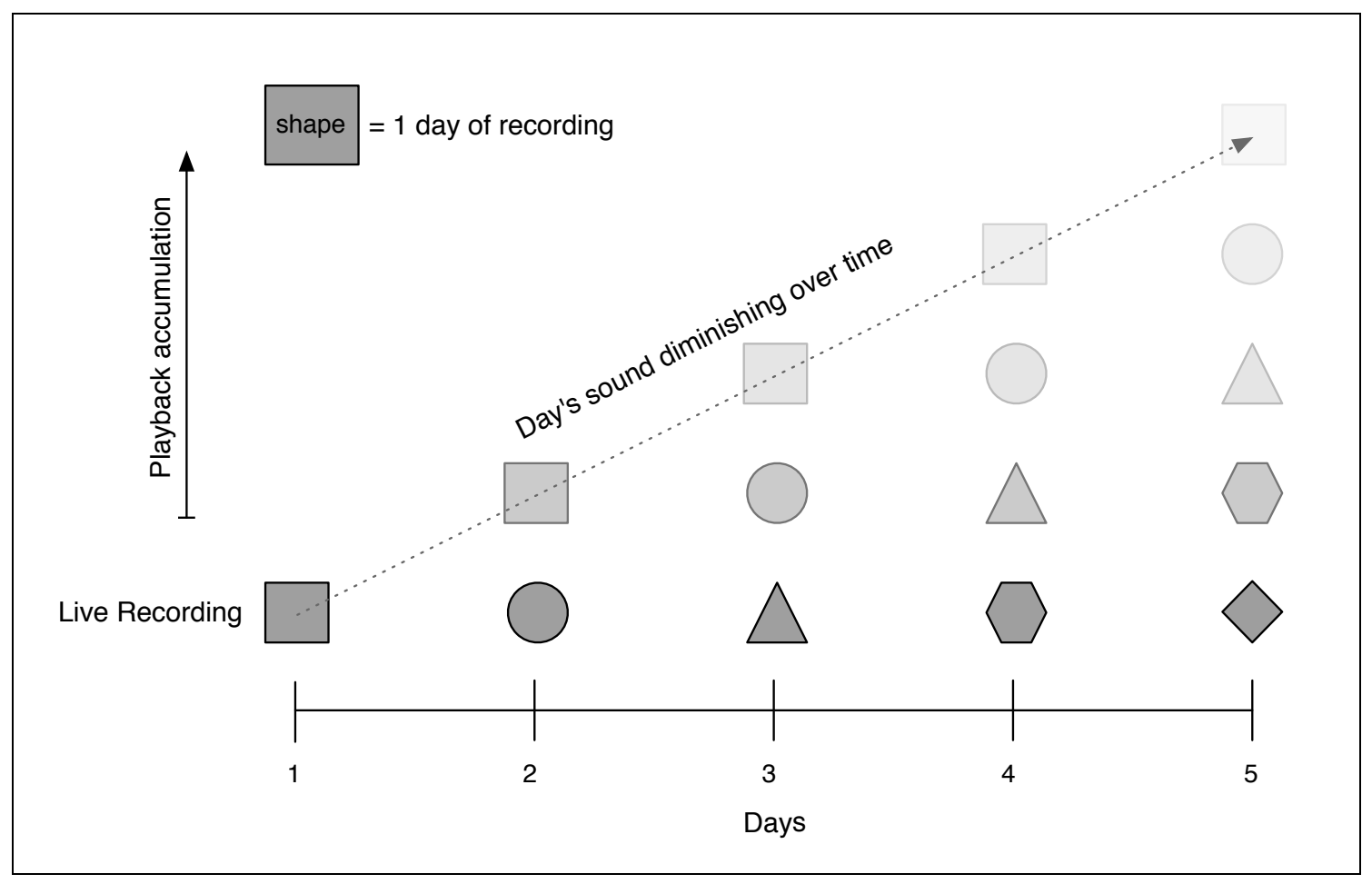

Fig. 5.6: Diagram showing accumulation and degradation of audio over time in Solera

While there was not as much cyclical traffic through the lobby as I had hoped, there was a noticeable rise and fall in sonic activity depending on the time of day that one listened. The most sonically active times, as expected, were the minutes between classes when students moved in and out of the building, passing through the space and conversing. The quietest times were in the early morning, at night, and on weekends. On several occasions, people in the building reported hearing sounds and conversation in the lobby that seemed as though they were coming from people present. As it turned out, the source was a recording from a previous day. 
Like ItSpace, Solera was also, in part, a social experiment. How would visitors to the space react to the sound, but more importantly, how would people who pass through the space daily - faculty, students, custodians, etc. - react to and interact with the piece when the resonance of their words and actions within this public space would persist for several days? Given the algorithmic nature of the piece, I could not control how it evolved, what the volume level was, when it would remain silent, and so forth. I let it run its course and expose the sonic life of the space over time. I had hoped that regular visitors to the space might create mini-pieces or performances within the installation, playing with the knowledge that a sound made at 1:30PM on a Monday would return at the same time on Tuesday, Wednesday, and so on. Yet I was reluctant to telegraph my expectations in the program notes that were displayed at the two entrances to the space. I wanted visitors to discover the possibilities for themselves. Other than some music students who visited the site, no one in the building intentionally contributed to the piece. Were they reluctant to make sound or make themselves vulnerable through performance? Did they consider the piece an invasion of privacy? Were most listeners completely unfamiliar with this type of art, and therefore lacking in a conceptual foundation from which to approach it? In the end, I contributed my own sound to the piece and spent many hours sitting in the lobby, listening to the playback, and listening to the individual corners. 


\section{Study No. 1 for Bodies, Metal, and Air (2010)}

Study No. 1 for Bodies, Metal, and Air originates from the same early spatial experiments, conducted in the summer of 2009, that lead to Solera. It is also a piece about physical space and, like Solera, it uses feedback as its primary sonic material. Spatially, it differs quite significantly: the focus of Study No. 1 is on the intertwined relationship between physical objects, including bodies, and the acoustic space they inhabit. When we enter into a space, we become part of its acoustic fabric - our bodies, our clothes, our material objects - all reflect or absorb sound, changing the sonic signature of a space. Lucier explored this phenomenon in his 1975 piece, Outlines of Persons and Things, in which persons and things were placed in front of speakers playing clusters of sine tones. The objects interfered with the tones, creating audible sound shadows and diffraction patterns (Lucier 2005, 430-431). Study No. 1 for Bodies, Metal, and Air takes a different approach, using microphone feedback as a means to make the spatial changes perceptible. Four dancers, choreographed by Dinah Gray, moved about the space using acoustically reflective sheet metal props to change the acoustic of the space, resulting in variations in the feedback tones.

The genesis of the piece came while I was playing with controlled feedback tones between my setup of four speakers and four microphones. In one corner of the room was a large chalkboard on wheels. I moved the chalkboard into the middle of the feedback field, gradually tilting it back and forth. The effect on the tones was instantaneous and dramatic as the hard surface of the board changed the acoustic of the space - reflecting 
and reinforcing tones and interfering with standing waves. It occurred to me that a group of people moving around a feedback field with acoustically reflective objects could potentially shape a piece.

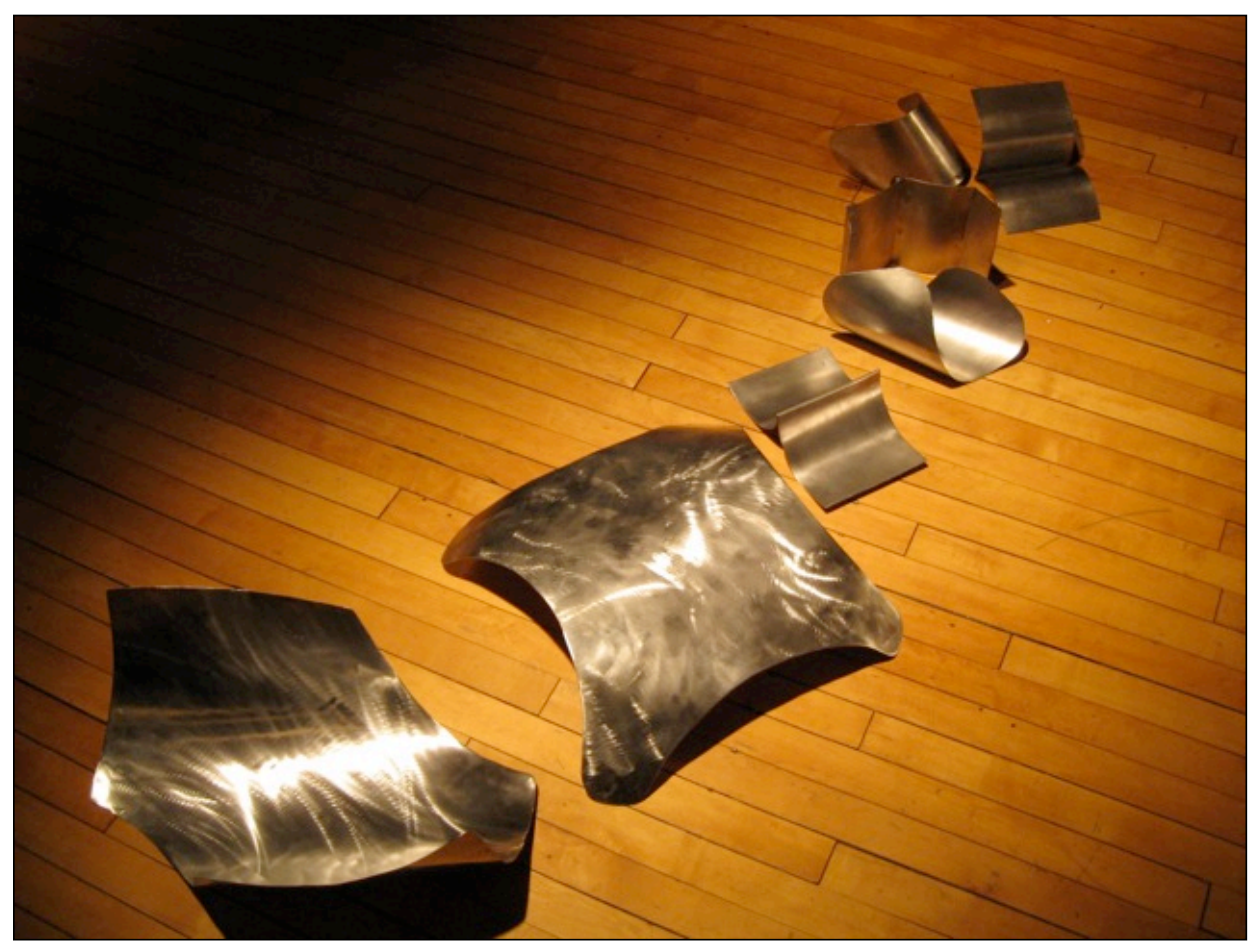

Fig. 5.6: Some of the metal pieces used by the dancers in Study No. 1: for Bodies, Metal, and Air

Although Study No. 1 uses digital technology to manipulate the sound, it would be possible to create the piece with feedback through analog filters and compressors. The real spatial manipulation happens through the physical presence of the dancers and their props. This process is not so much a technological decoupling as the creation of an environment that enables aural traces, much like the ripples made when a stick is dragged through the water. The traces in Study No. 1 are sonic artifacts that result from the dynamic relationship between bodies, objects, sound, and space. 
Study No. 1 encompassed a number of 'firsts' in my work, the most important of which included working with dancers and creating the sculptural props. I had learned the basics of metal inert gas (MIG) welding and plasma cutting while creating the suspension system for Solera. For Study No. 1, I acquired several large scraps of sheet metal, and began to cut and bend them into various shapes that were visually interesting to me and were acoustically effective for the purposes of the piece. Meanwhile, Dinah and I met to discuss the sonic and choreographic form of the piece. She also gave input regarding the weight, comfort, and usability of the props for the dancers. We divided the piece into four sections, each differing with respect to the objects, number of dancers, and registral ranges that were used. Figure 5.7 shows a table from a shared online document (incomplete) that we used early on to work out the properties of the four sections - this gave us some guidance as we moved into the rehearsal phase, but many changes were made during rehearsals. We began rehearsing in early January, 2010 for a scheduled premiere of March 5, 2010 at McGuffey Art Center in Charlottesville, VA.

We discovered early on that while the interference created by the objects could change the pitch and some timbral characteristics of the feedback, the effect was not entirely predictable. Small changes in volume, microphone gain, and microphone and speaker placement - to name but a few factors - could change the qualities of a section between rehearsals. We also did not know how a roomful of listeners would impact the acoustic, and thus the ability of the dancers to alter it with their movement and objects. 


\begin{tabular}{|c|c|c|c|c|}
\hline Properties: & Mvmt 1 & Mvmt 2 & Mvmt 3 & Mvmt 4 \\
\hline $\begin{array}{l}\text { num } \\
\text { dancers }\end{array}$ & 4 & $4---->1$ & $2($ or $2+1)$ & $2+2$ \\
\hline tone & high cluster & low, monitors 1,3 & & $\begin{array}{l}\text { low, plus mid, plus } \\
\text { high }\end{array}$ \\
\hline pulse & no & gradually introduced & $\begin{array}{l}\text { gradual }-> \\
\text { extreme/fast }\end{array}$ & $\begin{array}{l}\text { mixture (some } \\
\text { speakers pulsed, } \\
\text { some straight), end } \\
\text { slow. }\end{array}$ \\
\hline tempo & slow start & varied & varied & \\
\hline materials & hand reflectors & large sheet +1 hand & $\begin{array}{l}\text { maybe three med } \\
\text { pieces }\end{array}$ & $\begin{array}{l}\text { mixture? (large, plus } \\
\text { two med sheets) }\end{array}$ \\
\hline
\end{tabular}

Fig. 5.7: A table used to assign properties to the sections of Study No. 1: for Bodies, Metal, and Air

In order to have a greater degree of control over the sound, I created a Max/MSP patch (see Figure 5.8) that allowed for substantial control over the feedback tones that emerged from each speaker. I used a MIDI controller to move through different preset scenes, adjust volumes, and control four bandpass filters, one for each speaker/microphone pair. The sound from each pair could also be pulsed with an individual low frequency oscillator (LFO). This pulse was used in the latter half of the piece, as interference by movement and objects had a pronounced effect on its timbre. 


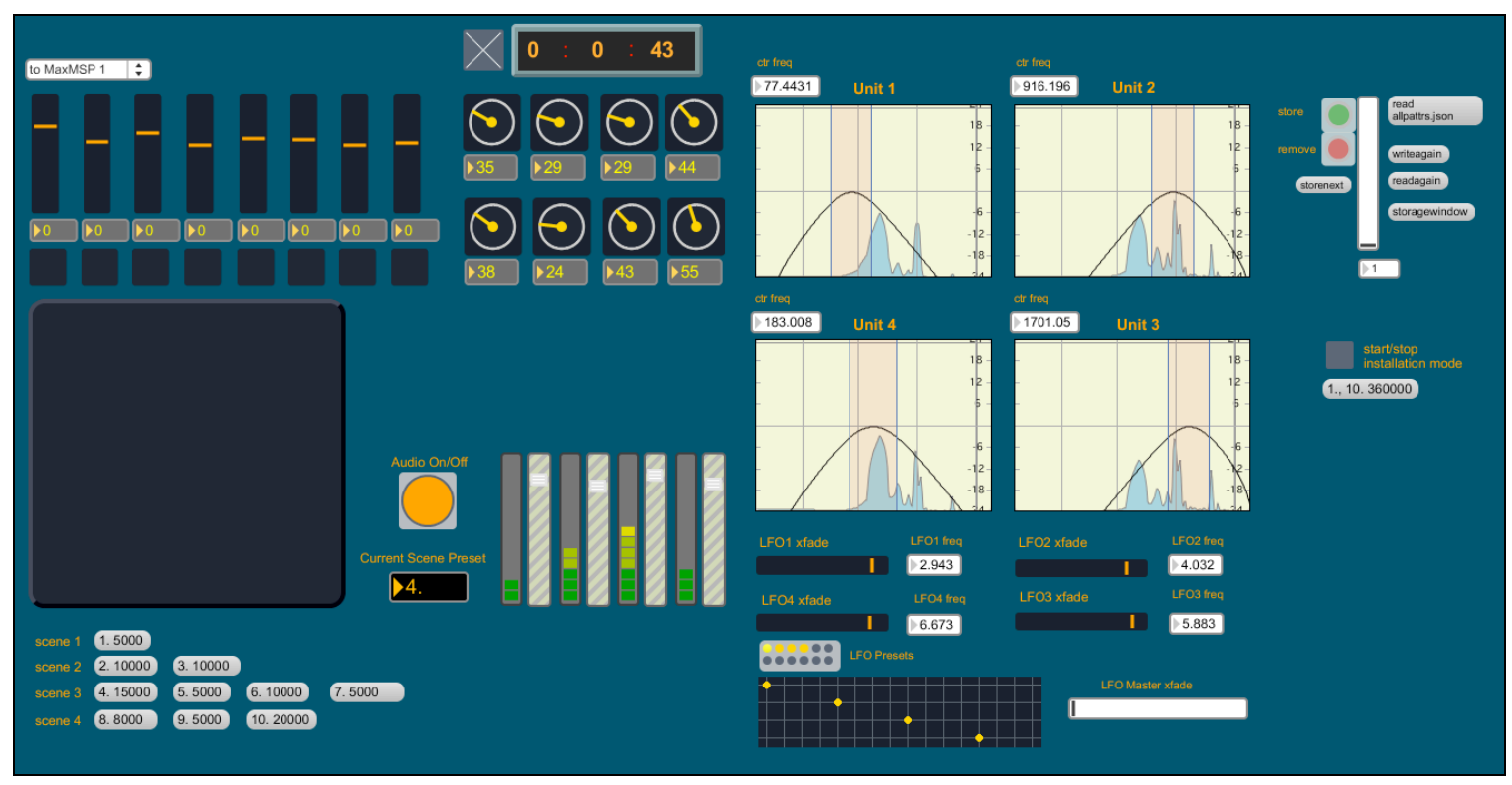

Fig. 5.8: The Max/MSP based performance interface Study No. 1 .

The final form of Study No. 1 took shape after numerous rehearsals and involved performative 'scene' changes in the software in conjunction with those of the choreography. During the live performance, I carefully adjusted filter settings to find unstable feedback tones that were ready to jump to more stable pitches when prompted by spatial and acoustic changes. Dancers Rose Pasquarello Beauchamp, Lisa Eller, Dinah Gray, and Aaron Wine used a combination of coordinated moves and improvisation to sound the space. As they were counting internally, I used a graphical timeline to guide my performance and keep track of their cues. We performed the piece three times on the evening of its premiere. In order to give the audience a better understanding of the acoustic phenomenon, I let the feedback continue to sound at the end of each performance, inviting the audience to pick up the objects and play with the sound. 


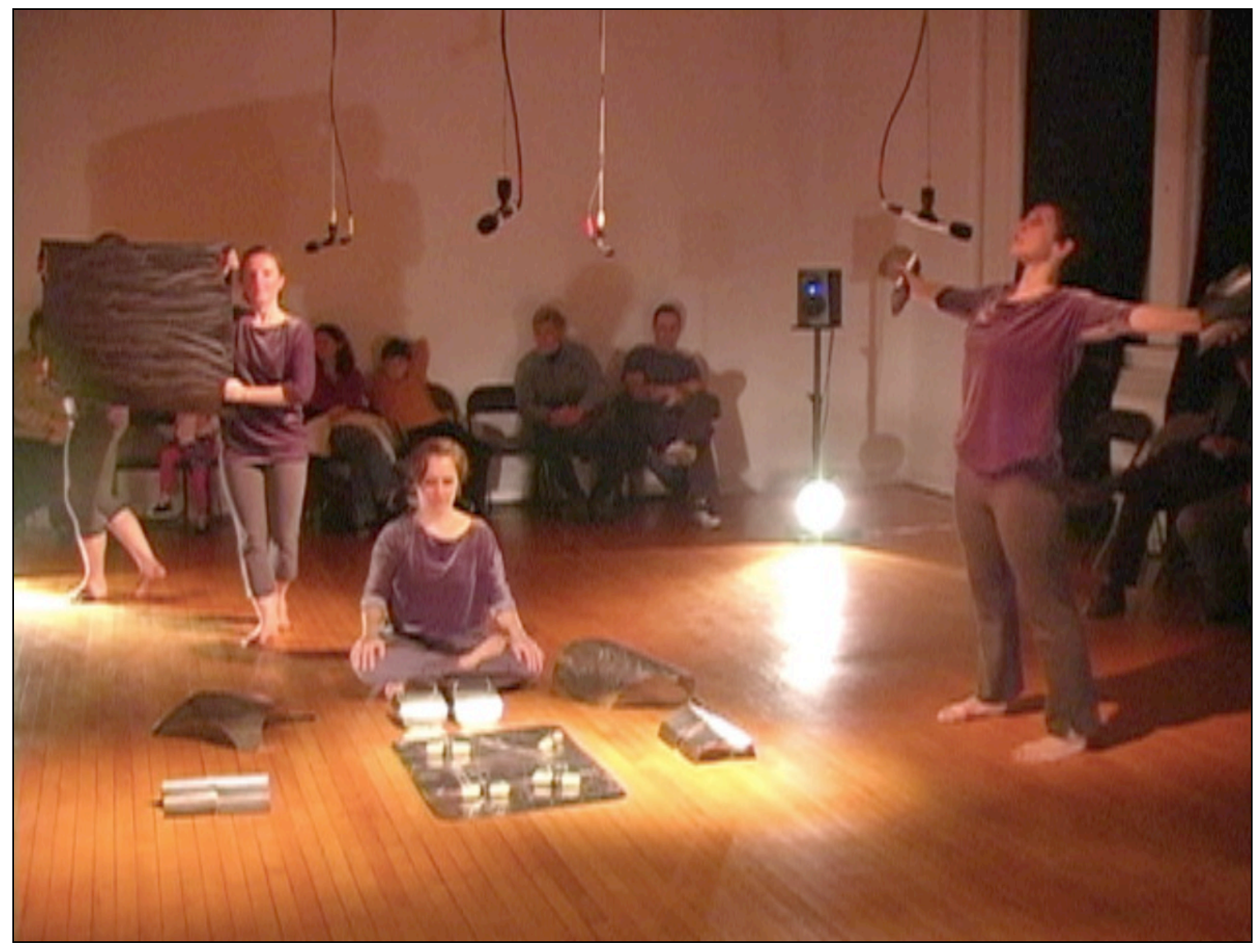

Fig. 5.9: Dancers performing the premiere of Study No. 1: for Bodies, Metal, and Air.

\section{Passages and Recesses: for solo flute and hybrid space (2010)}

My goal in Passages and Recesses was to create a hybrid aural space, using a network to aurally combine two physical spaces. It was part of a collaboration, with UVA undergraduate Eric Montgomery, supported by a grant from The Center for Undergraduate Excellence. We created a system to sonically combine two physical spaces via the network, and each of us composed a piece that utilized it. Eric programmed an object in Java for the Max/MSP environment, allowing us to send and receive uncompressed audio over a network connection. 
Our pieces each joined a different space with the Dome Room of Jefferson's Rotunda at UVA: Eric used the main lounge in UVA's Newcomb Hall and I used the inner stairwell in Old Cabell Hall. We planned to install a computer, stereo microphone, and a pair of speakers in each of two spaces: A and B. Live sound received by the microphone in space A would be sent over the network, or space N, and played out the speakers in space B, picking up space N's delay space B's resonant qualities. Space B's stereo microphone would then pick up the sound, and space B's computer would transmit it back through space $\mathrm{N}$ to space $\mathrm{A}$, where it would be played out of the speakers. This back-and-forth process would be continuous and instantaneous: sound would cycle back and forth between the spaces, accumulating the resonant qualities of each to create a hybrid resonance derived from both spaces (see Fig. 5.10).

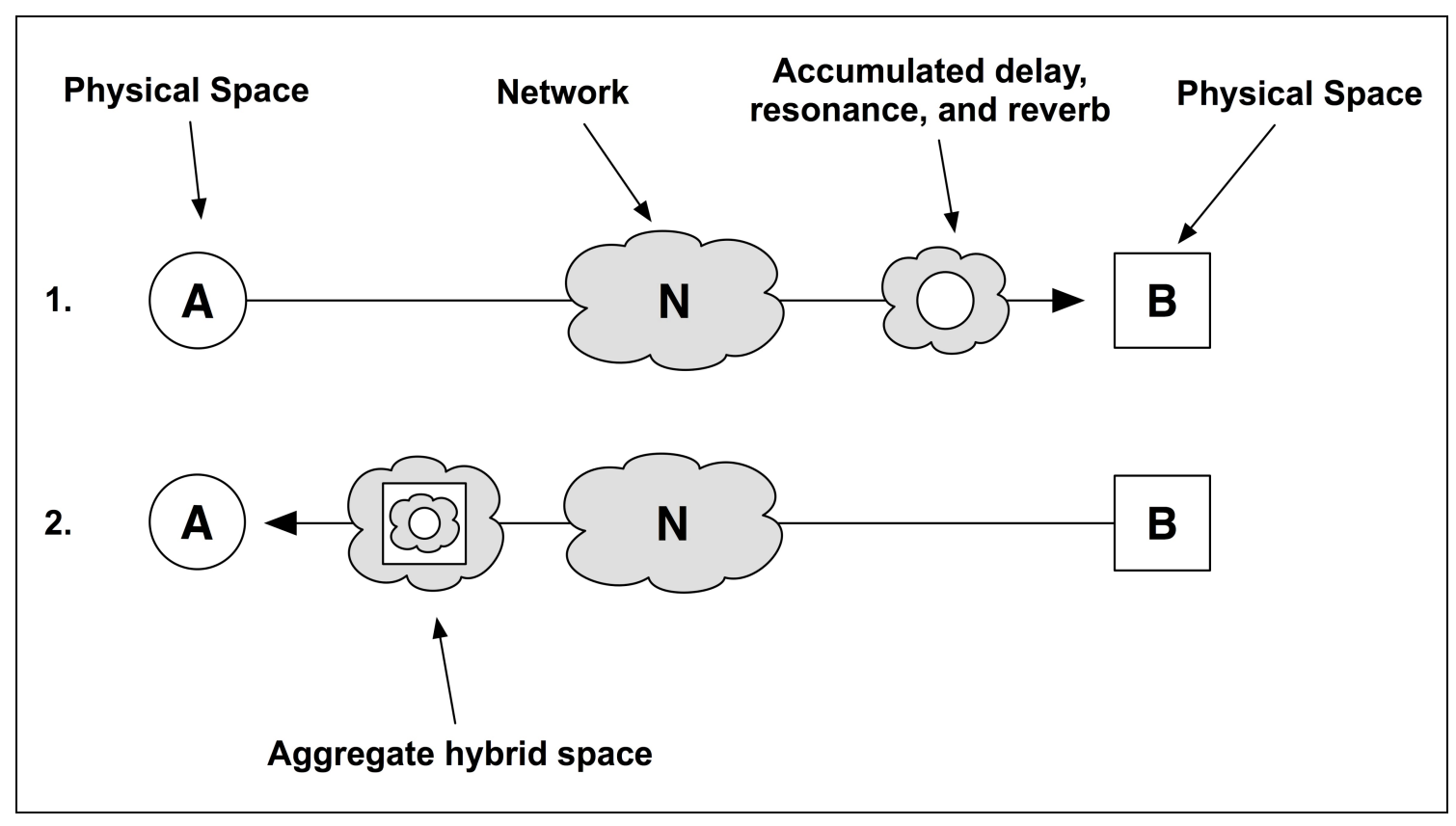

Fig. 5.10: Diagram showing the aural accumulation of spatial properties in one back-and-forth sharing cycle as audio moves from space A to space B, passing through the network (N) each time. 
The hybrid space we intended to create was not just a pure combination of the resonances of two physical spaces - the resulting sound would also include an unavoidable property of the network space: delay. This delay - caused by necessary buffering plus network transmission time - would become a significant component of the sound environment as the sound fed back between spaces A and B. In this sense, the metaphorical space of the network would contribute a very real aural property to the hybrid space. In addition, if the network connection dropped off at any point or couldn't handle our data rate, dropouts and sonic glitches would most likely be introduced. My score incorporates the addition of these network space properties as certain passages direct the performer to introduce glitches and dropouts into their playing. And, as the score is a mixture of through-composed passages and guided improvisation, the performer has the flexibility to adjust and adapt to the variable properties of the space as the piece unfolds.

In Passages and Recesses, the role of technology as decoupler, fragmenter, and recoupler of space is at the fore. The central spatial gesture of the piece is the decoupling of two aural spaces from their physical source, fragmenting the abstracted spaces into bits passed through computer hardware and network connections, and recoupling them as a new imaginary space. One can find analogs to this in other aspects of electronic music composition, such as cross-synthesis techniques in which two sounds are 'morphed' together. Within that context, this technique is an attempt at real-time spatial crosssynthesis using a network as the conduit over which the synthesis occurs. 
As discussed in Chapters III and IV, there is a significant aesthetic precedent for Passages and Recesses. The creation of shared spaces is seen in Max Neuhaus's Public Supply series, Maryanne Amacher's Music for Sound Joined Rooms, Jonas Braasch's Tele-Colonization, The Hub's Clocktower concert, and Alvin Lucier's Quasimodo the Great Lover, to name just a few. What I saw as unique about this project was the combination of using the network to transmit and receive the sound and feeding the sound back and forth between two spaces, such that a third hybrid space emerges that has acoustic qualities resulting from the repeated multiplication of the originating spaces against each other and the network.

In Passages and Recesses, I chose to combine the resonances of the stairwell of Old Cabell Hall with the Dome Room as I was familiar with its acoustics and its long, bright reverberation - especially from the top landing. It also has a large section of steel floor that could be used percussively in a performance. I was interested in the visual and acoustic contrasts between the two spaces: the stairwell is visually bland and utilitarian, yet far more acoustically dramatic than the surprisingly ordinary sound of the Dome Room - a space that is the visual, architectural, and intellectual heart of the University. By combining these two spaces, I sought to embody some qualities of each in the other. I wanted to lend some of the acoustic grandeur of the stairwell to the Rotunda, while also bringing some of the acoustic properties of the Rotunda back into the stairwell. The result 
would be a joining of the visually grand but acoustically ordinary with the visually ordinary but acoustically grand.

I composed the piece for flutist, Wayla Chambo. I began by recording her playing the entire range of three flutes in the stairwell: alto flute, $\mathrm{C}$ flute, and piccolo. I took note of which pitches had the longest reverberation times in the stairwell, and used those as the basis for the score's underlying pitch set. I also took measurements of the performance site as a means to visually map it in the score, and to look for any areas of interesting proportional similarity between the stairwell and the Dome Room.

I structured Passages and Recesses in three movements, with each using a different instrument and associated with a different space (see Appendix A). I also incorporated central graphical elements into the score that were not intended for conscious interpretation by the performer, but reflected my own interpretation of each of the spaces. I used measurements and floor plan images of the Dome Room and the stairwell to generate these images. In the third movement, the central image on the score, like the notated material, is a hybrid of the content in the previous two movements.

The first movement of Passages and Recesses used the piccolo, the smallest and highest in register of the flutes, and associated it with the smaller volume of the stairwell. As in the other two movements, the section involves guided improvisation consisting of musical passages that the performer must play through - sometimes repeating, sometimes 
just once. There are also directions to move closer or farther away from the microphone, as this alters the ratio of reverberation to direct sound captured by the mike. The phrases in the first movement are fast and repetitive, attempting to take advantage of the acoustic 'smearing' in the highly reverberant stairwell. Assuming one has a sufficient distance from the performer, the quickly played phrases run together into a smoother texture as the direct sound is lost in the acoustic reflections. I also included fast passages of particularly high and loud pitches that created otoacoustic effects. The otoacoustic tones were greatly amplified by the hard surfaces of the space, and are audible in the recording of the performance. ${ }^{24}$

The second movement associated the alto flute with the Rotunda. It is a softer section, reflective of the quiet austerity of the Dome Room. The performer slows down, playing longer tones at the lower end of the alto flute's range. The four-note motive with flutter tongue that begins the first movement is repeated, but this time transposed down, louder, and slower. In contrast to the almost exclusive use of pitched sounds in the first movement, the second movement introduces noise in the form of breath and whispered consonant sounds - when made at the lower end of the alto flute's range, these sounds are suggestive of a larger hollow space. Whispering 'p-p-p...' or 't-k-t-k...' into the flute is somewhat akin to clapping or clicking one's tongue within a room to sound it out. The performer also uses gentle foot stomps in the middle of the stairwell's metal floor section - the effect is similar to that of a thunder sheet.

\footnotetext{
24 The addition of otoacoustic effects to the piece was a direct result of my research on Maryanne Amacher and her concept of 'Third Ear Music'.
} 


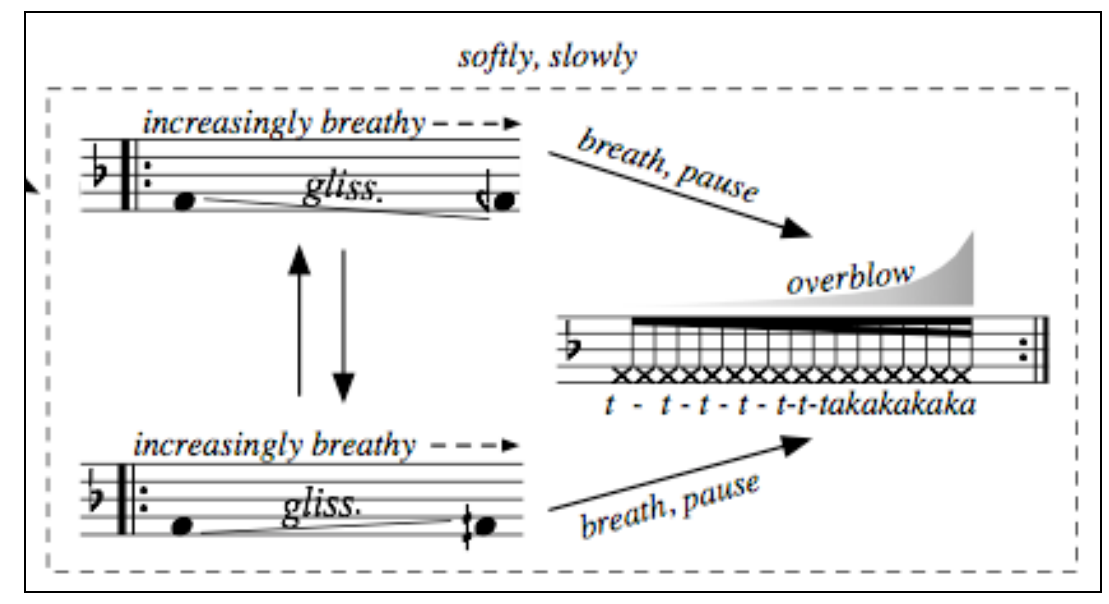

Fig. 5.11: Example of a phrase from the second movement of Passages and Recesses.

The final section, using the $\mathrm{C}$ flute, combines reworked phrases from both the first and second sections, as both of those spaces are present in the hybrid space. The pitches, tempo, and timbral material also reflect a combination of the previous two sections. As the movement progresses, pitched phrases are gradually replaced with noise, breath, and foot taps on the metal floor. The movement gets progressively quieter and the events more sparsely distributed. My prediction, going into this section, was that we would build up a significant resonant drone caused by the feedback between the two spaces. I wanted to gradually remove the performer from the resonating sound, and just leave the sounding trace behind (similar to how performances of my piece, ground loops, typically end).

For the technical implementation of Passages and Recesses, I designed a Max/MSP patch that contained Eric's objects. Both objects ran within Max/MSP's Java implementation object, 'mxj '. As in the case of Study No. 1 for Bodies, Metal, and Air, I added dynamic compression to prevent the system's feedback from 'blowing up'. Fig. 5.12 shows the 
patch in 'presentation' mode, which one typically uses during a live performance behind-the-scenes objects, such as Eric's network objects, are hidden. The Max/MSP patch was designed to be a clean and fast conduit for getting audio on to and off of the network. I also wrote a non-networked Max/MSP patch to simulate the effect of sharing resonance between two spaces. This enabled us to rehearse the piece before the network software was completed.

Unfortunately, when the performance date arrived, the software did not work as anticipated. We had a very slow network connection and poor signal strength. The software did not have sufficient buffering capability to handle anything other than very fast connection speeds.

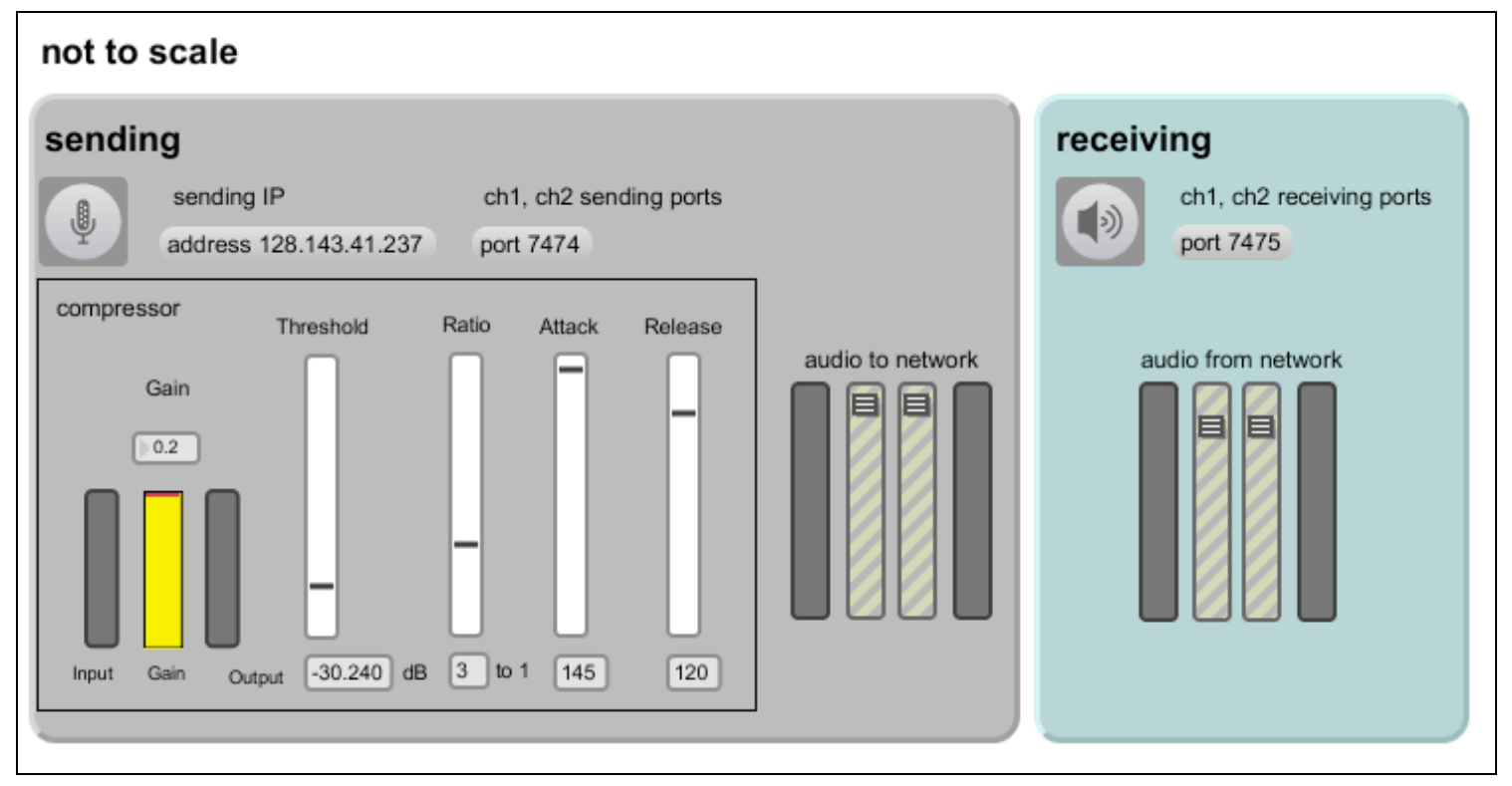

Fig. 5.12: Max/MSP patch for "Not to Scale" in performance mode. 
The software worked under ideal conditions - but ideal conditions are rarely encountered in real-world performances. As a result, during the stairwell performance, only a few seconds of sound came back from the Rotunda. We have no plans upgrade the software at this time. However, non-Max/MSP solutions, such as CCRMA's JackTrip software bundle, offer a promising route.

\section{Curve (2010)}

Curve, the final piece of my dissertation series, is a site-specific installation intended to make musical a unique sonic-spatial property of the installation site. The walkway behind the balcony of UVA's Old Cabell Hall is bounded by a curved wall creating an intense, prolonged, and stunning echo that varies dramatically as one moves along the space. I had been aware of the phenomenon for a number of years and had long desired to create a piece for it. Using four speakers placed at specific points along the wall, I created an enveloping sound environment that varied as listeners walked from one end of the balcony to the other. The installation's swells, drones, pops, pitches, and silences transformed the less-visited rear of the hall into a 155 -foot long immersive instrument.

Curve is a hybrid space in that it uses the abstracted space within a multi-channel system to sound out and interact with physical space, both built and corporeal. The multi-channel system is spaced out across the wall, creating its own overlapping curve that plays with the architectural aural space of the balcony. It also plays with corporeal space as the position of the listener's body within the space determines the echo variations they hear. 
The decoupling in Curve occurs in the digital domain, as millisecond-accurate delays are used to reveal and emphasize the wall's unique acoustic properties. The technology is used to create sound events that are rooted in the natural acoustics of the space, but that would likely never happen naturally within the space.

Creating Curve required a number of pre-compositional activities, most important of which was measuring the space. In this regard, I took a far more scientific approach in investigating the space than in the previous four pieces. Physical measurements were useful for figuring out the delay time, but I found that the sound recordings turned out to be the best means of measuring the delay from different points along walkway. The initial recordings showed that an impulse (hand clap) from one end of the space echoed back in 270 milliseconds. This meant that it took sound around $135 \mathrm{~ms}$. to travel from one end of the space to the other - a perceptible and musically useful amount of time. I also observed that the echo pattern changed depending on where one listened along the wall. An impulse played and heard from the center of the space echoed twice as fast as one from the end of the space. This was because sound travelled half the distance in either direction before returning to the center. Impulses played from other points along the wall would result in combined echoes of different rates, proportional to the listener's distance from either end. Once I had figured out how the phenomena worked and how to predict the delay times from different points, I started working with the speakers at the site. 
Given the consistency and predictability of the wall's echo, I thought it would be interesting to try to offset the delay times along the wall with millisecond delay times introduced in each speaker, corresponding to that speaker's position along the wall. Two speakers were placed at each end of the wall, and two more were placed one-third and two-thirds of the way across (see Fig. 5.13). Thus, the speakers were equidistant from each other and were $45 \mathrm{~ms}$. apart in sound-travel time. This enabled me to accurately control the effect of introduced delay and to predict how events would sound at various points along the wall. It also allowed me to create a simulation of the wall within Max/MSP, so that I could work on the installation at home and hear how certain sections would sound when heard at different points along the space.

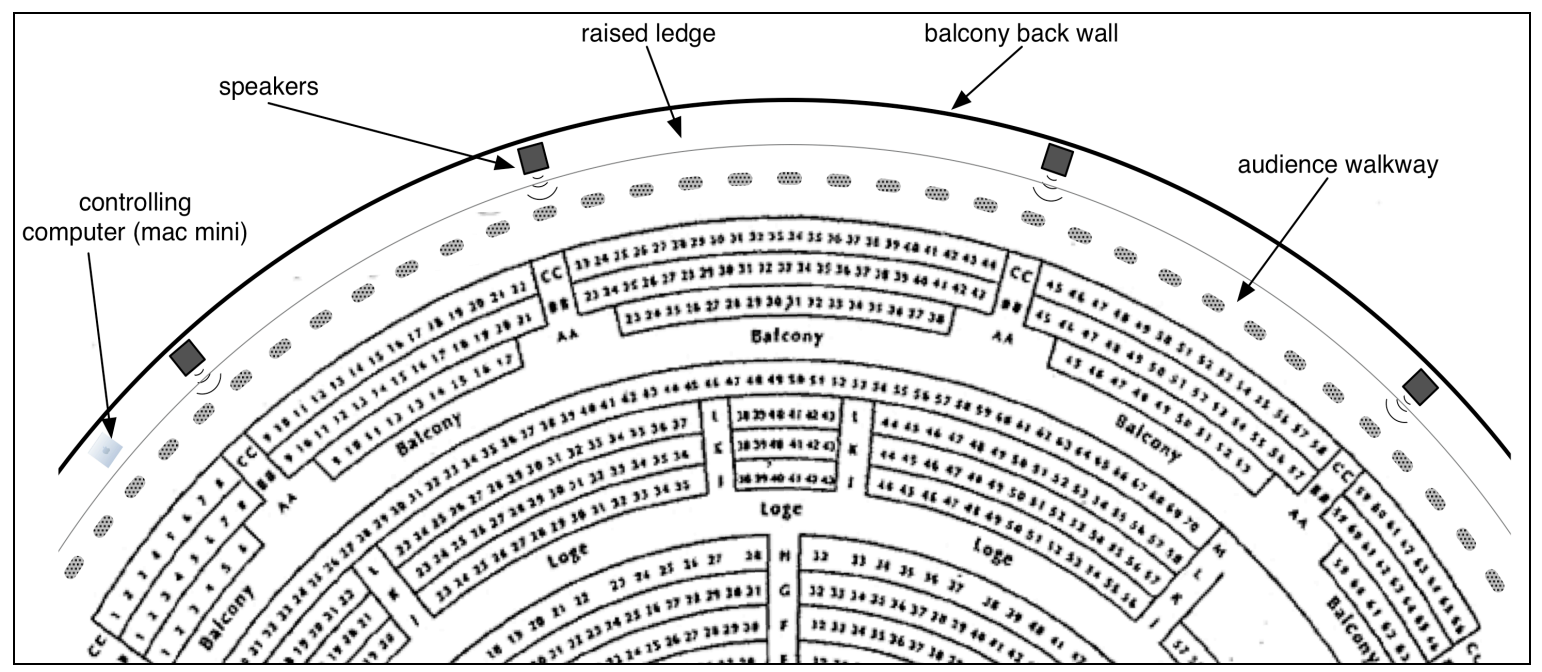

Fig. 5.13: Topographical diagram from the original proposal for installing Curve in the Old Cabell Hall balcony.

By playing an impulse from all four speakers and then adding an individual delay to each speaker, I could create a scenario in which an impulse or collection of notes would arrive 
all at once for a listener on one end of the space, but arrive separately for a listener at the other end. Fig. 5.14 shows how a listener would perceive an impulse that starts at the opposite side of the space, and is joined by successive impulses from the other speakers as the sound moves from one end to the other. The digital delays offset the delays inherent in sound travel time across the space, such that all four impulses reach the listener at the same time. This technique became very useful when working with pitched material.

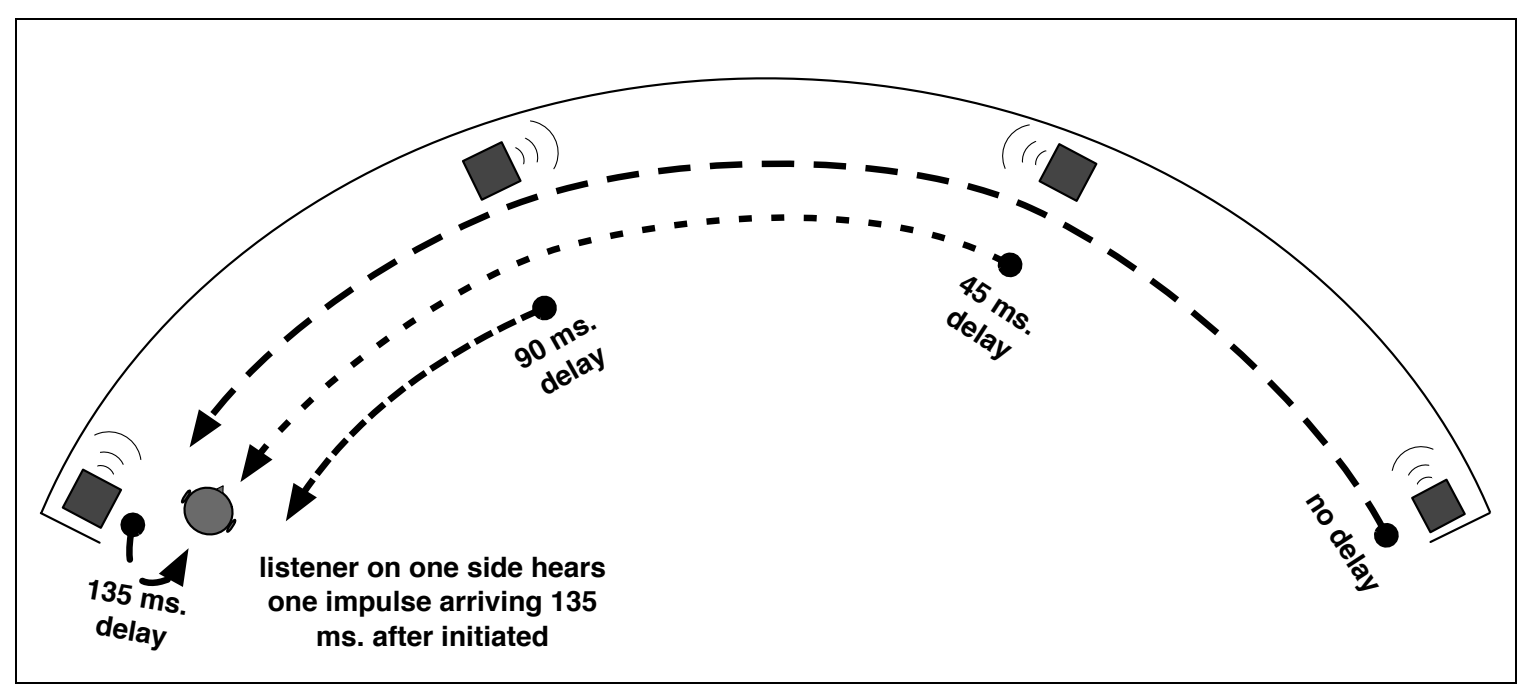

Fig. 5.14: Diagram showing an impulse spread over four speakers and delayed by 45 ms. increments between each speaker. All four impulses arrive at a listener on one side at the same time.

The perspective of the same impulse heard from the other end of the space, as shown in Fig. 5.15, was quite different: the impulses would arrive $45 \mathrm{~ms}$. apart from each other. This meant that one could play a group of pitches in such a way that a listener at one end would hear them as a chord, and at the other end as an arpeggio. Delays could be further 
tweaked so that a quick cluster of notes would appear to ascend when heard at one end, but descend when heard from the other.

In addition to the pitched material, other types of timbres and effects worked well within the space. I included sampled sounds from percussion recordings I had made over the past several years: marimba, goat bells, and tam-tam being just a few. I also used field recordings that had both percussive and textural qualities, such as cicadas and frogs in spring. At times I also introduced a synthesized bass drone to play with very low frequencies along the wall.

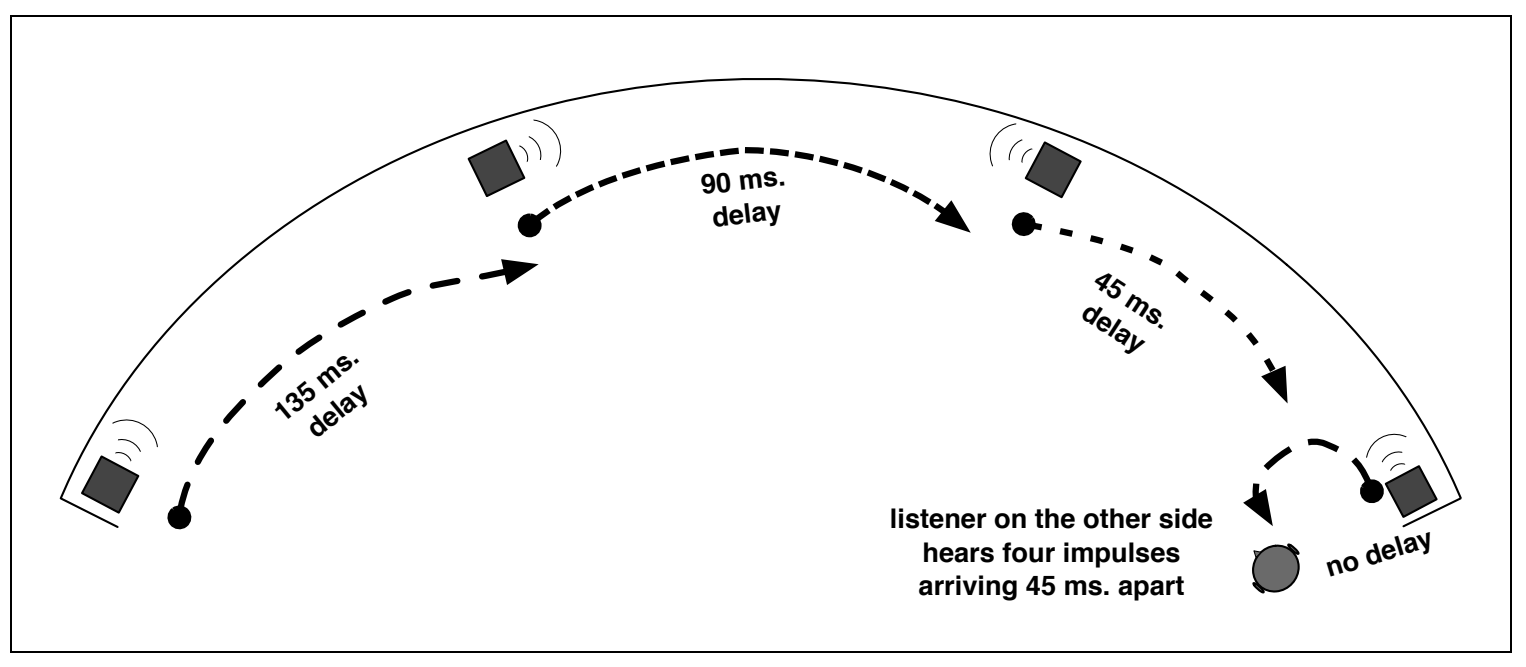

Fig. 5.15: The same impulse heard in Fig. 5.14 would sound very different when listened to from the other end of the space. Instead of the sounds arriving all at once, they each arrive 45 ms. apart.

The final installation piece was a nine-minute arrangement with a minute of silence at the end to allow listeners to make their own sounds in the space. The entire piece repeated every ten minutes, and consisted of pitched, percussive, and textural material arranged in 
and played from Ableton Live through Max/MSP. The Max/MSP patch distributed the sounds to the four channels and also controlled the amount of delay on each speaker. The delay assigned to each speaker changed over the course of the piece, so as to create different effects for listeners depending on their location.

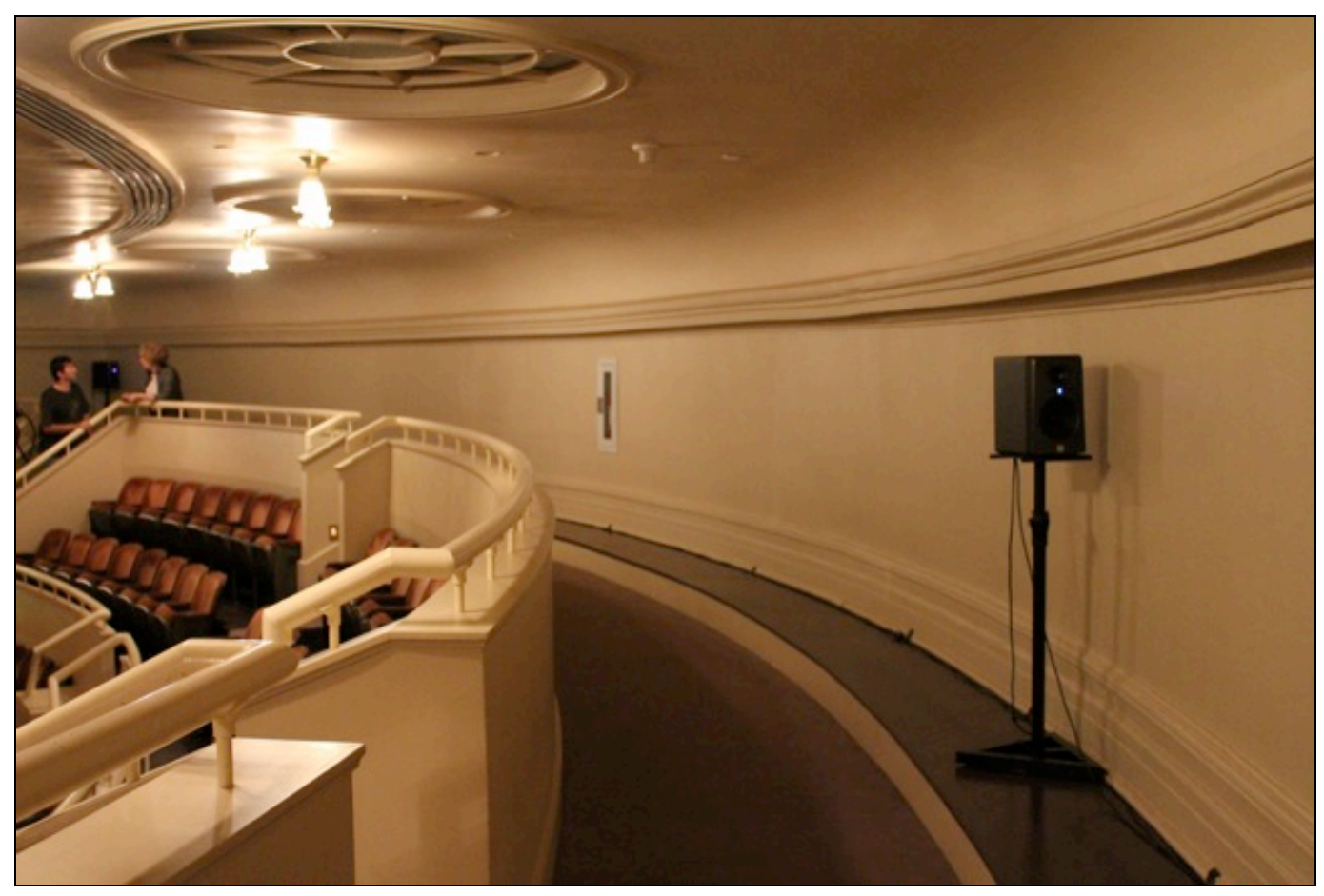

Fig. 5.16: A view of one-half of the Curve installation taken near the center of the walkway

The circumstances surrounding the premiere of Curve required that great consideration be given to the duration of the piece, and how much variation should be. Curve was set up for only one night during the annual "Digitalis" concert at UVA. Visitors could visit it before and after the concert, so unlike Solera, the installation had to 'do its thing' in a much shorter time-span. The final piece reflected all of these considerations: it was short enough to be heard in one visit and varied enough in register, rhythm, and timbre to play 
with a range of the space's musical possibilities. While I was very happy with how Curve turned out and with the results of my time spent in the space, I decided that future installations like Curve should exist apart from other musical activity, and visitors to the space should be encouraged to spend their time there with both a more participatory and sensitive approach to listening to their surroundings than they may be accustomed to.

\section{Conclusion}

Figure 5.17 returns to the spatial diagram from Chapter I and shows how I combined different spatial types in my Five Spaces series. ${ }^{25}$ In order to manipulate space as a compositional parameter, we need a conceptual framework through which to approach it, and arriving at that framework involves breaking conceptions of space into subsets. We can then combine these to construct new types of space. Conceptualizing space in this manner reflects the spatial processes that are happening within the pieces, which are also actions of decoupling, fragmenting, and reconstructing spaces. This approach to spatiality allows for it to be technically and conceptually treated as a malleable compositional parameter. The artists discussed in the previous chapters likely have very different systems for conceptualizing space in regards to their compositions, just as they are likely to have different ways of conceptualizing pitch, timbre, rhythm, structure, and so forth.

\footnotetext{
${ }^{25}$ You will notice that both Solera and Study No. 1 for Bodies, Metal, and Air, which used multiple speakers, are not connected to the multi-channel block. This is because I do not consider them as using multi-channel abstracted space. The multiple speakers in those pieces do not create a space of their own that mixes or interacts with the physical space, but are instead used as spatial resonators and reflectors, enhancing or augmenting the existing properties of the space.
} 


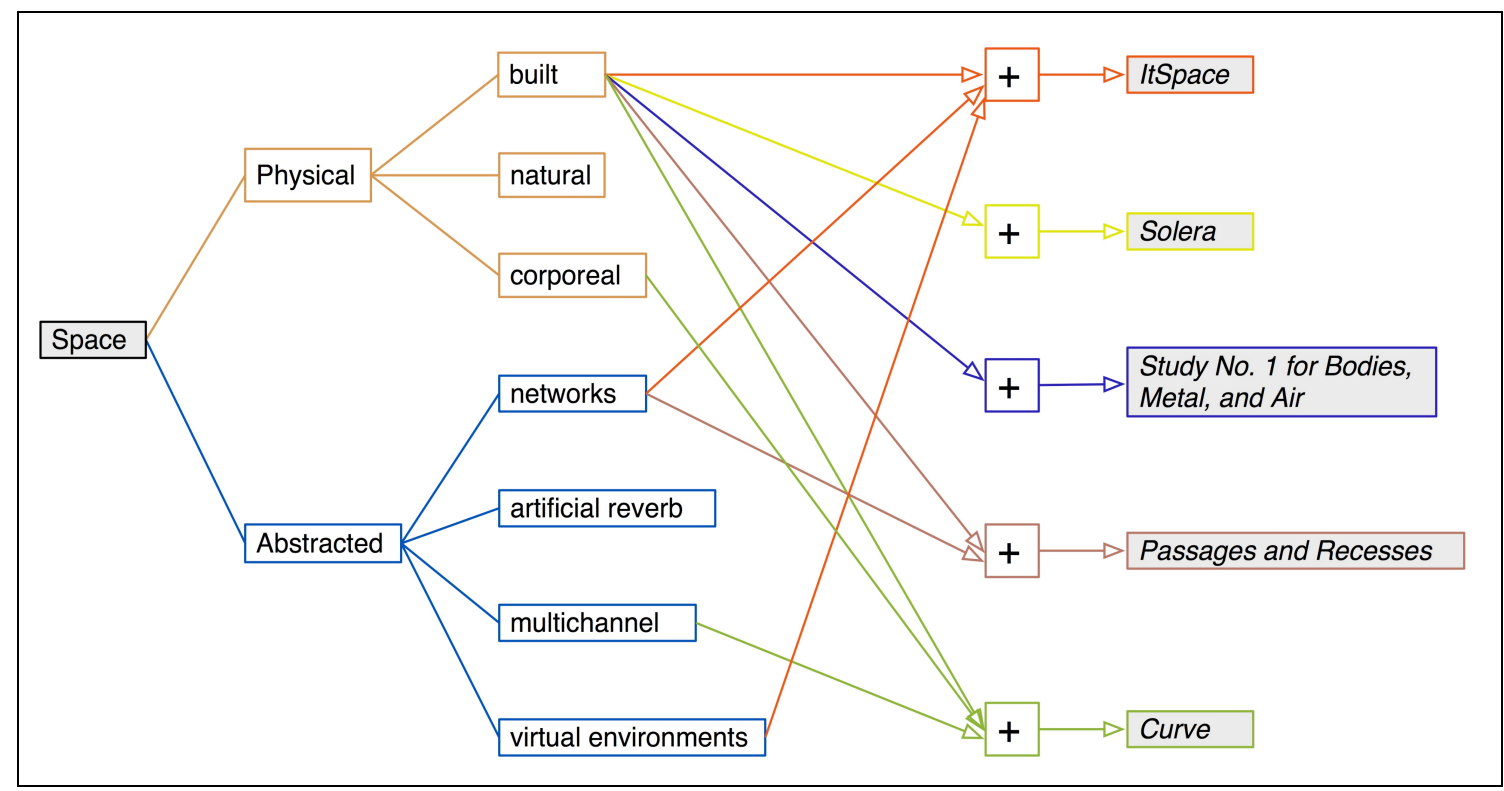

Fig. 5.17: Different spatial types are combined to form the Five Spaces series.

What is key is the idea that given these expanded conceptions of space, composers have developed new ways to focus on space as a central musical element. For my own work, this has been an essential undertaking. Creating a system for classifying space led to an expanded awareness of approaches to space and of the work of others in this area. It has also given me the tools to conceptualize new types of spaces and thus new spatial pieces. The Five Spaces series is the start of my ongoing engagement with space as a primary focus. 


\section{Epilogue}

In my dissertation, I have discussed current conceptions of space that have created new possibilities for compositional design in sound art. I have proposed defining space as a parameter than can be divided into three top-level categories: physical, abstracted, and hybrid. I have demonstrated how, in both my own work and that of a variety of other composers, these parameters can be utilized to project these types of space. The scientific revolution changed our understanding of acoustics, and the technological revolution gave us the tools to abstract aural space from site and from time, to fragment, replicate, redistribute, and transmit it. It is only in recent years that space has begun to support the kind of parameter development extensively explored in pitch and rhythm for centuries.

With these new possibilities, several common spatial composition techniques emerged. These include transplanting one aural space into another, displacing or accumulating time within a space, joining distant spaces, sounding spaces with their own resonant frequencies, and creating new spaces to map over existing ones. I have used all of these techniques in some way in my Five Spaces series and look forward to developing several of these techniques further. The drawing out or accumulating of time in a space, as in Solera, and the creation of a new space mapped over an idiosyncratic existing space, as in Curve, seem especially promising. 
Given the techniques used in Solera, I can imagine a number of compelling variations, including the use of shorter accumulation times, or different accumulation times in each corner of a space. Perhaps one speaker-microphone pair could cycle every hour, while another cycles every half hour, and yet another every fifteen minutes. Another variation could be to use this technique to capture and accumulate movement through a directional space such as stairwell. Yet another variation might be to combine this technique with shared network space, so that the accumulated audio of one space is played out in another, and vice versa. The spatial techniques used in Curve also have future promise. During the compositional process I became attuned to Old Cabell Auditorium's unique aural properties, and an engaging compositional challenge ensued in figuring out how to enhance and musically shape them. I may seek out other spaces with unique aural properties, such as tunnels, large halls, or spaces with prominent acoustic focal points. Large spaces, such as the Old Cabell Hall balcony, are also appealing because they allow one to compose spatial gestures around the delay inherent in sound travel time. Techniques that activate these types of spaces allow the composer to play with aural perspective in ways that link to visual perspective: as a function of the perceiver's location within a space and relative to the piece. Listeners are forced to engage the space in order to hear variations in the piece.

The ability to think in this way about potential future installations comes from a greater awareness of aural space as well as access to the relatively new tools that enable this kind 
of work. It is particularly exciting to consider that both the technologies and concepts that have brought us to this point are still in a state of growth.

While I cannot predict how common a practice composing space will be in the future, I believe that artists will continue to find new and compelling to ways to create and shape space with technology. Further, the borders between physical and abstracted spaces will continue to blur or dissolve as the public becomes ever more accustomed to the constant connection, via their portable gadgetry, to the hybrid space of the global network. While artists have pushed further into abstracted and hybrid spaces, these spaces have not-sosubtly invaded most facets of our lives. As our interactions with space change in tandem with developments in technology, new creative doors will appear that artists will surely want to open. 


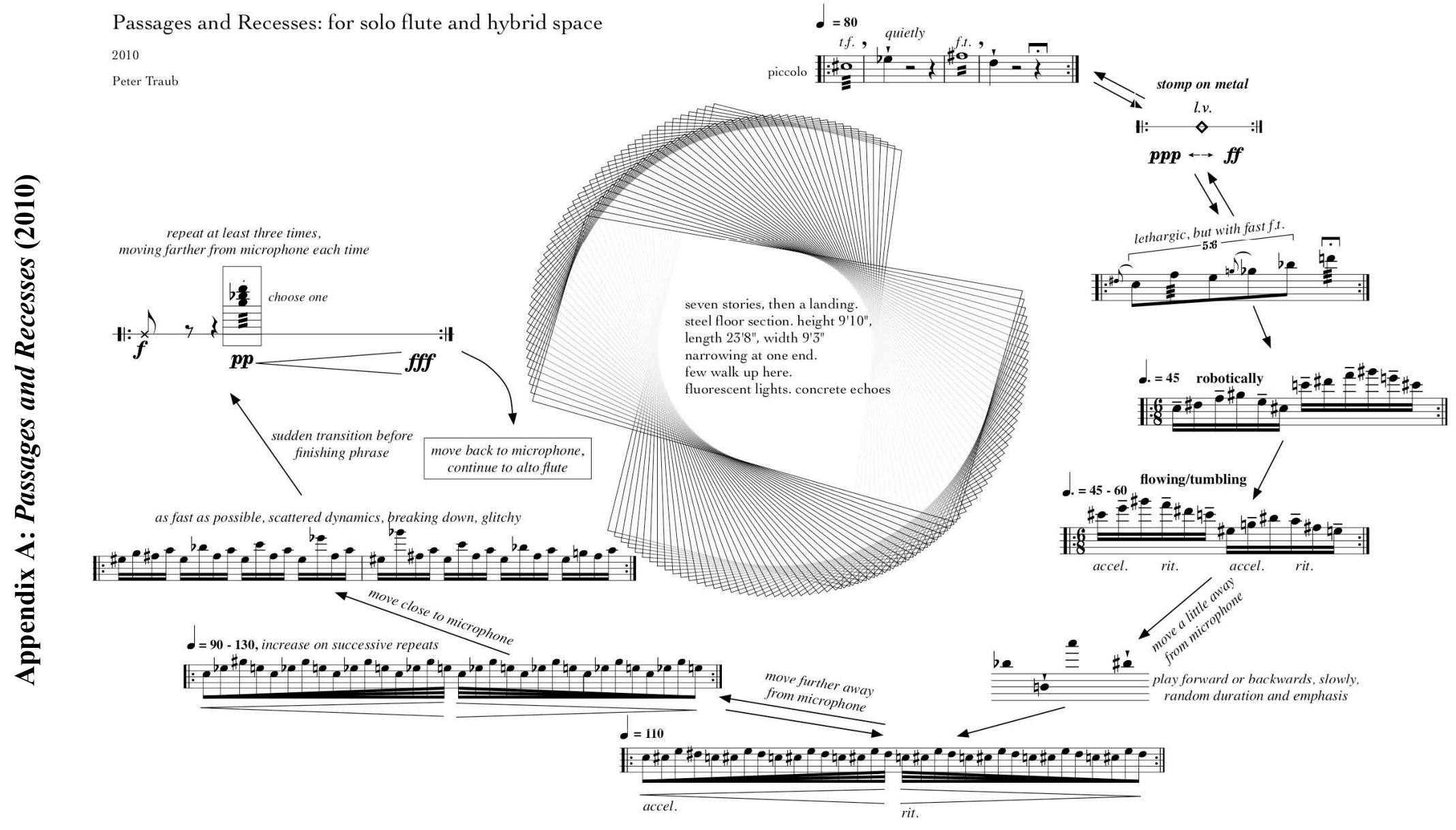


$\stackrel{9}{+}$

when playing this section, think about playing inside the Dome Room and project into that space

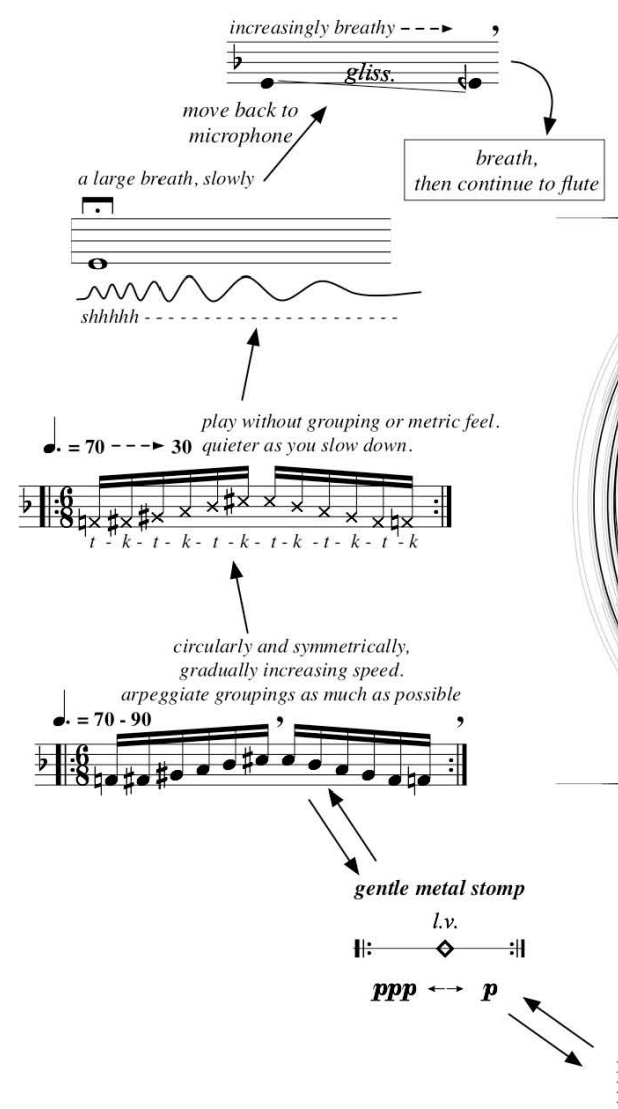

ato flute sofity, slowly

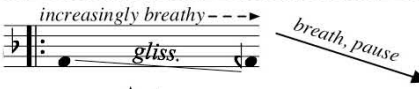

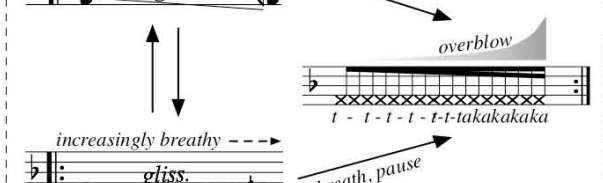
계: gliss.
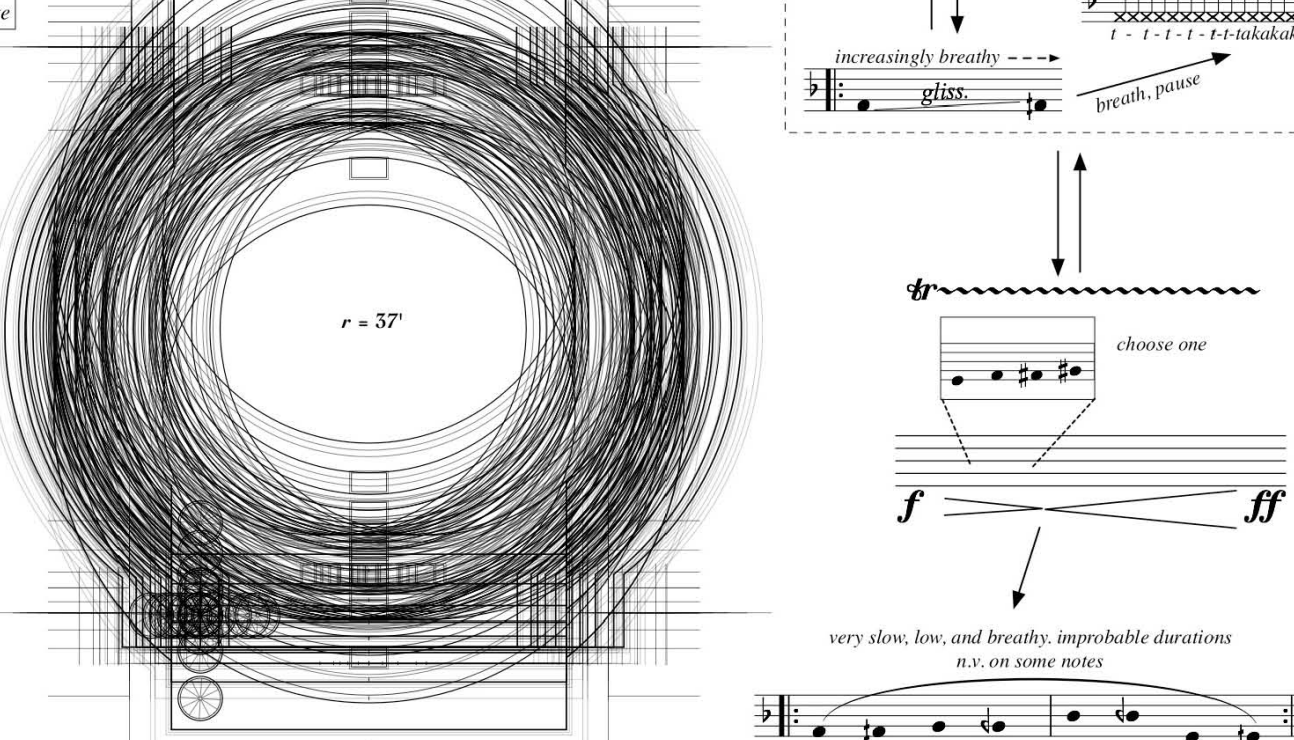

very slow, low, and breathy. improbable duration

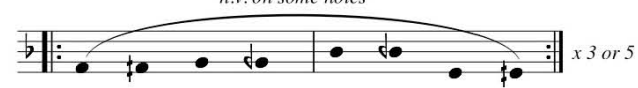

(whispered)
$p-p-p-p-p a-p a-p a-p a-p a-p a-p a$, path-ah-ah-ah-ah-ah-ah-aaaaaah

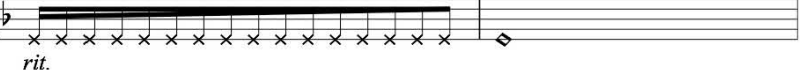




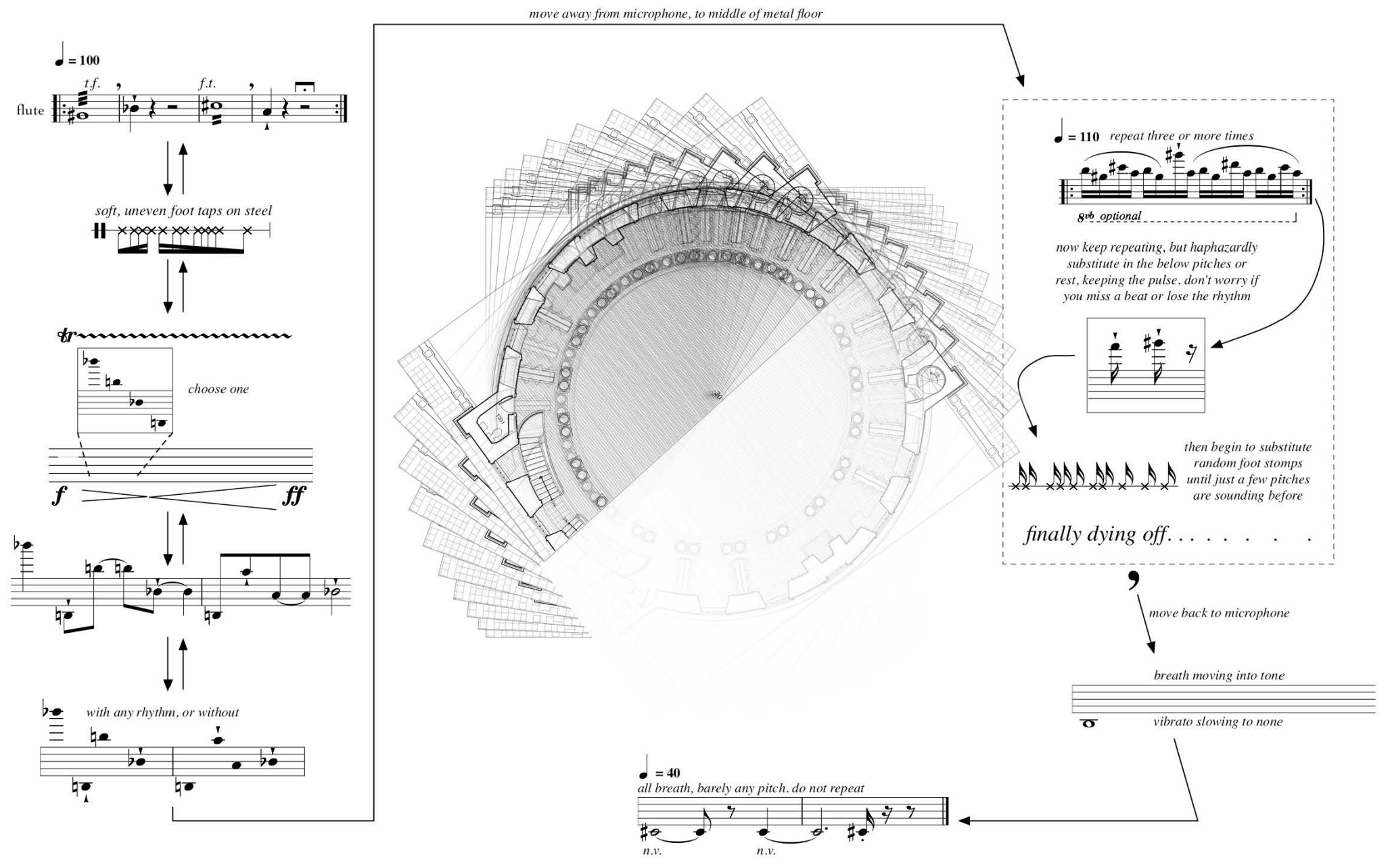




\section{Bibliography}

Amacher, Maryanne. 1999. Sound Characters [sound Recording]: (making the Third Ear). CD. New York, NY: Tzadik.

- 2009. Amacher Archive Project. http://www.maryanneamacher.org/Amacher_Archive_Project/Entries/2009/10/24 _music_for_sound_joined_rooms.html.

Austin, Larry. 2000. Sound Diffusion in Composition and Performance: An Interview with Denis Smalley. Computer Music Journal 24, no. 2 (Summer): 10-21.

Bagenal, Hope. 1930. Bach's Music and Church Acoustics. Music \& Letters 11, no. 2 (April): 146-155.

Bain, Mark. 2004. The Live Room: transducing resonant architectures. Organised Sound 8, no. 02 (January): 163-170.

Bandt, Ros. 2006. Sound Installation: Blurring the Boundaries of the Eye, the Ear, Space and Time. Contemporary Music Review 25, no. 4: 353-365.

Barbosa, Álvaro. 2003. Displaced Soundscapes: A Survey of Network Systems for Music and Sonic Art Creation. Leonardo Music Journal 13: 53-59.

Barrett, Natasha. 2003. Spatio-musical composition strategies. Organised Sound 7, no. 03: 313-323.

_ 2009. Interview: Natasha Barrett Interview by Peter Traub. http://turbulence.org/networked_music_review/2009/04/19/interview-natashabarrett/.

Beranek, Leo L. 1955. Loudspeakers and microphones. Audio, IRE Transactions on 3, no. 1: 13-20.

- 1962. Music, Acoustics \& Architecture. New York; London: John Wiley \& Sons, Inc.

Blesser, Barry, and Linda-Ruth Salter. 2007. Spaces speak, are you listening? : experiencing aural architecture. Cambridge, Mass.: MIT Press.

Braasch, Jonas. 2007. Tele-Colonization: A group improvisation based on a music concept and adaptive sound scapes by Jonas Braasch. 
- 2009. The Telematic Music System: Affordances for a New Instrument to Shape the Music of Tomorrow. Contemporary Music Review 28, no. 4: 421-432.

Brant, Henry. 1979. Spatial music progress report. Quadrille, A Magazine for Alumni \& Friends of Bennington College, Winter.

Brown, Chris, and John Bischoff. 2002. Indigenous to the Net: Early Network Music Bands in the San Francisco Bay Area. http://crossfade.walkerart.org/brownbischoff/IndigenoustotheNetPrint.html.

Cardiff, Janet. 2005. Interview between Janet Cardiff and Kelly Gordon (Hirshorn Museum). Interview by Kelly Gordon. http://www.cardiffmiller.com/press/texts/kg_jc-interview.pdf.

Cardiff, Janet, and George Bures Miller. 2007. Interview: Cardiff + Miller Interview by Peter Traub. http://turbulence.org/networked_music_review/2007/09/20/interview-janetcardiff-and-george-bures-miller/.

Chafe, Chris. 2009. Tapping into the Internet as an Acoustical/Musical Medium. Contemporary Music Review 28, no. 4: 413-420.

Chafe, Chris, S. Wilson, R. Leistikow, D. Chisholm, and G. Scavone. 2000. A simplified approach to high quality music and sound over IP. In COST-G6 Conference on Digital Audio Effects, 159-164.

Chafe, Chris, S. Wilson, and D. Walling. n.d. Physical Model Synthesis with Application to Internet Acoustics. https://ccrma.stanford.edu/ cc/soundwire/icassp02.pdf

Chandler, Annmarie, and Norie Neumark. 2005. At a distance : precursors to art and activism on the Internet. Cambridge, Mass.: MIT Press.

Chou, Mary L. 2007. Bill Fontana, Sounds Reconstructing Space, 2. http://www.nyartsmagazine.com/index.php?option=com_content\&task=view\&id $=4571 \&$ Itemid $=204$.

Davis, R. 2004. ' $\ldots$ and what they do as they're going...': sounding space in the work of Alvin Lucier. Organised Sound 8, no. 02: 205-212.

Emmerson, Simon. 2007. Living Electronic Music. Aldershot, England ; Burlington, VT: Ashgate. 
Fontana, Bill. Musical Information Networks. N.d. http://www.resoundings.org/Pages/musical\%20networks.html.

- 1987. The Relocation of Ambient Sound: Urban Sound Sculpture. Leonardo 20, no. 2: 143-147.

—. 1997. Resoundings. http://www.resoundings.org/Pages/Resoundings.html.

- 2007a. Pigeon Soundings at the new Kolumba Museum. http://www.resoundings.org/Pages/pigeon_Soundings.htm.

_ 2007b. Interview: Bill Fontana. Interview by Peter Traub. http://turbulence.org/networked_music_review/2007/11/01/interview-billfontana/.

Forsyth, Michael. 1985. Buildings for Music: The Architect, the Musician, and the Listener from the 17th Century to the Present Day. MIT Press.

Freeman, J., C. Ramakrishnan, and Kristjan Varnik. 2004. The Architecture of Auracle: a RealTime, Distributed, Collaborative Instrument. In New Interfaces for Musical Expression (NIME) 2004.

Gilbert, Jesse. 2005. Email Interview with Jesse Gilbert. Interview by Peter Traub. http://www.fictive.org/cmr/appendix/gilbert.html.

Hajdu, Georg, and Nick Didkovsky. 2009. On the Evolution of Music Notation in Network Music Environments. Contemporary Music Review 28, no. 4: 395-407.

Hanoch-Roe, G. 2007. Scoring the Path: Linear Sequences in Music and Space. In Resonance: Essays on the Intersection of Music and Architecture, 77-144. Ames: Culicidae Architectural Press.

Harley, J. 2002. The electroacoustic music of Iannis Xenakis. Computer Music Journal 26, no. 1: 33-57.

Harley, M. A. 1994. Spatial sound movement in the instrumental music of Iannis Xenakis. Journal of New Music Research 23, no. 3: 291-314.

_ 1997. An American in Space: Henry Brant's" Spatial Music". American Music 15, no. 1: 70-92.

Harrison, Jonty. 1998. Sound, Space, Sculpture--Some Thoughts on the 'What', 'How', and 'Why' of Sound Diffusion. Organised Sound 3, no. 2 (August): 117-127. 
1999. Diffusion: theories and practices... eContact! 2, no. 4. http://cec.concordia.ca/econtact/Diffusion/Beast.htm.

Holmes, Thom. 2002. Electronic and Experimental Music: Pioneers in Technology and Composition. 2nd ed. New York; London: Routledge.

Kac, Eduardo. 1993. Telepresence Art. http://www.ekac.org/telepresence.art._94.html.

Krebs, Joachim, and Sabine Schäfer. 2003. Sound - Time - Space - Movement: The Space-Sound Installations of the Artist-Couple. Organised Sound 8, no. 2: 213225.

Leitner, Bernhard. 1998. Bernhard Leitner : Sound, Space. Ostfildern; New York: Cantz; Distributed by Distributed Art Publishers.

Lévy, Pierre. 1997. “Collective Intelligence : Mankind's Emerging World in Cyberspace”. New York; London: Plenum.

Lucier, Alvin. 1994. Thoughts on Installations. http://www.kunstradio.at/ZEITGLEICH/CATALOG/ENGLISH/lucier-e.html.

- 2005. Reflections: Interviews, Scores, Writings 1965-1994 = Reflexionen: Interviews, Notationen, Texte 1965-1994. 2nd ed. Köln: MusikTexte.

Malham, David G. 2001. Toward Reality Equivalence in Spatial Sound Diffusion. Computer Music Journal 25, no. 4 (Winter): 31-38.

Manovich, Lev. 2006. The poetics of augmented space. Visual Communication 5, no. 2 (June 1): 219-240.

Martin, Elizabeth. 1994. Architecture as a Translation of Music. Vol. 16. New York: Princeton Architectural Press.

Mavash, K. 2007. Site + Sound: Space. In Resonance: Essays on the Intersection of Music and Architecture, 53-76. Ames: Culicidae Architectural Press.

Moore, A., D. Moore, and J. Mooney. 2004. M2 Diffusion-The live diffusion of sound in space. In Proc. ICMC, 4:317-320.

Muecke, Mikesch W., and Miriam S. Zach. 2007. Resonance: Music and Architecture. In Essays on the Intersection of Music and Architecture, 251-272. Ames: Culicidae Architectural Press.

Nash, Adam. 2007. Interview: Adam Nash. Interview by Helen Thorington. http://turbulence.org/networked_music_review/2009/07/13/interview-adam-nash/. 
Neuhaus, Max. 1994. The Broadcast Works and Audium. http://www.auracle.org/docs/Neuhaus_Networks.pdf.

- 2005. Interview: Max Neuhaus. Interview by Peter Traub. http://turbulence.org/networked_music_review/2007/08/20/interview-maxneuhaus/.

Novak, Marcos. 1991. Liquid Architectures in Cyberspace. In "Multimedia: From Wagner to Virtual Reality", 272-285. WW Norton \& Company.

Oteri, Frank J. 2004. Extremities: Maryanne Amacher in Conversation with Frank J. Oteri. NewMusicBox, May 1. http://newmusicbox.org/article.nmbx?id=2460

Otondo, F. 2008. Contemporary trends in the use of space in electroacoustic music. Organised Sound 13, no. 01: 77-81.

Otondo, Felipe. 2007. Creating Sonic Spaces: An Interview with Natasha Barrett. Computer Music Journal 31, no. 2 (Summer): 10-19.

Ouzounian, Gascia. 2006. Embodied Sound: Aural Architectures and the Body. Contemporary Music Review 25, no. 1: 69-79.

Palmer, John. 2002. High Spirits with Jonty Harrison. 21st Century Music 9, no. 1 (January): 1 - 4.

Pinder, D. 2001. Ghostly footsteps: voices, memories and walks in the city. Cultural Geographies 8, no. 1: 1 .

Rebelo, Pedro. 2004. Performing space. Organised Sound 8, no. 02 (January): 181-186.

Rudi, Joran. 2005. "From a Musical Point of View, the World is Musical at any Given Moment": an Interview with Bill Fonatana. Organised Sound 10, no. 2: 97-101.

Rueb, Teri. 2007. Core Sample. http://www.terirueb.net/core_sample/.

Salter, Chris. 2001. The Architecture of Listening. http://crossfade.walkerart.org/salter/.

Sands, J. 2007. Transgressing Boundaries: Considering a Societal Function of Music and Architecture Through Markus Pernthaler's Helmut-List-Halle. Resonance: Essays on the Intersection of Music and Architecture: 213-230.

Schafer, R. Murray. 1994. The Soundscape : our sonic environment and the tuning of the world. Rochester, VT: Destiny Books. 
Sheridan, Ted, and Karen Van Lengen. 2003. Hearing Architecture. Exploring and Designing the Aural Environment. Journal of Architectural Education 57, no. 2: $37-44$.

Smalley, D. 2007. Space-form and the acousmatic image. Organised Sound 12, no. 01: $35-58$.

Smith, B. R. 2004. Listening to the Wild Blue Yonder: The Challenges of Acoustic Ecology. In Hearing Cultures: Essays on Sound, Listening and Modernity, ed. Veit Erlmann, 21-41.

de Souza e Silva, Adriana. 2006. From Cyber to Hybrid: Mobile Technologies as Interfaces of Hybrid Spaces. Space and Culture 9, no. 3 (August 1): 261-278.

Sterken, S. 2007. Music as an Art of Space: Interactions between Music and Architecture in the Work of lannis Xenakis. In Resonance: Essays on the Intersection of Music and Architecture, 21-52. Ames: Culicidae Architectural Press.

Talman, Jeff. 2007a. Jeff Talman: Select Installations. DVD.

. 2007b. White Sound Down project description. November.

- 2007c. A Million Keys: Interview with Jeff Talman Interview by Ceci Moss. December. http://amillionkeys.com/interview-with-jeff-talman.

- 2008. Interview: Jeff Talman. Interview by Peter Traub. August. http://turbulence.org/networked_music_review/2008/08/19/interview-jeff-talman/.

Thompson, Emily. 2002. The soundscape of modernity : architectural acoustics and the culture of listening in America, 1900-1933. Cambridge, Mass.: MIT Press.

- 2004. Shaping the Sound of Modernity. In Hearing History: A Reader, 1st Ed.:331-363. Athens: University of Georgia Press.

Thorington, Helen. 2005. Breaking Out: The Trip Back. Contemporary Music Review 24, no. 6: 445-458.

Traub, Peter. 2005. Sounding the Net: Recent Sonic Works for the Internet and Computer Networks. Contemporary Music Review 24, no. 6: 459-481.

Trochimczyk, Maja. 2001. From Circles to Nets: On the Signification of Spatial Sound Imagery in New Music. Computer Music Journal 25, no. 4 (December 1): 39-56. 
Truax, B. 1998. Composition and diffusion: space in sound in space. Organised Sound 3, no. 02: 141-146.

Van Lengen, Karen. 2008. Interview: Karen Van Lengen. Interview by Peter Traub. http://turbulence.org/networked_music_review/2008/05/29/interview-karen-vanlengen/.

Wishart, Trevor. 1996. On sonic art. Amsterdam: Harwood Academic Publishers.

Zvonar, Richard. 2005. A History Of Spatial Music. eContact! 7, no. 4. http://cec.concordia.ca/econtact/Multichannel/spatial_music.html. 